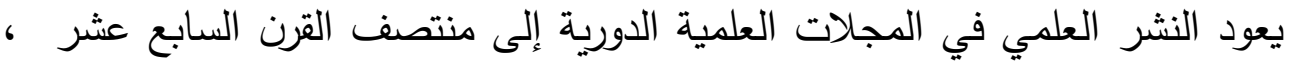

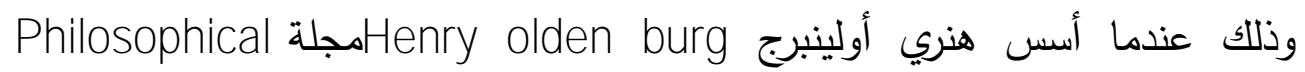
Transaction

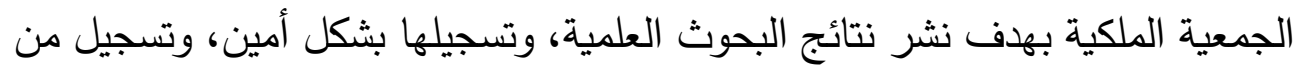

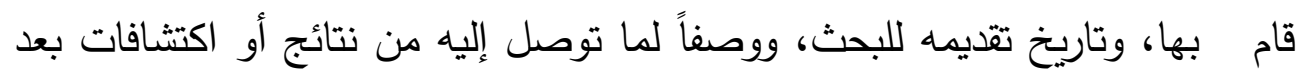
التأكد من صحتهام(Mabe, 2005,P.56). Olden وكان مجلس الجمعية الملكية يقوم بمراجعة الأبحاث التي تصل إلى أو لدينبرج

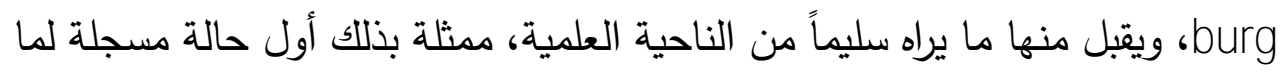

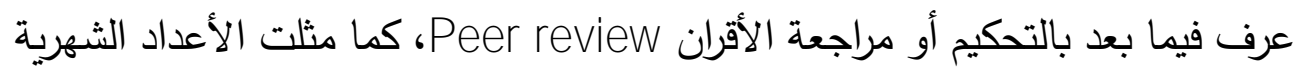

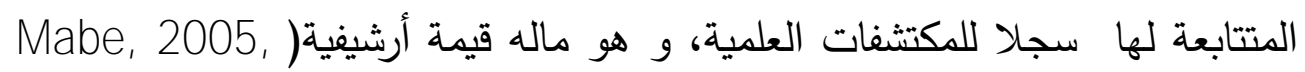

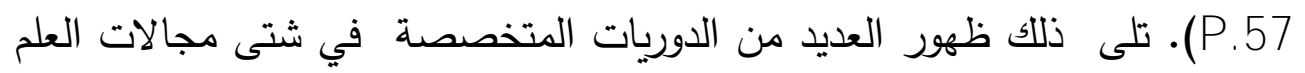

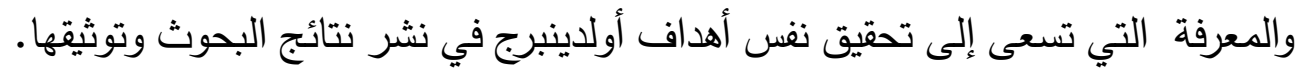

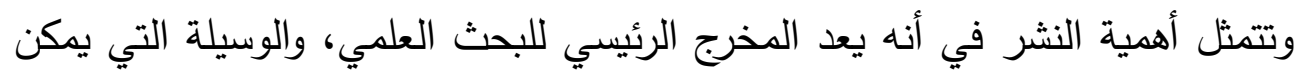

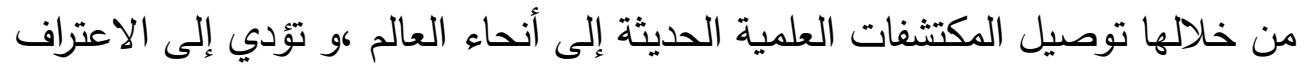

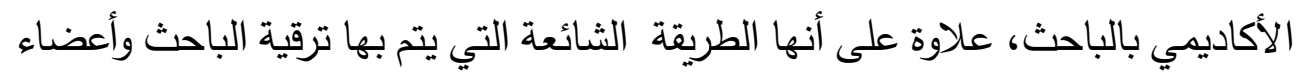
هيئة التدريس من معظم دول العالم) (Man et al, 2009, P. 811).

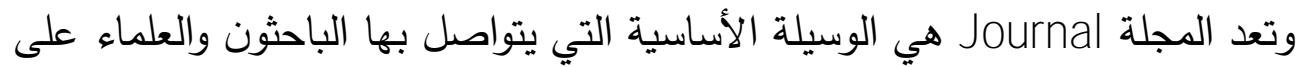

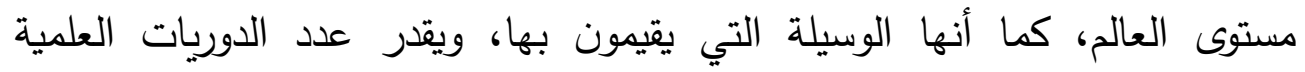

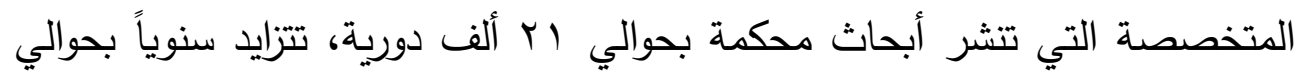

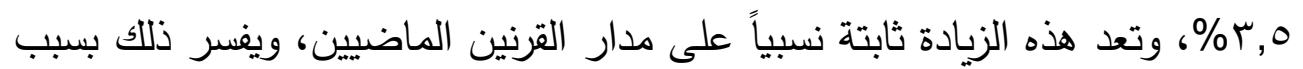


موقق المجلات التربوية العربية من بعض القضايا الخاصة ا..م. دـ ـ محمد أحمد محد اسماعيل

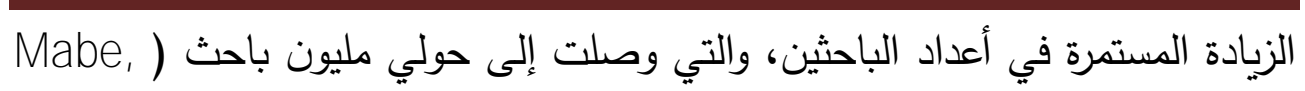
.(2005, P.56

وتعد الدوريات العلمية التربوية مكون هام من مكونات العقل التربوي خاصة، وأن

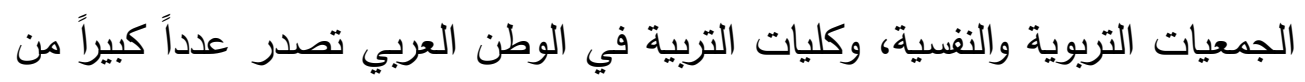
المجلات العلمية التربوية، التي تهتم بنشر البحوث العلمية (Research J ournal). ومن هذه المجلات ما تخصص في نثر البحوث التربوية بصفة عامة، ومنها ما

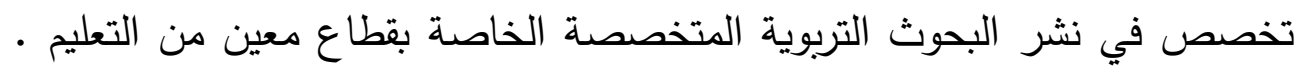

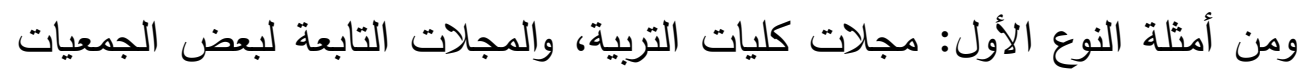

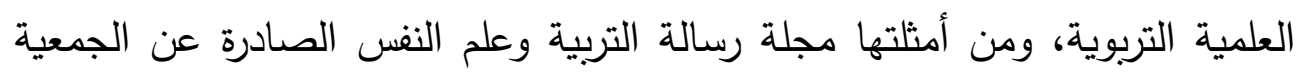

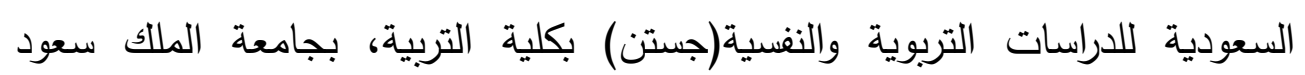

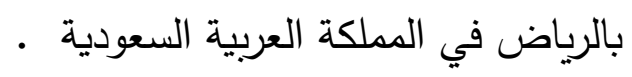
ومن أمثلة النوع الثاني: مجلة تعليم الجماهير التي تمثل اللسان الناطق باسم حركة النيا تعليم الكبار في الوطن العربي، وتصدر عن الجهاز العبي لمحو الأمية وتعليم الكبار

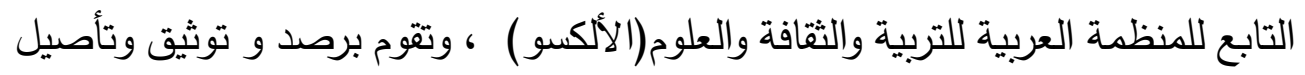

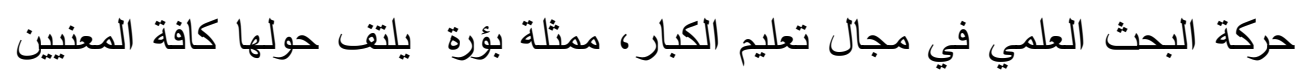

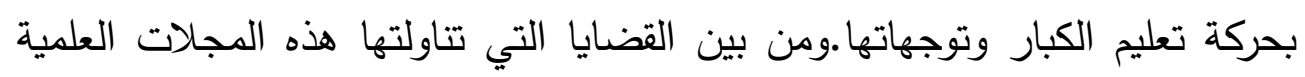

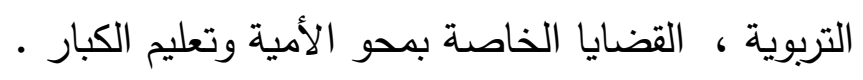

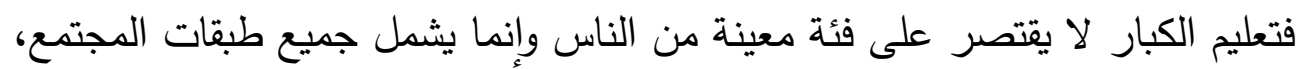

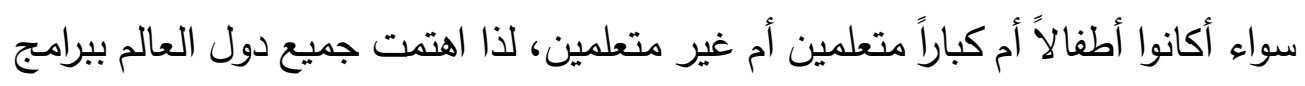

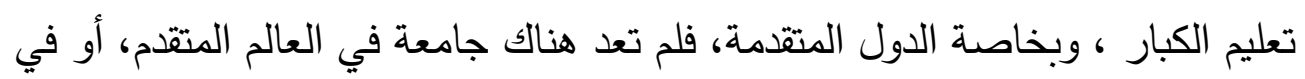
الدول النامية، إلا ولديها على الأقل وحدة مسئولة عن برامج تعليم الكبار (الرواف، لكاف

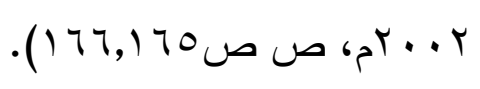


ولقد تتاولت المجلات موضع الدراسة بعض قضايا تعليم الكبار برؤى مختلفة ، ومن

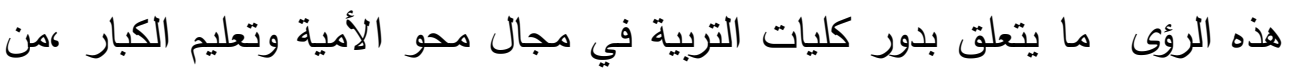
منطلق أن التعليم الجامعي يشغل مكاناً مهماً بين المراحل التعليمية المختلفة للنظام التعليمي كله، باعتباره سبيلاً لمساعدة المجتمعات المختلفة خاصة النامية منها للحاق بركب الحضارة عن طريق ما يسهم به في مجالي التعليم، والبحث العلمي، والإسهام

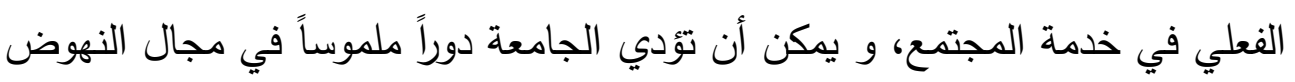
بتعليم الكبار من خلال ما تقوم به من أدوار . وتعد كليات التربية من أكثر المؤسسات الجامعية أهمية للإسهام في مجال تعليم الكبار بالبلاد العربية ، من خلال أطر واتجاهات حديثة يمكن لكليات التربية أن تسهم في تناولها.

\section{مشكلة الدّراسة:}

تتمثل مشكلة الدراسة في المعالجة التحليلية النقدية للأبحاث التي تتاولت دور كليات التربية في مجال محو الأمية وتعليم الكبار ، والمنشورة في بعض المجلات التربوية العربية -تعليم الجماهير - اتحاد الجامعات العربية- رسالة الخليج العربي - رسالة التربية

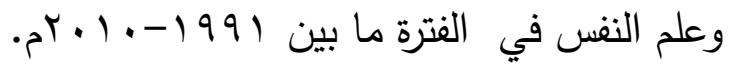
على اعتبار أن هذه المجلات تعكس بوجه عام الوعي المجتمعي، والاجتماعي بالقضايا التربوية خلال عقدين من الزمن. فمجلة تعليم الجماهير ، تولى أهمية خاصة للاتجاهات والقضايا المستجدة المؤثرة من حركة تعليم الكبار بالمنطقة العربية، كما تفرد مساحة كبيرة لتغطية الاتجاهات والمستجدات الدولية المساهمة في تحديد وتقرير العمل في محو الأمية، وتعليم الكبار ، و منها دور كليات التربية تجاه هذا المجال، فهي تعد رافداً جوهرياً لحركة تعليم الكبار في المنطقة العربية حيث أنها تعكس من جانب كبير من مادتها بصفة عامة انجازات حركة محو الأمية وتعليم الكبار في المنطقة العربية خلال الربع $\mu \cdot v$ 
موقق المجلات التربوية العربية من بعض القضايا الخاصة ا.م. دـ ـ محمد أحمد محمد اسماعيل

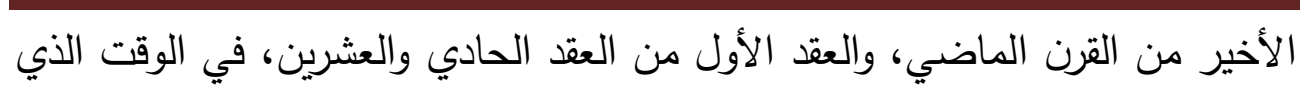

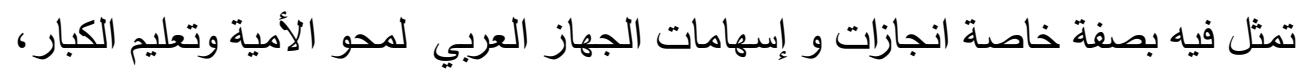
وفي نشر الدقالات والبحوث التربوية الخاصة بتعليم الكبار .

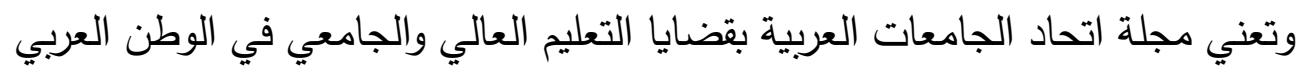

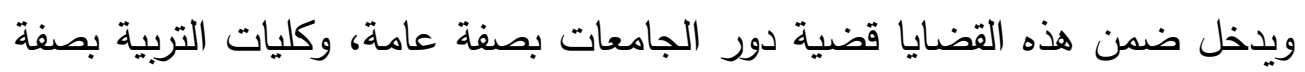
خاصة في مجال محو الأمية وتعليم الكبار. كما أن مجلة رسالة الخليج العربي، تعنى بالدراسات التربوية والثقافة العامة كما تقدام

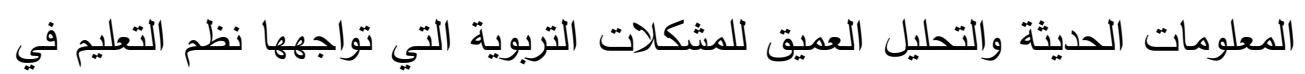

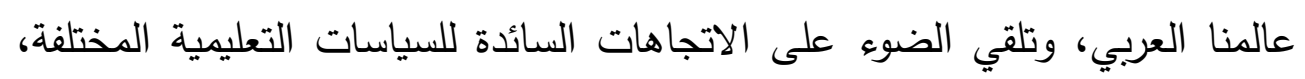
وكيفية تتفيذها.

كذلك تعنى مجلة رسالة التربية وعلم النفس بنشر الأبحاث التي تلقي الضوء على تأثير

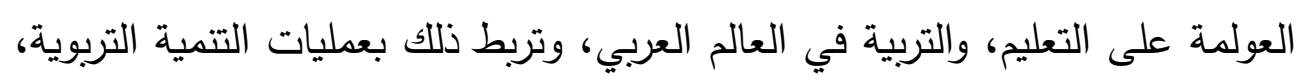

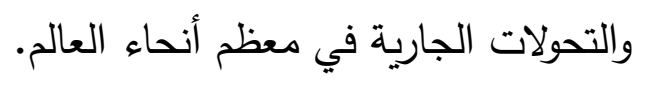
لذا فضى أكثر من عشرين عاماً على صدور هذه الجهلاء لعات واستمرار صدورها يجعل

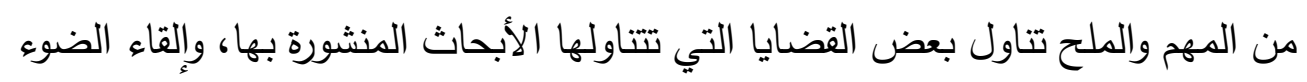

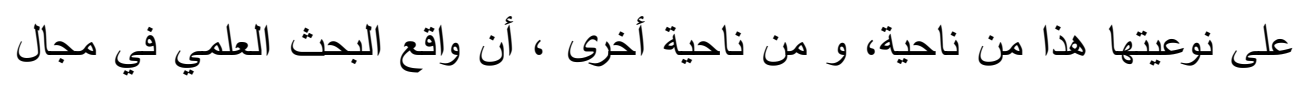

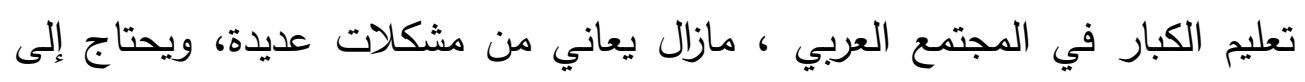

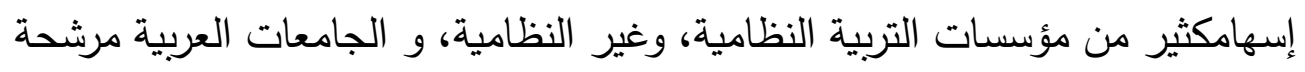

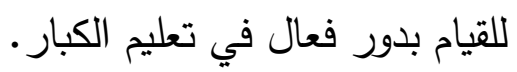

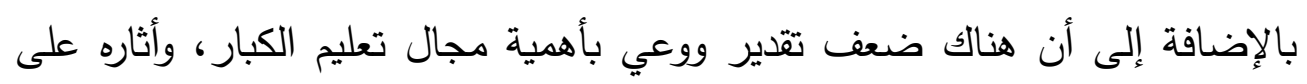

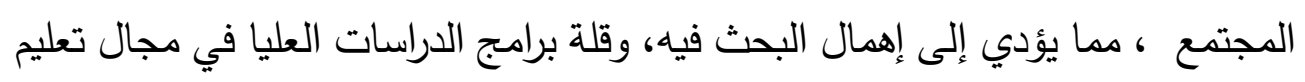

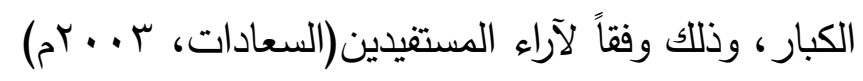


وأن هناك الكثير من المعوقات التي تواجه البحث العلمي التربوي، وتحول دون الاستفادة منه في تطوير التعليم والتدريب(الملا وفيصل، V +. . rم)، وأن البحث العلمي في مجال تعليم الكبار في حاجة ماسة إلى تطوير منهجيته بحيث تتناسب وخصوصيته وطبيعته، والظواهر التي يدرسها والأثخاص الذين يتعامل معهم.

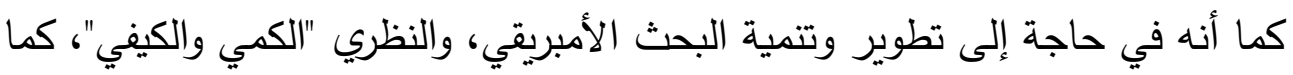
أنه لا يستفيد بطريقة منظمة من دراسات وبحوث العلوم الاجتماعية المختلفة ، باستثناء ما يقدمه علم النفس في مجال التعلم ونظرياته(عبد الجواد، 991 (م)كما أنه لم يعد نشاطاً إنسانيا لدراسة الحاضر والمستقبل على السواء. ومن ناحية أخرى يشغل التعليم الجامعي مكاناً مهماً بين المراحل التعليمية المختلفة

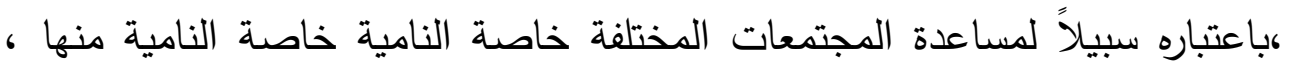
للحاق بركب الحضارة عن طريق ما يسهم به في مجال التعليم و البحث العلمي و الاسهام الفعلي في خدمة المجتمع، وإعداد القوى العالمة بما يتمشى مع حاجات المجتمع و سوق العمل، ويضمن للتمية في شتى جوانبها ركائز قوية ورصينة. وعلى ذللك يتعين ألا تنعزل الجامعة عن حركة الحياة في المجتمع ، وعن واقع الحياة

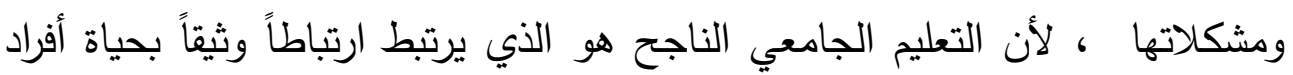

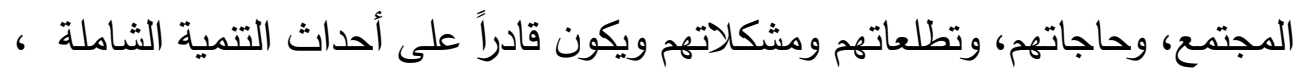
خاصة وأن بعض الدراسات العربية التي أجريت على جامعات عربية مختلفة أظهرت أن دور الجامعة كان متوسط الأهمية في خدمة المجتمع.(الرواشدة، r ا • rم). و في المرتبة الثالثة بمجال التدريب والتعليم المستمر ، وفي المرتبة الأخيرة بالنسبة للاستشارات العلمية(معروف، 11 1 • بم).وأن مستوى الخدمات التي تقدمها الجامعة كانت بدرجة متوسطة، وإن كان في مجال البحث العلمي قد جاء في المرتبة الأولى (الجهني

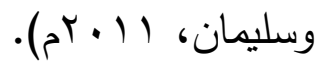


موقق المجلات التربوية العربية من بعض القضايا الخاصة ا.م. دـ ـ محمد أحمد محمد اسماعيل

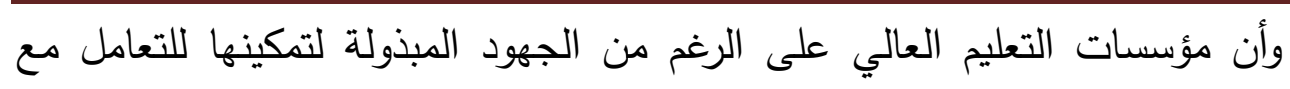
المتغيرات الدولية والإقليمية، والمحلية مازالت تعاني من قصور في مجالات الداليمات الدراسات

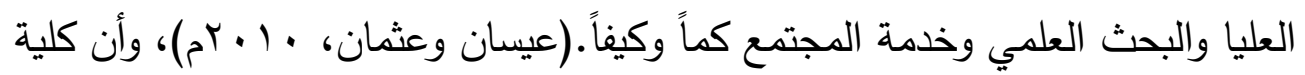
التربية بصفة خاصة قد أخفقت في مجال خدمة المجتمع، خاصة في مجال التعليم

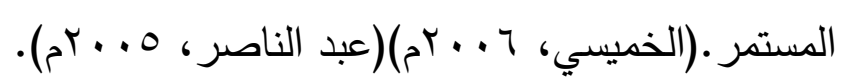

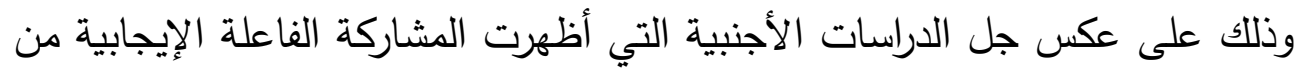
الجامعة في خدمة مجتمعها (إيقينمان وبلو منقتون، Eiqenmann and Bloominton

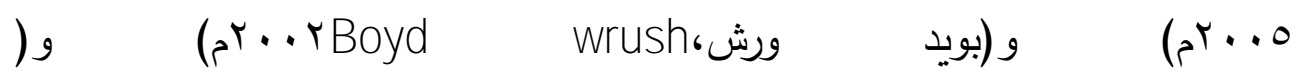

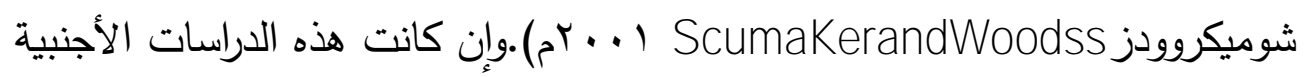

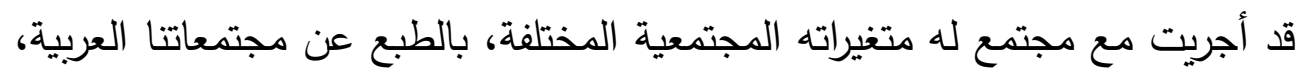

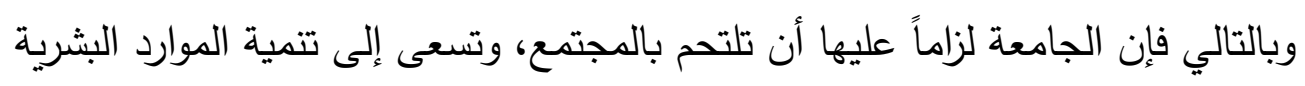

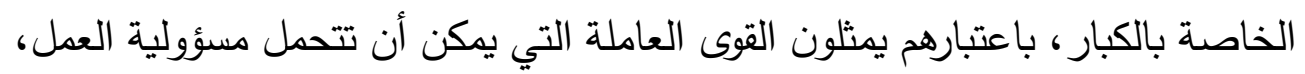

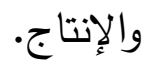

ويمكن أن تؤدي الجامعة دوراً ملموساً في مجال النهوض بتعليم الكبار من خلال ما تقوم به من وظيفة خدمة المجتمع كالأنشطة، والبرامج والخبرات التي التي تتهيأ

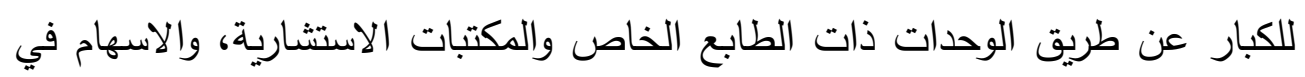
حملات التوعية، والقوافل الثقافية والندوات، واللقاءات النكات النكرية وغيرها من الأنشطة التي التي

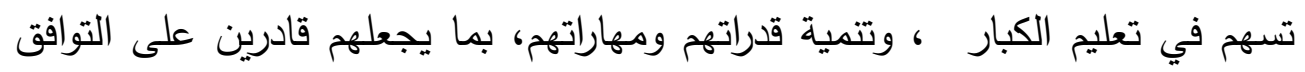

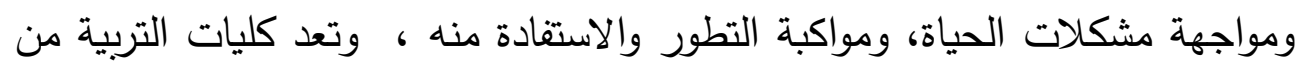

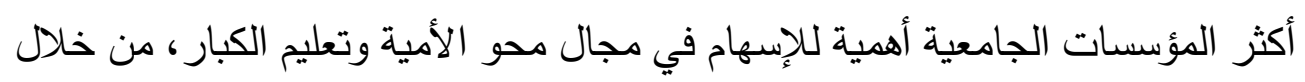

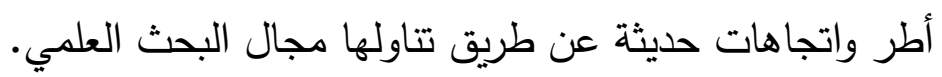




\section{من هذا المنطلق تطرح الدّراسة السؤال الرئيسي التالي:}

ما دور كليات التربية في مجال محو الأمية ، وتعليم الكبار ، كما تعكسها البحوث

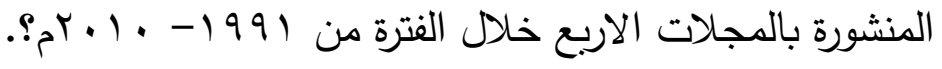
ويتفرع من هذا السؤال الأسئلة الفرعية الآتية:

1- ما مفهوم البحث العلمي التربوي في مجال تعليم الكبار ، و ما أنواعه ، و مبادئ ممارسته ، و أهدافه ؟

r

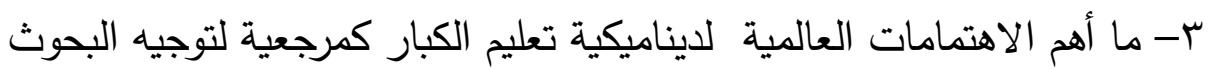

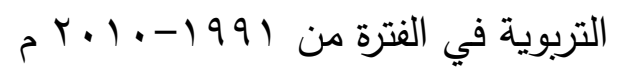

ع - ما العوامل والمتغيرات المجتمعية التي أدت إلى زيادة الاهتمام بدور كليات التربية في مجال محو الأمية وتعليم الكبار؟

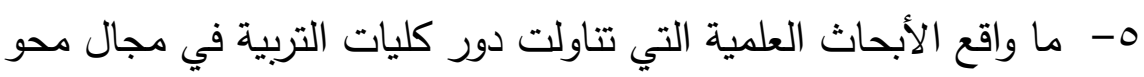

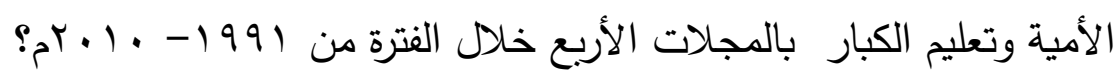

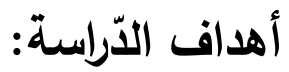
تهدف الدراسة الحالية :

ا - تعرف مفهومالبحث العلمي التربوي في مجال تعليم الكبار ( أنواعه و مبادئ

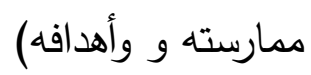
r - تعرف مفهوم محو الأمية، و تعليم الكبار. r - الكثف عن الاهتمامات العالمية لديناميكية تعليم الكبار كمرجعية لتوجيه البحوث التربوية في الفترة من (991 - • • • م م ع- تحليل و تفسير العوامل والمتغيرات المجتمعية التي أدت إلى زيادة الاهتمام بإجراء البحوث في مجال محو الأمية، وتعليم الكبار • 


\section{موقف المجلات التربوية العربية من بعض القضايا الخاصة أ.م. دـ ـ محمد أحمد محمد اسماعيل} 0 - تحليل المضمون الكمي والكيفي للأبحاث المنشورة في مجلات تعليم الجماهير ، واتحاد الجامعات العربية، ورسالة الخليج العربي، ورسالة التربية وعلم النفس والتي تتاولت دور كليات التربية في مجال محو الأمية وتعليم الكبار في الفترة

$$
\begin{aligned}
& \text { من 1991- • (199 } \\
& \text { حدود الدراسة : }
\end{aligned}
$$

تتحدد الدراسة بالحدود الآتية

$$
\text { الحد الموضوعي }
$$

ويتمثل في تحليل مضمون القضايا الخاصة بدور كليات التربية في مجال محو

الأمية و تعليم الكبار ، كما تتاولتها البحوث المنشورة بمجلات " تعليم الجماهير اتحاد الجامعات العربية - رسالة الخليج العربي - رسالة التربية و علم النفس" و مبررات اختيار المجلات الأربع تتمثل في :

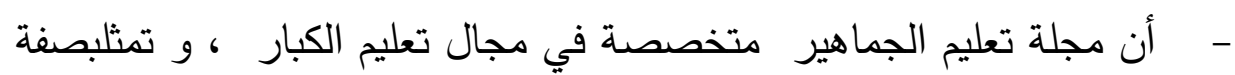
خاصة انجازات و إسهامات الجهاز العربي لمحو الأمية وتعليم الكبار • - - و مجلة اتحاد الجامعات العربية تعنى بقضايا التعليم العالي والجامعي في

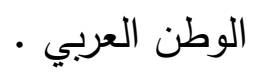

- و مجلة رسالة الخليج العربي، تعنى بالدراسات التربوية والتحليل العميق للمشكلات التربوية التي تواجهها نظم التعليم في عالمنا العربي، وتلقي الضوء على الاتجاهات السائدة للسياسات التعليمية المختلفة، وكيفية تنفيذها. - و مجلة رسالة التربية وعلم النغس تمثل نموذج للمجلات التي تصدرها الجمعيات العلمية التربوية في عالمنا العربي خاصة و هي بكلية التربية جامعة الملك سعود و بها مساقات لتعليم الكبار و برامج ماجستير و دكتوراه لتعليم الكبار الع 
تقتصر الدراسة على البحوث المنشورة بمجلات " تعليم الجماهير - اتحاد الجامعات العربية - رسالة الخليج العربي - رسالة التربية و علم النفس" في الفترة

$$
\begin{aligned}
& \text { من (991-1.1. •r م } \\
& \text { أهمية الدّراسة: }
\end{aligned}
$$

ا - أنها تتناول التقيم لهذه المجلات ، فنها التي مضى على صدورها أكثر من

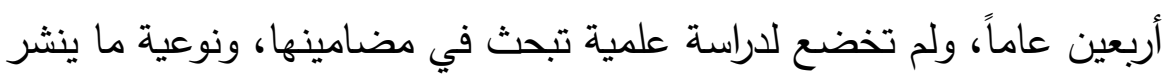

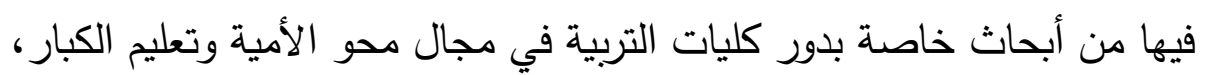
باستثاء دراسة عبد العزيز السنبل ه م. . ب م .

ץ- إنها تتظر إلى البعد العلمي لتعليم الكبار في شقه البحثي الخاص بدور كليات التربية في مجال محو الأمية وتعليم الكبار •

ب- تتبع أهمية الدراسة من أهمية المنهجية المستخدمة "منهجية تحليل المضمون" ولهئ والتي تستلزم وقتاً وجهاً أطول مما تستلزمه المنهجيات التقليدية، خاصة المسحية.

ع - تؤسس هذه الدراسة لبروز رؤية جديدة ومستحدثة لمسيرة المجلات التربوية، " تعليم الجماهير، رسالة الخليج العربي، اتحاد الجامعات العربية، رسالة التربية و علم النفس " ـ فيما يتعلق بدور كليات التربية في مجال محو الأمية وتعليم

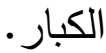

0- تطرح هذه الدراسة بعض الرؤى والتوصيات للارتقاء بحركة البحث العلمي الخاص بدور كليات التربية في مجال محو الأمية وتعليم الكبار بصفة عامة ،

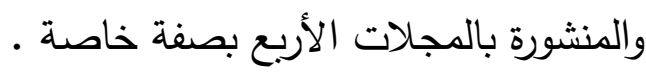
منهجية الدراسة: 


\section{موقف المجلات التربوية العربية من بعض القضايا الخاصة أ.م. دـ ـ محمد أحمد محمد اسماعيل}

اتساقاً مع طبيعة الدراسة فإنهاتستخدم تحليل المضمون Content)

Analyses) للمجلات موضوع الدراسة، وذلك لتحقيق أهداف الدراسة المطروحة سلفاً، كما أن تحليل المضمون يتيح تحقيق تكامل بين الأبعاد الكمية والكيفية للمادة المدروسة، فالبعد الكمي منطلقاً للحكم على مدى انتشار الظواهر في المحتوى ، ومؤشراً للدقة في البحث وصدق نتائجه ،عن طريق ترجمة المحتوى إلى أرقام وتقديرات كمية(طعيمه، ؟ . . Yم، ص YV TV). والبعد الكيفي يتخطى حدود رصد الواقع تكرارياً، ولرفع كفاية التحليل ودقتهوشموليته في التعبير عن خصائص المضمون بعيداً عن

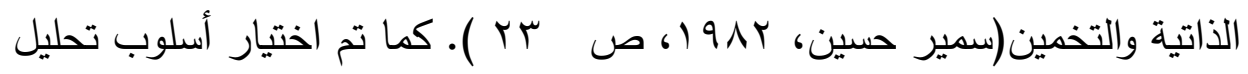
الموضوع(ThemticalAnalysis)، كشكل أساس من طرائق تحليل المضمون الذي ينسجم مع طبيعة الدراسة الحالية، وقد ارتكز تحليل تلك المضامين على عدة فئات ومستويات، منها مستوى العلاقات بين موضوعات الأبحاث المنشورة بعضها ببعض، ومستوى عرض إشكالية كل دراسة، وطبيعة البدائل التي تطرحها كل دراسة، ومدى لئ قابليتها للتنفيذ.

وبذلك تدرك الأشياء والظاهرات عن طريق فصل عناصر تلك الأشياء، والظاهرات بعضها عن بعض ومعرفة الخصائص التي تمتاز بها هذه العناصر ، فضلاً عن

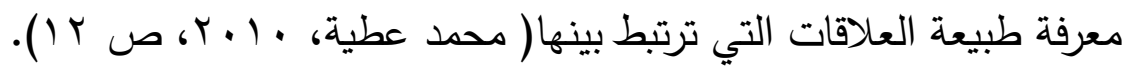
مصطلحات الدراسة: - محو الأمية وتعليم الكبار يعرض الباحث مصطلحات محو الأمية وتعليم الكبار في متن البحث تحت عنوان "الإطار الفكري والمفاهيمي. الدراسات السابقة 
تعد إشكاليات البحث التربوي واحدة من أعقد الإشكاليات التي تواجه تطور

مجال تعليم الكبار في مستويات التطبيقية والنظرية.فهذا المجال في الوطن العربي لا يزال في مرحلة انتقالية، حيث تقل فيه الدراسات خاصة، تلك التي تبحث في مسألة البحث التربوي على وجه الخصوص، فمراجعة الدراسات والأبحاث التربوية في هذا المجال، أظهرت أن مسألة البحث التربوي في مجال تعليم الكبار، شغلت اهتمام بعض

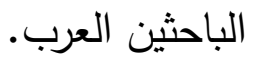

وفيما يلى عرض الدراسات السابقة العربية و الأجنبية المرتبطة بموضوع الدراسة ، و يعرضها الباحث من الأقدم إلى الأحدث ، مبتدئ بالدراسات السابقة العربية ثم الأجنبية على النحو التالي:أولاً: الآّراسات السيّابقة العربية:

$$
\text { 1- دراسة يعقوب حسين نشوان ( } 1991 \text { (م ) ) }
$$

هدفت الدراسة الكثف عن أوليات البحث التربوي في مجال تعليم الكبار. وخرجت الدّراسة بمجموعة من النّتائج منها: أ - أن جلّ البحوث المنشورة ، هي بحوث وصفية نظرية، وهدفت إلى التّعرف على بعض المعلومات المرتبطة بالتسرب، واتجاهات المعلمين الكبار، وكفايات المعلمين. ب - أن ثلاثة بحوث من أصل ثلاثين بحث ،كان بمثابة بحث ميداني، وقد أدى هذا الزخم من البحوث النظرية على حساب البحوث الميدانية إلى توسيع الفجوة بين النظرية والتطبيقفي تعليم الكبار • ج - أن معظم الدراسات كانت تقارير نظرية، تظهر وجهة نظر الباحثين في مجال تعليم الكبار، و ما يرونه عن طرائق، وأساليب لتحسين وتطوير تعليم الكبار . د - لم تتناول الأبحاث الثلاثين التي تم تحليلها قضية تقويم برامج تعليم الكبار في

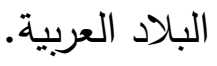


موقف المجلات التربوية العربية من بعض القضايا الخاصة ا..م. دـ ـ محمد أحمد محمد اسماعيل

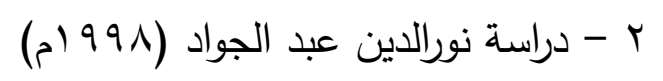

هدفت الدراسة الكثف عن واقع منهجية البحث في مجال تعليم الكبار . وخرجت الدراسة بمجموعة من النتائج منها:-

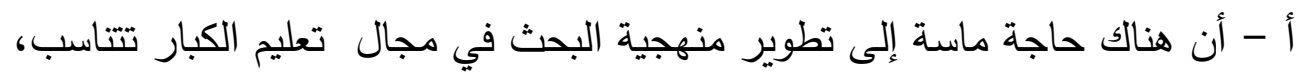

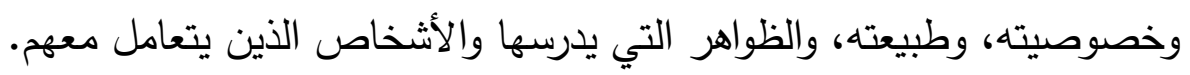

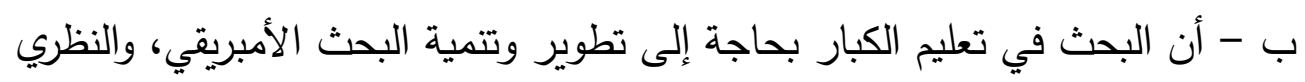

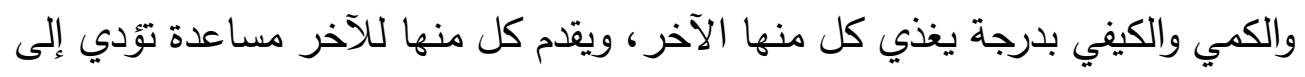
مزيد من البحث. ج - أن البحث في تعليم الكبار لم يستفد بطريقة منظمة ومنتظمة من دراسات وبحوث

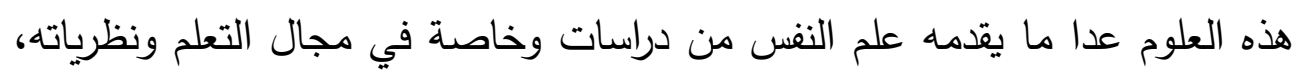

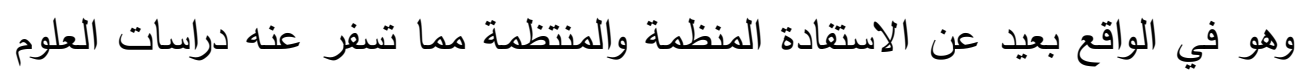

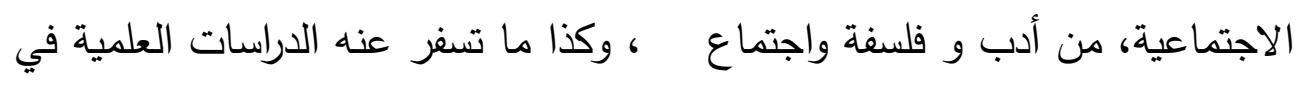

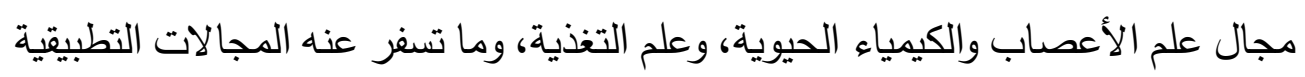
ذات العلاقة مثل دراسات الاتصال واستخدام التقنيات الحديثة.

$$
\text { r - دراسة عبد العزيز البسام (99191م) }
$$

هدفت الدراسة تحليل بعض الإثكاليات النظرية التي تواجه البحث التربوي في مجال تعليم الكبار، والتي تعيق إجراء البحوث فيه.

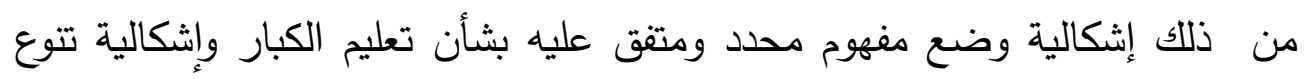
أهداف تعليم الكبار ، والفئات المشاركة بأنثطة تعليم الكبار ومستوياتهم الثقافية.

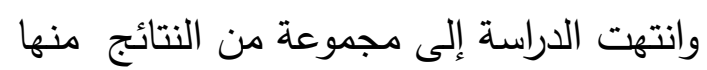
إلى أن هناك مجموعة من الخصائص في مجال أبحاث، ودراسات تعليم الكبار وهذه التهاته

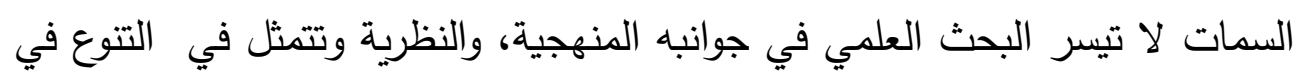


شتات بلا توافق ولا ترابط، والتغير بلا تواصل واستمرار والتفكك والتباعد والانقطاع، وضعف التنظيم وغياب مفهوم المنظومة فجميع هذه الخصائص لا تيسر البحث العلمي في جوانبه المنهجية والنظرية.

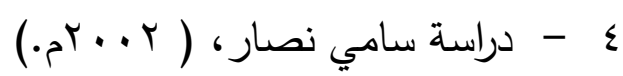

هدفت الدراسة تحليل ما نشر منذ عام 910 1- وحتى عام 1990 في مجال تعليم الكبار في الولايات المتحدة، وبريطانيا للتوصل إلى الاتجاهات الجديدة، وخلصت الدراسة إلى تتوع الاتجاهات الجديدة في تعليم الكبار ويحكم ذلك ثلاث مدارس فكرية هي المدرسة الليبرالية التقدمية، والمدرسة النقدية، والمدرسة الفردية، وشملت المجالات الحديثة التعليم التقافي، والتعليم للجميع، ورابط التدريب المهني بالتعليم الليبرالي.

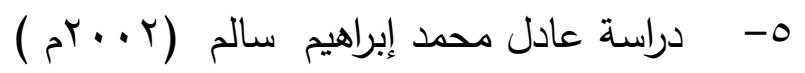
هدفت الدراسة تحديد مشكلات البحث في مجال تعليم الكبار ، والتي تمثلت في وجود عناصر قيادية غير متخصصة، وضعف التواصل بين المؤسسات البحثية، والافتقار إلى التسيق، والتكامل بين البحوث مما يؤدي إلى تكرارها وعدم وجود خريطة بحثية للمجال.

لذا أوصت الدراسة بوضع هذه الخريطة، مع دعم التواصل بين الجامعات، والمراكز البحثية، وإنشاء آليات ومراكز للربط والتتسيق بين الجامعات. T هدفت الدراسة تطوير إجراء البحوث التربوية في مجال تعليم الكبار ، وذلك من خلال تعرف الوضع الحالي، والصعوبات التي تواجها ووضع مقترحات بالعلاج. وخلصت الدراسة إلى أن البحث في تعليم الكبار يعاني من ضعف الاتصال بين المهتمين به سواء الأفراد أو المؤسسات وأن القائمين عليه لابد أن يتمكنوا من مهارات البحث وتكون متطلبات البحث نابعة من المجتمع ومشكلاته. 


\section{موقف المجلات التربوية العربية من بعض القضايا الخاصة أ.م. دـ ـ محمد أحمد محمد اسماعيل}

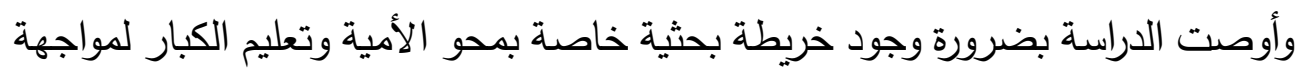

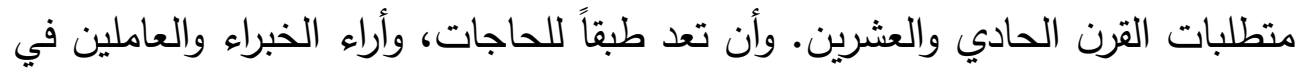

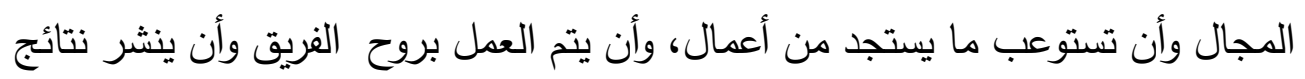
هذه البحوث

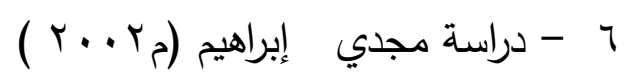

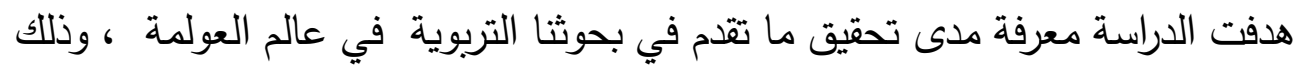
بعد عرض رؤية مقترحة للخروج من إثكالية تمويل البحث التربوي. وتوصلت الدّراسة إلى مجموعة من النّائج منها:

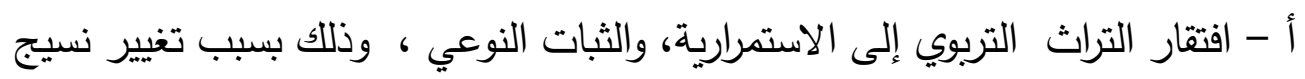
رؤية الإنسان عن طريق الوسائل التي استحدثت على مر الزمان. ب - البحث التربوي لم يعد نشاطاً إنسانيا لدراسة الحاضر والدستقبل على السواء.

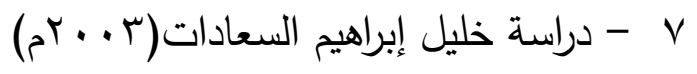
هدفت الدراسة الكثف عن أسباب ندرة البحث العلمي في ميدان تعليم الكبار . وخرجت الدَراسة بمجموعة من النّتائج منها: أ - ندرة المتخصصين في مجال تعليم الكبار ما يؤدي إلى عدم ممارسة البحث في هذا

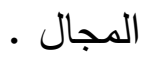

ب - عدم التقدير والوعي بأهمية هذا المجال، وآثاره على المجتمع ، مما يؤدي إلى

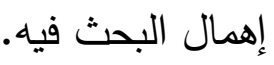
ج - قلة برامج الدراسات العليا في مجال تعليم الكبار ، وذللك وفقاً لآراء المستفيدين.

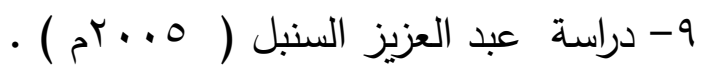

هدفت الدّراسة تحليل مضامين البحوث المنشورة في مجلة تعليم الجماهير خلال عقد

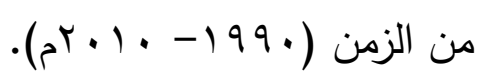


وخرجت اللّراسة بمجموعة من النتّائج منها:

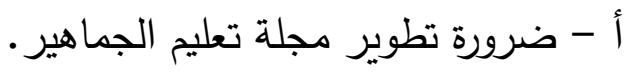

ب - ضرورة تطوير البحث العلمي في ميدان تعليم الكبار في الوطن العربي. ج - كثف نتائج الدراسة الحالية أن مجلة تعليم الجماهير كان لها سبق الفضل في التعريف بالعديد من المجالات الحديثة في مجالات تعليم الكبار، كما استوعبت موضوعاتها المنشورة العديد من القضايا التنموية. د - أن معالجة قضايا تعليم الكبار لم تكن فكراً أو تحليلاً، وتطبيقاً، باستمرار على نفس هونس المستوى المطلوب والمأمول ، كما غابت عن تلك المعالجات في إطارها العام المنهجية العلمية الواجبة. هـ - هناك تراكمات في مجالات تعليم الكبار على حساب مجالات أخرى لها نفس ألى الهـ

$$
\begin{aligned}
& \text { الأهمية إن لم تكن أكثر. }
\end{aligned}
$$

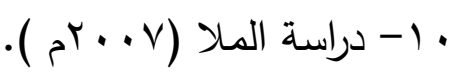

هدفت الدراسة تقصى المعوقات التي تواجه البحث العلمي التربوي وتحول دون الاستفادة من نتائجه في تطوير التعليم والتدريب، وتقويم أنسب الحلول لها.

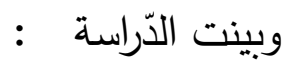
أ - أن أكثر المعوقات التي تواجه البحث العلمي التربوي وتحول دون الاستفادة منه في تطوير التعليم والتدريب من المعوقات المادية حيث جاءت في المرتبة الأولى، وتليها المعوقات الإدارية في المرتبة الثانية، والمعوقات المنهجية في المرتبة الثالثة، وأخيراً المعوقات الذاتية الثخصية في المرتبة الرابعة. ب - - جاء المقترح المتعلق بزيادة الدعم المادي لأنشطة البحث العلمي في المرتبة الأولى ضمن الحلول المقترحة لحل المعوقات التي تواجه البحث التربوي وتحول دون برن الاستفادة منه في تطوير التعليم والتدريب. 


\section{موقف المجلات التربوية العربية من بعض القضايا الخاصة أ.م. د ـ محمد أحمد محمد اسماعيل} وفي ضوء هذه النتائج قدمت الدراسة مجموعة من التوصيات التي يمكن أن تسهم في الحد من المعوقات التي تواجه البحث العلمي التربوي وتحول دون الاستفادة من نتائجه.

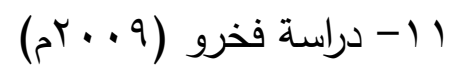

هدفت الدراسة معرفة المقصود، بمفهوم التميز البحثي في السياق المعلوماتي و المعرفي المعاصر ، ومعرفة الخبرات، و المرجعيات التي توضح معايير التميز في البحث العلمي والكثف عن حاجات الجامعات، ومراكز البحث في البلاد العربية الى معايير التميز البحثي ووضع الإطار المقترح لمعايير التميز في البحث العلمي العربي • وخرجت الدراسة بمقترح خاصة بوضع معايير التميز البحثي في مجال البحث العلمي كنظام معرفي مجتمعي، وفي مجال البحث العلمي كمنظومة تعليمية أكاديمية.

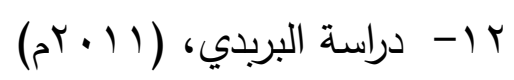

هدفت الدراسة إلى تحديد الأسباب الكبرى التي أنتجت هذه المستوى من الافتقار للإبداع في المحيط الأكاديمي العربي، وإبراز أهم تجليات هذه المشكلة. وخلصت الدّراسة إلى: ألى أن هنالك ثلاث أسباب رئيسة لضعف الإنتاج الإبداعي تتمثل في: أ - عدم الانبثاق من الإطار الحضاري العربي الإسلامي. ب - افتقاد الإطار المعرفي (الابستمولوجى ) الإسلامي. ج - ضعف بيئة الإبداع في الساحة الأكاديمية والبحثية العربية، وحددت الورقة أربعة الإنة مظاهر لمشكلة ضعف الإنتاج الإبداعي وهي: - عدم تشجيع كتب مناهج البحث العربي للإبداع. - تأكيد نتائج بعض الأبحاث العربية على قلة الاهتمام بالإبداع. - غلبة الأسلوب الكمي في البحث العربي. - ضعف الأنظمة الثقافية لدى الباحثين العرب. 
وتقترح الورقة البحثية مصطلح الانفة الثقافية "ليعكس مستوى قناعة وقبول الأكاديميين العرب ثقافياً وحضارياً ونفسياً ونظرياً لتبني نماذج ونظريات فلسفية ومعرفية لا تتتاغم مع المركب الحضاري العربي الإسلامي، وقد بلورت الدراسة بعض التوصيات الهامة للأبحاث المستقبلية و للمؤسسات العلمية، والثقافية العربية.

ثانياً : الاراسات الأجنبية : Quigley دراسة كويجلى1999 -

هدفت الدراستة

- الكثف عن طبيعة البحث و التطبيق في تعليم الكبار - معرفة معطيات البحث العلمي في تعليم الكبار • - الكثف عن الواقع البحثي في مجال تعليم الكبار . - مناقشة بعض طرق البحث العلمي في مجال تعليم الكبار . و خرجت الدراسة بمجموعة من النتائج منها - ضرورة تشجيع طلبة الدراسات العليا على عمل البحوث أثناء عملهم الوظيفي و ليس فقط لإنهاء رسالة أو أطروحة . - ضرورة تعليم منهجية البحث ذات العلاقة بتعليم الكبار بطرق مختلفة .

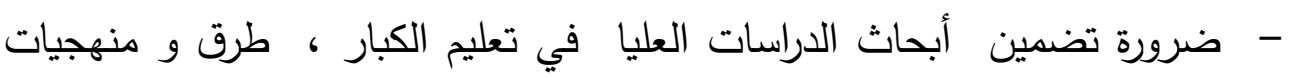

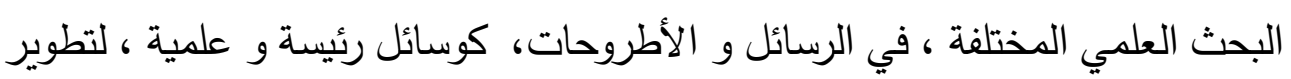

قواعد المعلومات ، و التطبيقات العملية في هذا المجال . Dean 1999 ب دراسة دين هدفت الدراسة - تحديد بعض العوامل و الأسباب التي أدت إلى تحول البحث في تعليم الكبار و

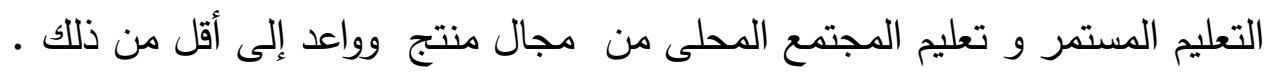




\section{موقف المجلات التربوية العربية من بعض القضايا الخاصة أ.م. دـ ـ محمد أحمد محمد اسماعيل}

- الكثف عن مدى تحقيق البحث في مجال تعليم الكبار لاحتياجات هذا المجال وخرجت الدراسة بمجموعة من النتائج منها : -

- إن البحث في مجال تعليم الكبار لايحقق احتياجات الذين يريدون أن يقوموا

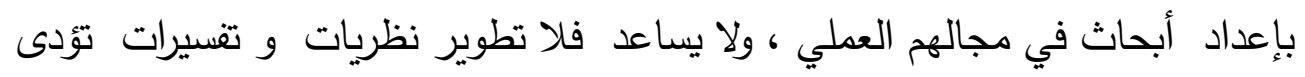
إلى تحقيقات ، و اكتثافات مفيدة في المستقبل و لايساعد في فهم تعقيدات

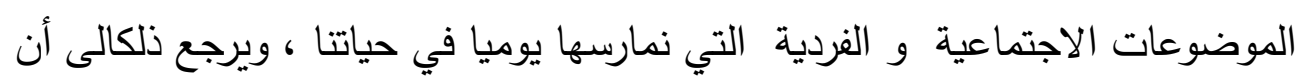

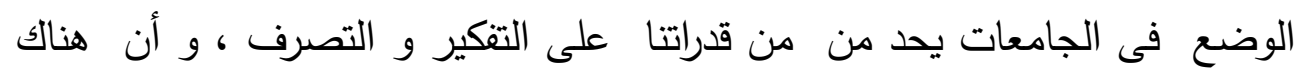

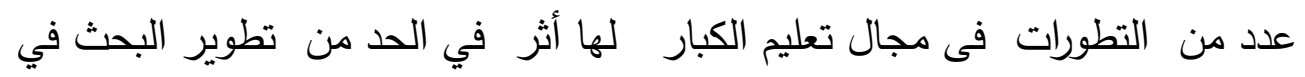
هذا المجال

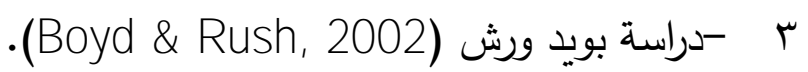
هدفت الدراسة معرفة واقع إسهامات أعضاء هيئة التدريس بجامعة سانتاكروز

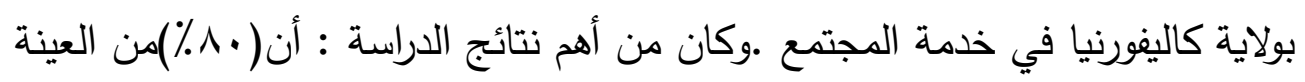

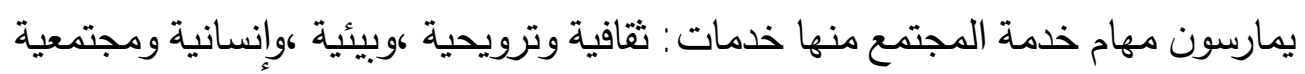

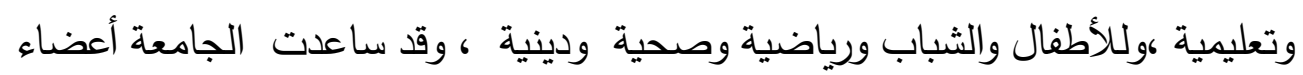

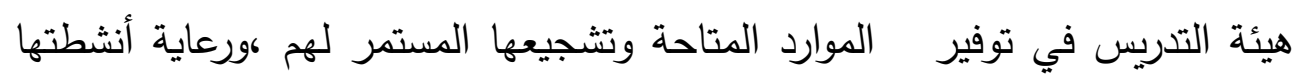
المختلفة وإيجاد مقررات دراسية مرتبطة بخدمة المجتمع .

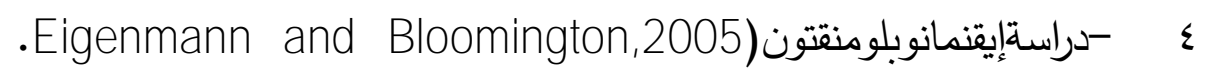
هدفت الدراسة تعرف دور كليات التربية في تعليم ودمج الطالب في الحياة واستخدم الباحثان الدنهج الوصفي التحليلي وتكونت أداة الدراسة من استبانة للطلبة واستبانة

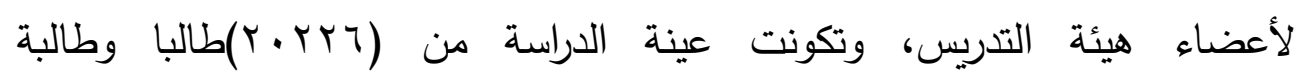

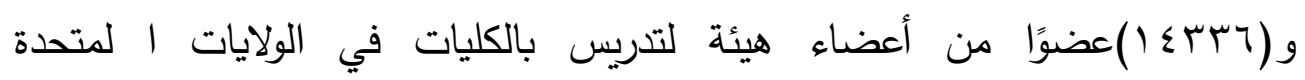

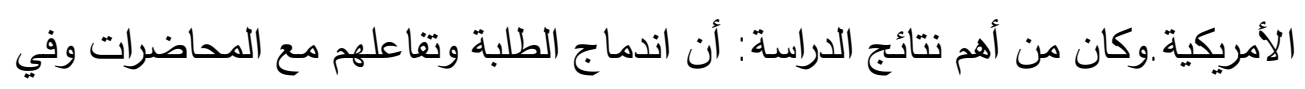


المجتمع كانايجابيًا بنسبة أكثر من أعضاء هيئة التدريس من وجهة نظر الطلبة، وأن اندماج أعضاء هيئة التذريس بالكليات وتفاعلهم في المجتمع كان إيجابيًا من وجهة نظر أعضاء هيئة التدريس.

\section{التعقيب على الاراسات السابقة:}

يتضح من عرض الدراسات السابقة، أن بعضاً منها تتاول منهجيات ومشكلات

$$
\text { البحث من مجال تعليم الكبار • }
$$

حيث تتاولت تعليم الكبار كمجال بحثي، وهدفت إلى توضيح المجال ومفهومه ونظرياته ومجلاته البحثية المختلفة، ومشكلات البحث فيه، وخلصت نتائجها إلى أنه علم نام، ولم تكتمل صورته البحثية، لذا فإنه يحتاج إلى تحديد وتعرف توجهاته المستقبلية ، لما لما له من دور في مواجهة التحديات العالمية، ووضع أسس البحوث به، وتطوير منهجيات هذه البحوث، كذللك هنالك حاجة إلى تحقيق التواصل بين المراكز البحثية ومتخذي القرار ، حتى يتم الاستفادة من نتائج البحوث المختلفة، واقترحت بعض الدراسات وضع خرائط

بحثية لمجال تعليم الكبار •

كذللك تناولت بعض الدراسات تحليل الإنتاج الفكري في مجال تعليم الكبار اتخذت كل منها شكلا من أثكال الإنتاج الفكري لتحليله وموضوعاً محداً في المجال واستخدمت لإلج جميعها المنهج الوصفي، مع تحليل للمضمون، وخلصت إلى حداثة المجال، وبالرغم من خطورة موضوعاته إلا أن الموجود من الابحاث فيها ضعيف مثل محو الأمية، كذلك يتسم الإنتاج الفكري لهذه الأبحاث بالتكرار والفردية في الاختيار .لذا فهناك حاجة إلى رسم خريطة بحثية للمجال توضح ما تم وما ينبغي أن يتم . كذلك يتضح من خلا عرض هذه الدراسات أن الإنتاج الفكري في تعليم الكبار يعاني العديد من المشكلات مثل الذاتية في اختيار موضوع البحث وتكراره في أكثر من جامعة ، والفجوة بين نتائج البحوث واتخاذ القرار ، كل هذا أدى إلى ضعف لهن 
موقف المجلات التربوية العربية من بعض القضايا الخاصة أ.م. دـ ـ محمد أحمد محمد اسماعيل تأصيل المجال، وبالتالي ضعف الممارسات به، وعدم الاستفادة من نتائج الدراسات لذا تختلف الدراسة الحالية عن الدراسات السابقة ، في أنها تتناول بالتحليل الأبحاث التربوية التي تتاولت دور كليات التربية في مجال محو الأمية و تعليم الكبار بالمجلات الأربع

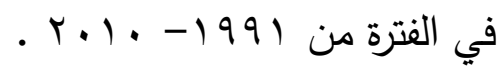
أولاً: الإطار الفكري و المفاهيمى للدراسة و يتناول : - البحث العلمي التربوي في مجال تعليم الكبار ( مفهومه - أنواعه- مبادئ ممارسته)

- مفهوم محو الأمية و تعليم الكبار

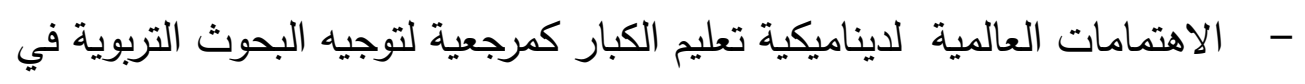

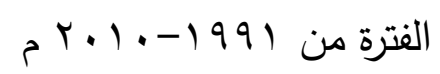

- تحليل و تفسير العوامل والمتغيرات المجتمعية التي أدت إلى زيادة الاهتمام بإجراء البحوث في مجال محو الأمية، وتعليم الكبار أ : البحث العلمي التربوي: - - التعريف و المفهوم: -

يعرف البحث العلمي بأنه: مجموع الجهود، والإجراءات المنظمة التي تستهدف التوصل إلى حقائق جديدة، أو التحقق من وجودها، والإسهام في المعرفة الإنسانية، والتوصل

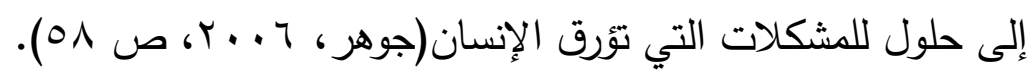
أما البحث العلمي التربوي فيعرف بأنه: عملية تستهدف ربط الظواهر التربوية بالتغيرات الاجتماعية، والثقافية، والاقتصادية الحادثة في المجتمع ،من أجل توظيف

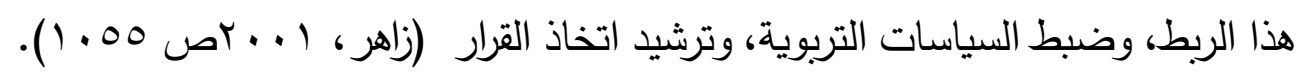

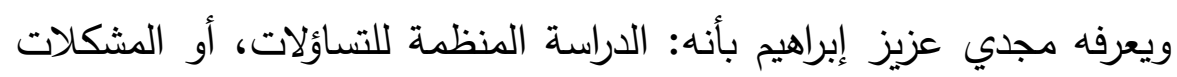
ذات الصلة أو العلاقة بالعملية التربوية التعليمية بعامة، أو بالمنهج أو بالمواقف إنف التهائ 
التدريسية بخاصة، سواء أكانت هذه الصلة أو العلاقة مباشرة ،أم غير مباشرة،كما يعرف بأنه: استقصاء منظم يختص بحدث معين ، أو مجموعة أحداث معينة ،بقصد توسيع

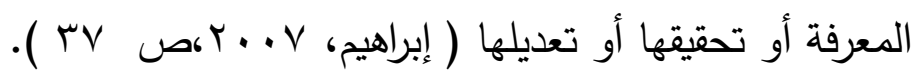
لذلك فان مفهوم البحث التربوي يتمثل في كونه يفسر الظواهر الموجودة بالفعل من

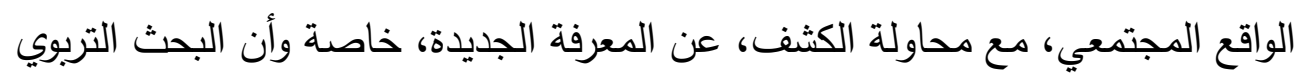
في مجتمع المعلومات العالمي، مطالب بأن يتجه إلى التجديد، واقتراح أساليب في إطار نظرية، أو رؤى فلسفية تؤكد على تكافؤ الفرص التعليمية من حيث المساواة في إتاحة التعليم للجميع، والتتوع الملائم لمتطلبات الفئات المتتوعة في المجتمع. ب -تصنيف أنواع البحث العلمي التربوي . تصنيف الأبحاث التربوية لمحاور متعددة، أهمها : البحوث الاساسية أو البحتة (Basic research)

وتهدف إلى اختبار أو تطوير النظريات والتوصل إلى مبادئ وقوانين علمية، وإضافة ما هو جديد للمعرفة العلمية، وتجري هذه البحوث في المختبرات، كالبحوث إنى التي تهدف إلى اكتشاف علاقات ومبادئ عامة في التعليم والتعلم (الثايب، 9 . . بم). البحوث التطبيقية Deripxine research ويطلق عليها البحوث الميدانية، وهي تعني بصورة رئيسة بتحديد العلاقات بين الظواهر التربوية، واكتشافها، و تهدف لإيجاد حل لمشكلات قائمة، فتختبر النظريات والمبادئ و الفروض من مواقف واقعية، أو محاكاة النظرية للواقع المعتمدة على التجارب والدراسات الميدانية للتأكد إمكانية تطبيق النتائج على أرض الواقع في المجال التربوي ( الشايب، 9 ... ج ) 
موقف المجلات التربوية العربية من بعض القضايا الخاصة ا..م. دـ ـ محمد أحمد محمد اسماعيل

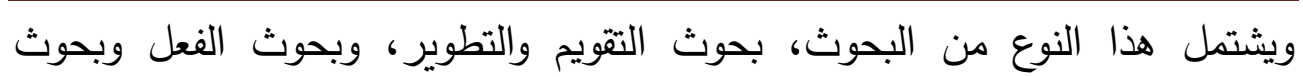

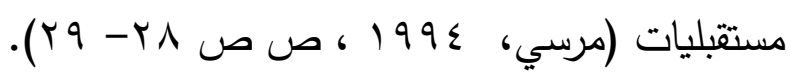

بحوث التقييم والتقويم Evaluation Research وتهذف لتطوير نتاجات فاعلة، يمكن استخدامها في المجال التربوي لتلبية حاجات

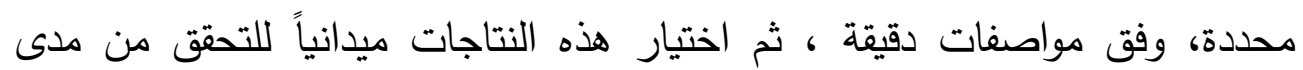
فاعليتها، وهذا النوع من البحوث يتسم بارتفاع كلفته، إلا أن له مردود إيجابي على

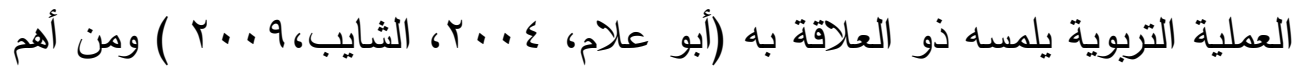

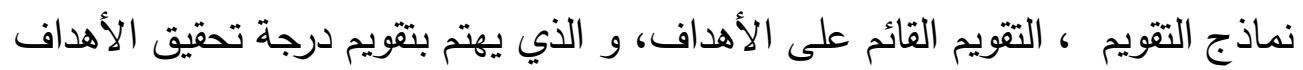
التربوي.والتقويم القائم على تحليل النظم، والتكاليف ،كتقويم التخطيط البرامج وآثارها وفاعليتها الاقتصادية، والتقويم الموجه نحو اتخاذ قرارات، حيث يقوم على أساس نظرية

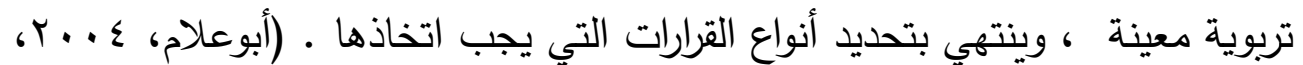

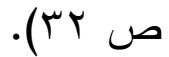

Research Development بحوث التطوير وتهدف لتطوير نتاجات فاعلة يمكن استخدامها في الميدان التربوي لتلبية حاجات محددة، وفق مواصفات دقيقة، ثم اختبار هذه النتاجات ميدانياً لتحقق مدى لتى لتري فاعليتها. وهذا النوع من البحوث يتسم بارتفاع كلفته إلا أن له مردود ايجابي على العملية

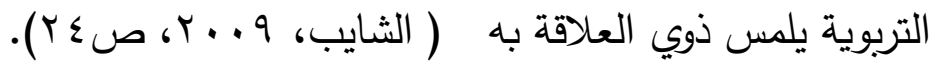

$$
\begin{aligned}
& \text { البحوث الإجرائية Action Research }
\end{aligned}
$$

وتهذف لحل مشكلات محلية باستخدام خطوات الطريقة العلمية ، والباحث هنا لا يهتم بتصميم نتائج بحثه على المواقف البحثية الأخرى، ولا يمارس عناصر الضبط الذي يمارسه الباحث في الأنواع الأخرى من البحوث بنفس الدرجة، ولا تتعدى فوائد 
البحوث الإجرائية، حدود الأشخاص الذين يقومون المعلمين في صفوفهر (الثايب،

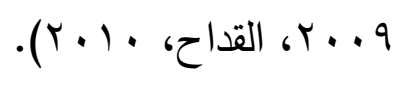

التصنيف وفقاللمنهج

\section{وتصنف البحوث وفقا للمنهج إلى نوعين:}

البحوث الكمية والبحوث الكيفية (النوعية)فتوجد البحوث الكمية التي تهدف إلى إكى

وصف كمي للمعلومات، والبحوث الكيفية التي تهدف إلى وصف الظاهرة وتطوير

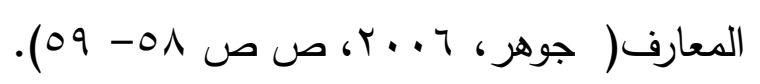

ويعرف البحث الكمي (Quantitate Research ) بأنه يهتم بجمع البيانات من خلال استعمال أدوات قياس كمية يجري تطبيقها على عينة ممثلة للمجتمع الأصلي ، و تتم معالجة البيانات بأساليب إحصائية تقود إلى نتائج يمكن تعميمها على المجتمع

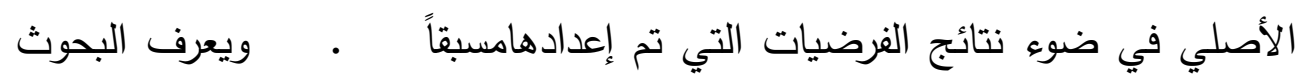
النوعي ResearchQualitative بأنه البحث الذي يعتمد على دراسة الظاهرة في

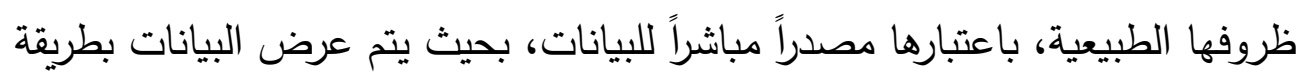

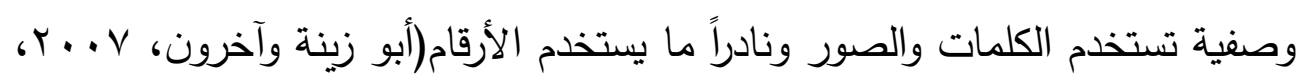

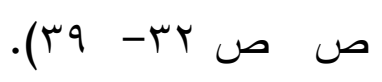

ويصنف البحث النوعي عادة في صنفين هما: البحث النوعي التفاعلي ، و البحث النوعي غير التفاعلي.

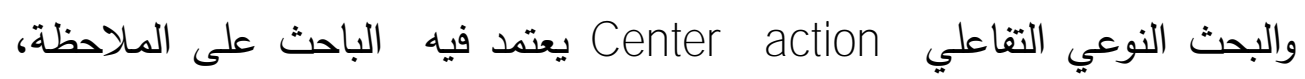
والمقابلات وتحليل الوثائق، أو مجموعة منها لتوفير فهم متعدقة للظاهرة موضوع الدراسة وفي العادة يكون الباحث في موقع الدراسة لفترة طويلة من الوقت من أجل الفهم التام للأشخاص والظواهر موضوع البحث. 
موقف المجلات التربوية العربية من بعض القضايا الخاصة أ.م. دـ ـ محمد أحمد محمد اسماعيل والبحث النوعي (غير التفاعلي) يدرس المفاهيم، والاحداث التاريخية والقانونية ، وتلك المتعلقة بالسياسات العامة، من خلال تحليل الوثائق، بالإضافة إلى التاريخ الثفوي

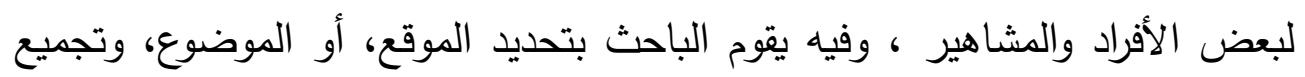

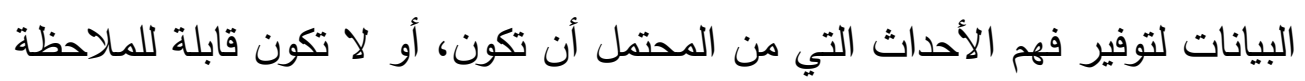
Hannon 2000.p ) المباشرة وفي العادة تكون هذه الأحداث قد وقعت في الماضي. .$(80-83$

\section{مبادئ ممارسة البحث التربوي:}

يرى كل من سوان و جون Swann ,joanna\&johnpratt أن للقيام ببحث تربوي جيد لا بد من توافر

1- الهدف فلابد من وضوح الهدف المراد للوصول إليه في النهاية، واختيار الطريقة

التي سوف يتم البحث بها، بناء على طبيعته المستقلة.

r- الدقة في اعداد فكرة البحث، حتى يمكن اختيار المنهجية المناسبة.

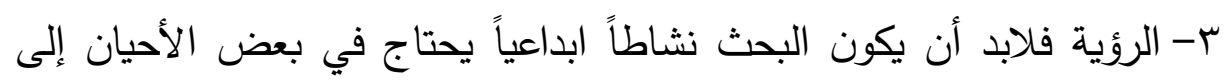
استخدام الخيال للوصول إلى حل للمشكلات. ع - العناية بالأدوات والتخطيط وكتابة البحث.

ه-بذل المجهود وتوافر الوقت و الموارد ( Swann,Pratt Joanna\& J ohn,2000,PP192- 193 ) البحث التربوي في تعليم الكبار:

هي تلك الجهود التي تتوفر فيها الأركان الأساسية للبحث العلمي ، والتي تجري في إطار الجامعة والمراكز والأقسام البحثية المعنية بتعليم الكبار ، وتهدف إلى تتمية الرصيد

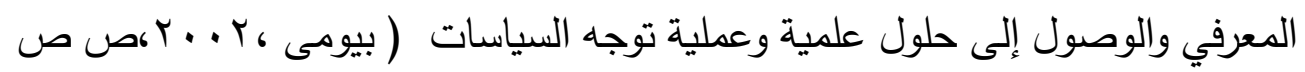

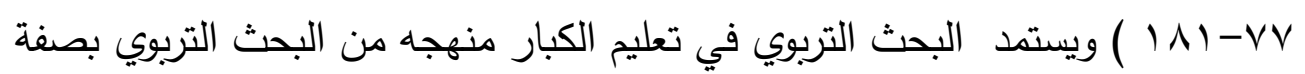


عامة،و تتضح أهميته من حاجة المجال إلى معايير وأحكام علمية يمكن من خلالها التعامل مع تعليم الكبار كظاهرة لها أبعادها السياسة والاقتصادية والاجتماعية والتربوية، وبدون ذللك سيظل مجالاً للاجتهاد الشخصي والمحاولة .

مفهوم محو الأمية و تعليم الكبار

$$
\text { أ - محو الأمية }
$$

شهد مفهوم الأمية عدة تحولات هامة منذ منتصف القرن العشرين فانتقل من المستوى العالمي إلى المستوى المحلى ومن الجهود الفردية إلى الجهود الحكومية المنظمة ومن كونه ظاهرة اجتماعية إلى اعتباره عقبة في سبيل التقدم و الرقى الاقتصادي و الاجتماعي كما انتقل أخيرا من المفهوم التقليدي الضيق إلى المفهوم

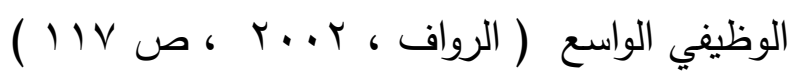

و حقيقة الأمر إن هناك غموض و لبس في مفهوم الأمية و تعدد أنماطها ، و يرجع

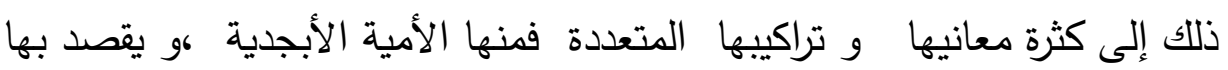
أمية الحرف أو الرمز أي الجهل بأساسيات القراءة و الكتابة و إجراء العمليات

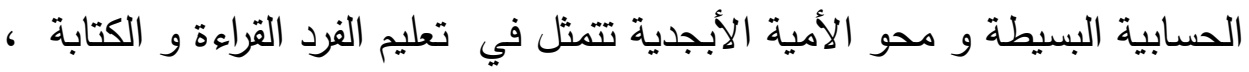

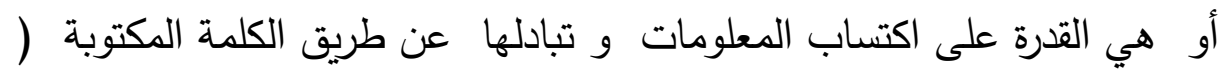

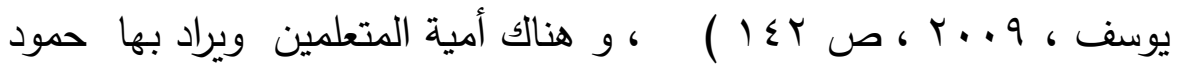
المتعلمين على المستوى الثقافي الذي تركوا فيه الدراسة و لم يسعوا لمتابعة

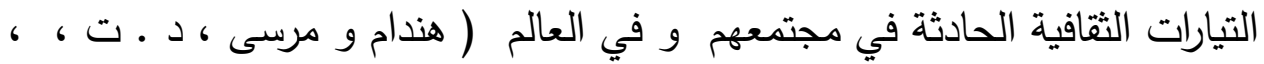

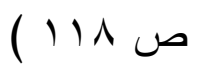
كذلك هناك الأمية الوظيفية التي لها مدلولات تختلف من مجتمع إلى أخر ، ومن تخصص لآخر ومنها الأمية الوظيفية التعليمية التي تعنى ان الفرد لا يمتلك الكي

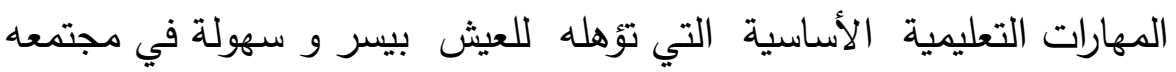


موقف المجلات التربوية العربية من بعض القضايا الخاصة أ.م. دـ ـ محمد أحمد محمد اسماعيل و محو الأمية الوظيفي يعنى أن التعلم لايقف عند حد تتمية الأفراد بإشباع حاجاتهم

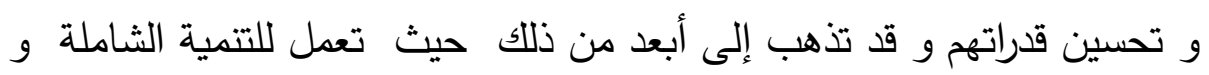
إشباع حاجات السوق و العمالة مثل محو الأمية الصحية و التربوية و الفنية و غيرها ، و هناك كذلك الأمية الحضارية التي تدل على قلة إلمام الشخص بتراث أمته و علومها و حضارتها و يتمثل محو الأمية الحضارية في إحداث تغييرات

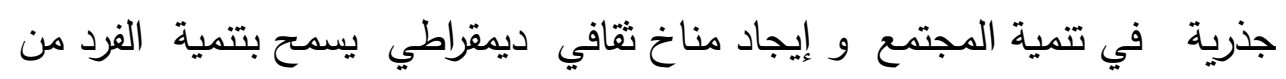

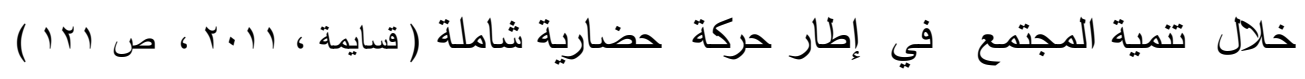
ب - بعليم الكبار : لا يوجد تعريف محدد وشامل ومتفق عليه بشأن تعليم الكبار ، وذلك لتعدد تعريفاته ،

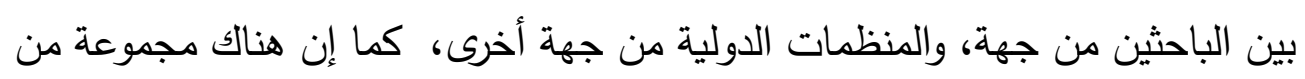
العوامل و المتغيرات أدت الى ضبابية مفهومه ، منها متغيرات تربوية تتمثل في عدم توفير التعليم لمن هم في سن التعليم الأساسي ، و تسرب للدارسين ، ومتغيرات تنموية تتمثل في الحاجة إلى برامج تنمية للعاملين في مجالات التنمية المختلفة لتطوير قدراتهم العلمية و زيادة انتاجيتهم ، مما يدفع بعجلة التتمية الثاملة ، و هنا تصبح برامج التتمية

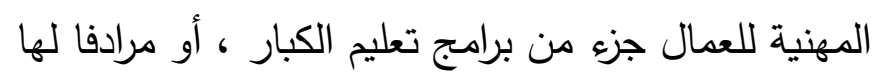
ففي ضوء الحاجة إلى التتمية و تطوير المهارات الاجتماعية لأفراد المجتمع و بهات العاملين في المهن المختلفة ، فان البرامج الموجهة للكبار تغلب عليها الصبغة الاجتماعية،لما لذلك من ضرورة في تتمية العمل الجماعي ، و تعمل البرامج هنا على ربط أواصر المجتمع ببعضه ،و التقريب بين أفراده ، وزيادة الوعي المجتمعي بالقضايا و المشكلات الملحة وهنا تصبح برامج تعليم الكبار مرادفة للتنمية المجتمعية و العمل

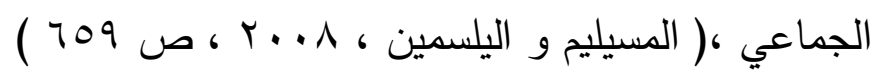


لذلك نجد جيرالد أيس erald Apps وهو أحد المعنيين بمجال تعليم الكبار يورد عدة مصطلحات له، منها التربية مدى الحياة ife long education أوالتربية غير Continuous learning المستمرة Non continuous education وتعليم الكبار Adult education Past secondary التربية بعد المرحلة القانونية Permanent education ائمة Paية Non ورالدراسات غير التقليديةAndrayagog بوعلم تعليم الكبار Malcolm know less إلى المصطلحات أضاف مالكو كم نولز السابقة مصطلح تأهيل الدارسين in service pmogram Develop ment العاملة Man power develop ment التربية من أجل التطوير education ومن التعريفات الخاصة بتعليم الكبار ،تعريف كومبسPيث عرديث عرفه بأنه: أي نشاط تعليمي منظم يقع خارج النظام التعليمي المؤسسي بقصد خدمة الأفراد الراغبين في التعليم، ولتحقيق أهداف تعليمية معينة (حزام وآخرون، د.ت، ص ب ( ).

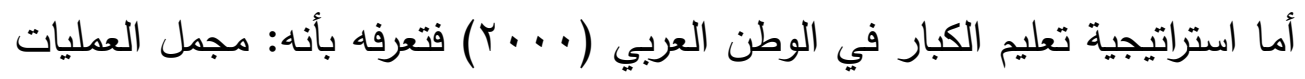
التعليمية التي تجري بطريقة نظامية أو غير نظامية، والتي ينمي بفضلها الأفراد والكبار

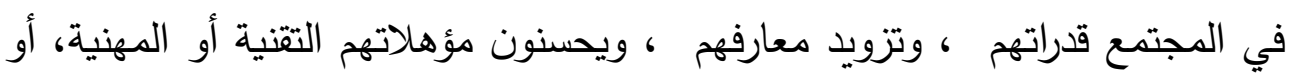
يسلكون بها سبيلاً جديداً لكي يلبوا حاجاتهم وحاجات مجتمعهم. ويشمل التعليم النظامي و غير النظاميوالتعليم المستمر، وكافة أشكال التعليم غير الرسمي.(المنظمة العربية للتربية، والثقافة، والعلوم، ، . . . Y، ص و ؟).

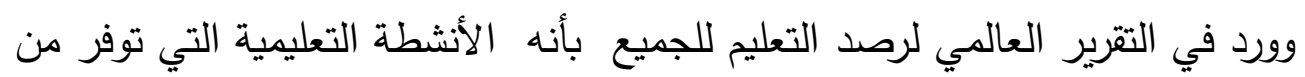
خلال أطر التعليم النظامي أو غير النظامي أو العرض غير الرسمي، والتي تستهدف لئه 
موقف المجلات التربوية العربية من بعض القضايا الخاصة ا..م. دـ ـ محمد أحمد محمد اسماعيل

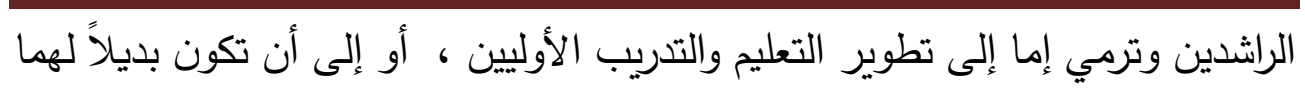

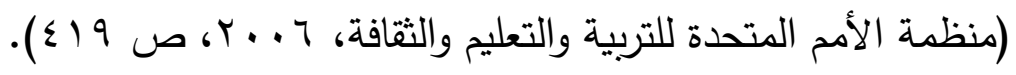

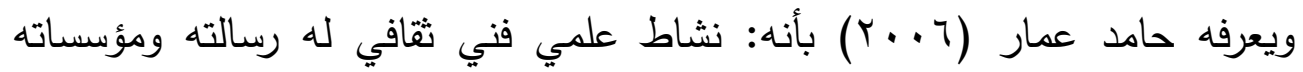

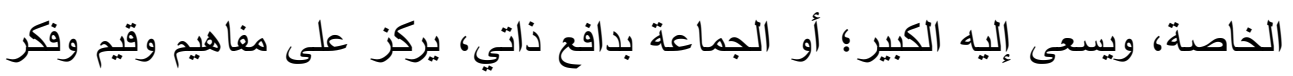

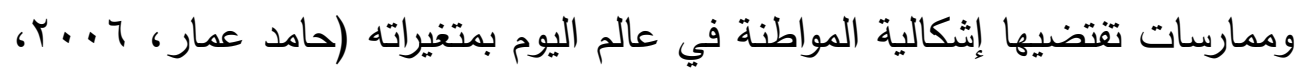
ص ص (V) ويلاحظ من تعريف حامد عمار أنه يؤكد على التقدم الذي تعيشه البشرية اليوم، وما تثملها من متغيرات تتطلب السعي نحو التعلم. ويعرفه برستون Pmeston بأنه: مجمل العمليات التعليمية التي تجري بطريقة نظامية

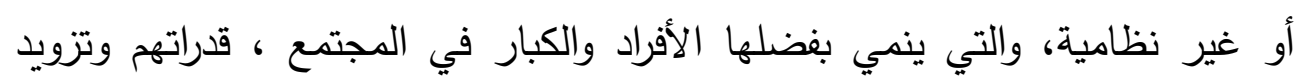

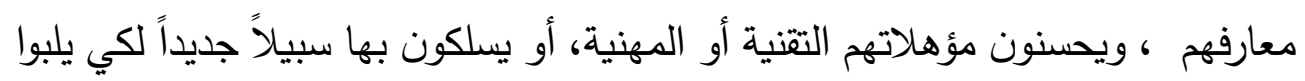

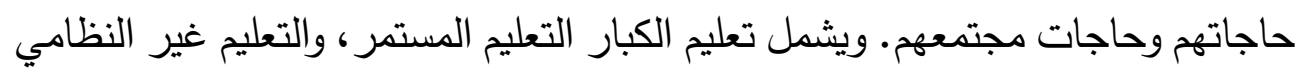

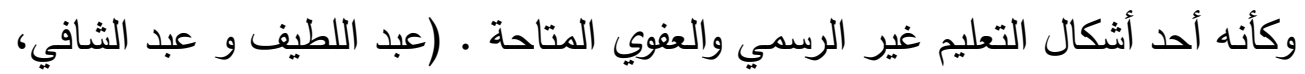

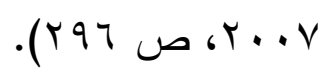

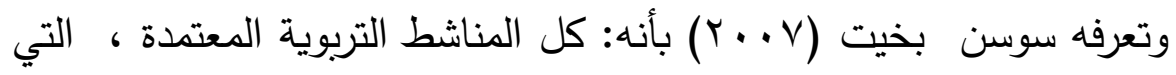

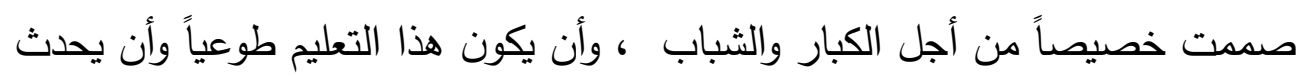

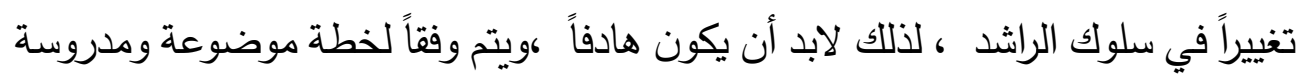

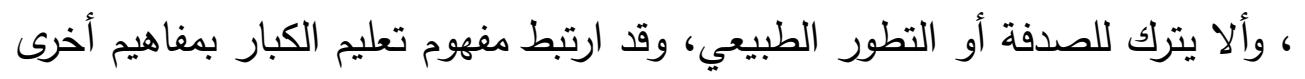

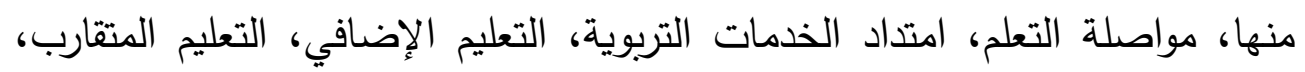

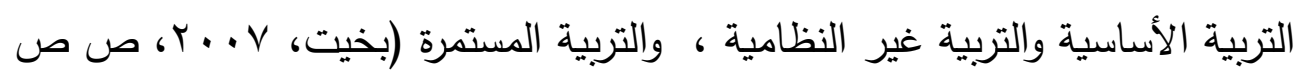
. (rTO-rTr 
وتجمع جل التعريفات على اختلاف خلفياتهم الاجتماعية والاقتصادية ، على أن تعليم الكبار، يمكن أن يتم على ضوء تحديد أهداف المتعلمين من المعرفة التي يسعون إلي

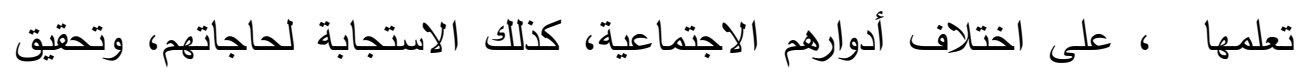
طموحاتهم عن طريق إتاحة الفرص أمامهم للتعرف على مجالات المعرفة المناسبة لهم، وتتمية مهاراتهم، وتمكنهم من تحقيق القدرة على التعلم بأنفسهم ، ليتمكنوا من الاعتماد على أنفسهم في التعلم والممارسة العملية، وأن يصبحوا أكثر إدراكاً ومسؤولية تجاه مجتمعهم، وان يتطور التعلم بالنسبة لهم كجزء من تحقيق الذات الفردي والاجتماعي،

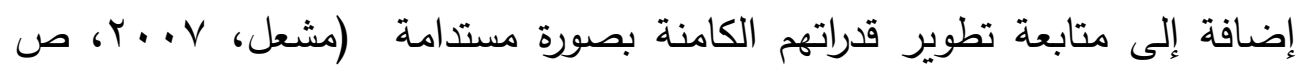
.$(19)$ أهم الاهتمامات العالمية لديناميكية تعليم الكبار كمرجعية لتوجيه البحوث التربوية في

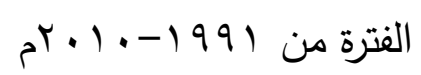

انشغل العالم في العقد الأول من القرن العشرين ، و العقد الأخير

من القرن الواحد و العشرين ، بقضية العولمة و تجلياتها و تداعياتها ، والعولمة أساسا مفهوم اقتصادي قبل أن تكون مفهوم علمي ، أو سياسي ، أو تثقافي.

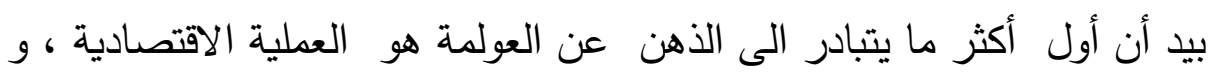
يعزى ذلك الى أن النظام الاقتصاديالعالمي خلال فترة التسعينات من القرن العشرين

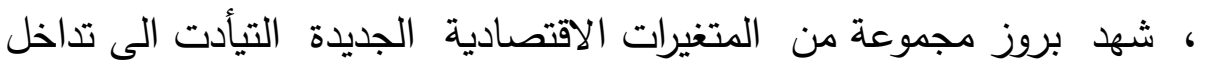

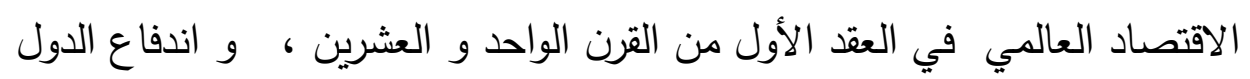

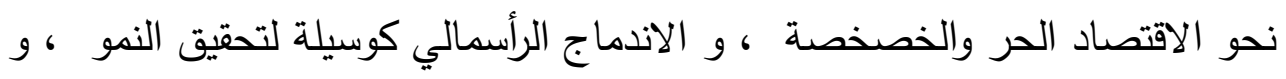
تحول المعرفة و المعلومة الى سلع استراتيجية ، و الى مصدر جديد للربح ، و و تحول اقتصاديات الدول المتقدمة من التركيز على الصناعة الى التركيز على الخدمات ، و بروز ثلاثة تكتلات تجارية رئيسة ، يتركز حولها الاقتصاد 


\section{موقف المجلات التربوية العربية من بعض القضايا الخاصة أ.م. دـ ـ محمد أحمد محمد اسماعيل}

العالمي ، و بروز دول منطقة شرق آسيا كطرف فاعل في الاقتصاد العالمي ، و احتمال انتقال مركز الثقل الاقتصاديالعالمي من المحيط الأطلسي الى المحيط الهادي ، بالإضافة الى بروز منظمة التجارة العالمية و الشركات متعددة الجنسيات و تزايد دورها في النشاط التجاريوالاستثمار العالمي، و شكلت هذه المتغيرات في مجملها العولمة الاقتصادية ،التي تفترض ان العالم قد أصبح وحدة اقتصادية واحدة ، تحركه قوى السوق التي لم تعد محكومة بحدود الدولة الوطنية ، انما ترتبط بمجموعة من المؤسسات العالمية و التجارية و الصناعية متعددة الجنسيات ( السيد

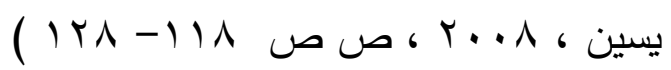

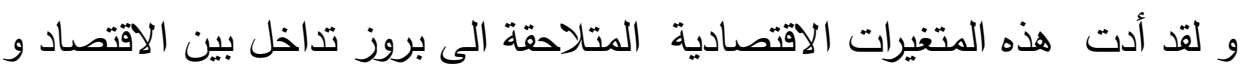

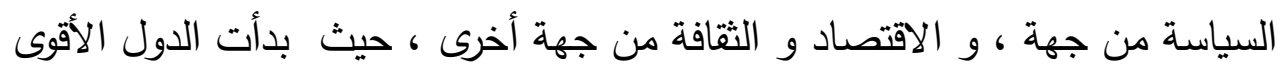
في فرض توجهات سياسية او ثقافية في اطار تحركاتها الاقتصادية ، وأدى ذلك بالتالي الى ما يعرف بالعولمة السياسية .

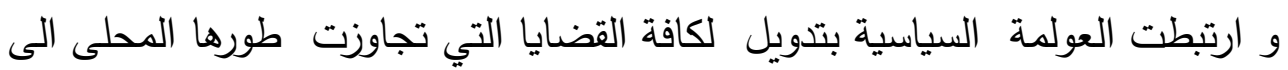

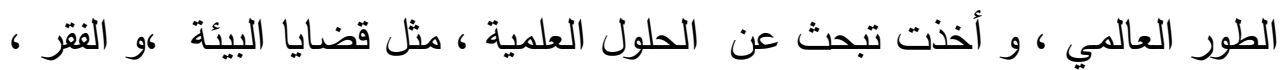
و محو الأمية ، و حقوق الانسان ، و مساعدة الأميين و غيرها من الموضوعات التي تزايد الحديث عنها مع بروز ملامح نظام عالمي جديد يستتد الى الأحادية ، و تعززت في سياقات العولمة أهمية كثير من القيم الانسانية المستحدثة ، خاصة تلك التي ترتبط بحقوق الانسان والسلم و السلام الدوليين و انتشرت كثير من مؤسسات المجتمع المدنيالتي تعمل في هذا المجال (السيد يسين ، 0. . ب ، ص ص

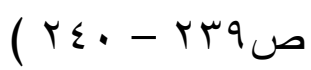

و على الرغم من أن الصراع الأقوى المناهض و المؤيد للعولمة تم في المستويات السياسية و الثقافية العليا ، بيد أن ديناميكية تعليم الكبار و المتخصصين فيها 
كانت لهم رؤيتهم حول هذه القضية ، فاذا كان الحال على مستوى السياسة يقبل هذا التباين في الرؤى ، فان ديناميكية تعليم الكبار المنحازة الى من لا يملكون يغلب على مواجهتها للعولمة جانب المناهضة و الرفض ، حتى في مستوى التنظيمات القائمة في الدول المتقدمة .

و لقد أصدرت مؤسسة التعاون الدولي للاتحاد الألماني لتعليم الكبار ( DVV) و المجلس العلمي لتعليم الكبار ( ICAE) ، ومعهد اليونسكو للتربية ( UIE) مجلد حول " العولمة ...... تعليم الكبار .....آثار و قضايا " و تضمن نقد صريحا للنظام

الاقتصادي الرأسمالي و للعولمة ، مؤكدين على أن العولمة في تجلياتها تغلب خطاب المنافسة على خطاب التضامن ، وتحل التجمعات الاقتصادية محل الدولة ، و تدهور دور المجتمع المدني ، و تزيد من وطئه الضغط النفسي على المواطنين ، و

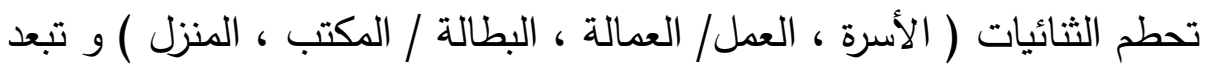
مواقع القوة في اتخاذ القرارات في اتجاه العالمي على حساب المحلى ، و اعتبرت أن لكل هذه الإشكاليات انعكاسات كبيرة على ديناميكية تعليم الكبار و مسيرته في

بلدان العالم ( Watter,1997,P 18 ) و تتسجم هذه الأفكار المناهضة للعولمة من قبل المتخصصين في مجال تعليم الكبار ، مع عبروا عنه من آراء حول العولمة في البيان الختامي للجمعية

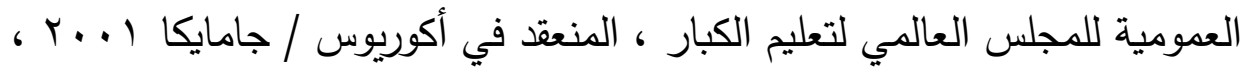
حيث صرحوا بالقول بأن العولمة الاقتصادية تزيد الثقة اتساعا بين من يملكون و

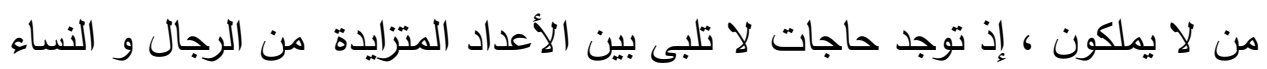
المستبعدين ، و تشتت تركيز التعليم من الجماعي إلى الفرد . ان هذا السياق يفاقم الأشكال المختلفة للتميز القائم على النوع و الوقت ،ورئ عدم القدرة ،و الطبيعة الاجتماعية و الدين ، و العمر و الاختلافات اللغوية و 


\section{موقف المجلات التربوية العربية من بعض القضايا الخاصة أ.م. د ـ محمد أحمد محمد اسماعيل}

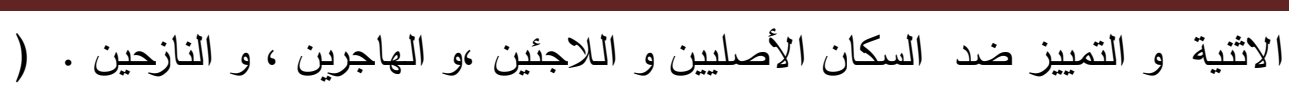

(International Council For Adult Education, 2001 , P

و على الرغم من المعارضات التي تبديها ديناميكية تعليم الكبار لتجليات العولمة و آثارها ، إلا أن هذه التغييرات قد أفرزت كثير من الأفكار و القيم ، و الاتجاهات

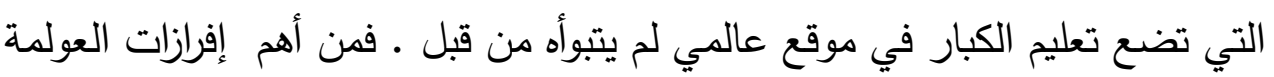
تنامي الاهتمام بحركة حقوق الإنسان و الفئات المهشمة و المرأة ، و تتامي دور تعليم الكبار في الخطط التربوية الرامية إلى تحقيق مبدأ التربية المستمرة للجميع في كافة أنحاء المعدورة .

كل هذه الاعتبارات ساهمت في تكوين مناخ دولي يساهم في دفع ديناميكية

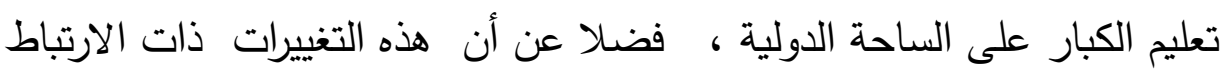
بالعولمة ، ساهمت إلى حد كبير في تتامي الوعي بأهمية تعليم الكبار كثأن

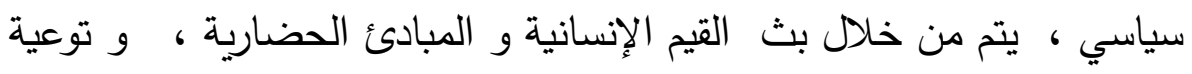

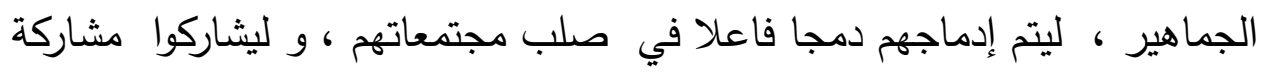
فاعلة في صياغة حياتهم و بناء مستقبلهم و مستقبل مجتمعهم ،في إطار من التوازن بين الأصالة و المعاصرة

و تعكس هذه المواقف للعولمة ، الموقف الرسمي المعلن للمجلس العالي لتعليم الكبار ، و المحلل لوظائف المجلس و أنشطته يتبين الدور السياسي الصارخ لهذه المؤسسة . فمن حيث الوظائف يقوم المجلس بوظيفتين أساسيتين أولهما : أدوار المناصرة ( Advocacy) ) و التضامن ( Solidarity ) للمجموعات التي تصارع ضد العنف و القهر و تبحث عن حقوقها و حريتها ، و مؤازرة مجموعات الضغط الشعبية في أماكن مختلفة من العالم .والدور الآخر يتمثل بالتوعية 
الإعلام ، و التعريف بحقوق الإنسان وواجباتهم في القضايا المصيرية كقضايا حقوق الإنسان و الديمقراطية و السلام •

و تنعكس هذه الأدوار على البرامج الأساسية التي ينشغل بها المجلس ،

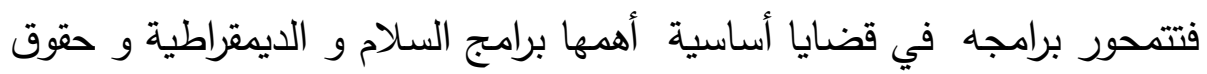
الإنسان و البرامج الدولية المساندة لـحو الأمية بمفهومها الحضاري الواسع (برجية

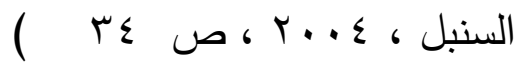
و لعل أهم تجل من تجليات العولمة في مجال تعليم الكبار يتمثل في مبادرة التعليم للجميع (199 ) ، الرامية إلى تدويل إثكالية الأمية ، و تحويلها إلى

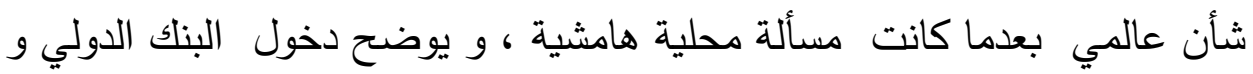
وبرنامج الأمم المتحدة للإنماء في هذه المبادرة ، البعد السياسي لهذه القضية حيث ترى هذه المؤسسات أن الاقتصاد و السياسة وجهان لعملة واحدة ، و علاقة التأثير و التأثز بينهما متساوية ، كما أن المرجعيات الدستورية العليا لهاتين المؤسستين الدوليتين هي مرجعيات سياسية ، تمثل بلدانها و تشرف على صناعة القرار في هاتين المؤسستين • و لقد ركز الإعلان العالمي حول التعليم للجميع على الرؤية الموسعة للتعليم التي أكدت على أهمية تأمين حاجيات التعليم الأساسية للكبار من خلال إكسابهم مهارات الحياة اليومية ، و ربطهم بتراثهم الثقافي ، و تأمين فرص التعليم لهم في التهيل مواقع العمل و فئ المدارس • كما ركزت الرؤية الموسعة للتعليم ، على القضايا المرتبطة بتعميم الالتحاق بالتعليم للصغار و الكبار ، و النهوض بالمساواة ، و و

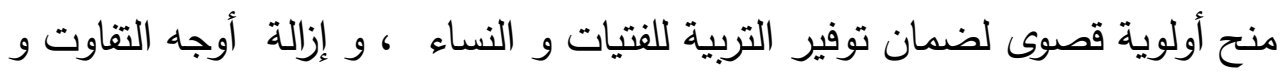
العناية و الرعاية المبكرة للطفولة ، و تدعيم التضامن الدولي ، ووضع المؤتمر رؤية 
موقف المجلات التربوية العربية من بعض القضايا الخاصة أ.م. دـ ـ محمد أحمد محمد اسماعيل لآلية تتفيذ البرنامج الدولي المقدم ، هذا البرنامج الذي لاقى فيما بعد العديد من

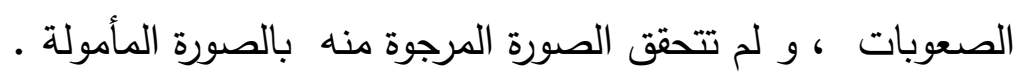

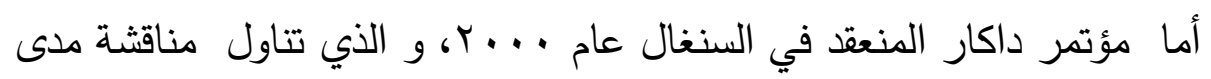

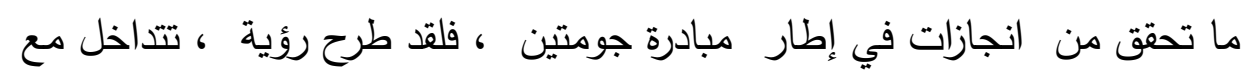

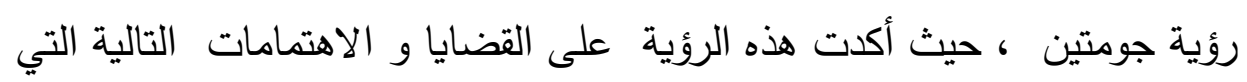

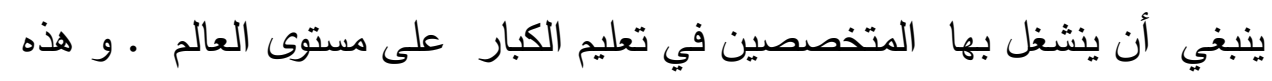

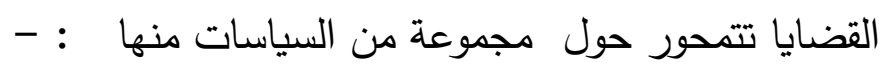

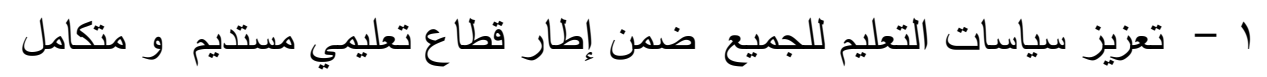
حقا ، و مرتبط بشكل واضح بالاستراتيجيات الخاصة بالقضاء على الفقر و بالتتمية

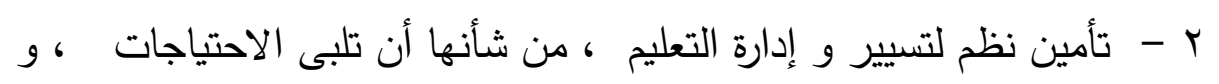
تؤمن مشاركة الجميع ، وتكون قابلة للتقييم •

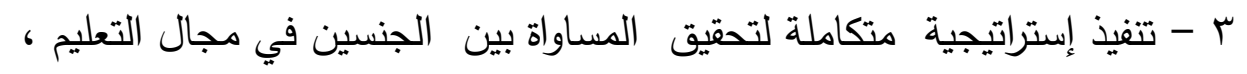

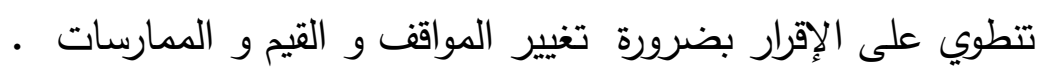
ع - إيجاد بيئات تعليمية سليمة و صحية و استيعابية ، و تتوفر لها الموارد بصورة منصفة ، بما يؤدى إلى الامتياز في التعلم ، و إلى تحديد واضتح لمستويات

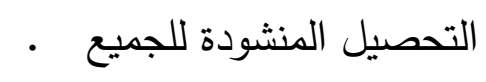
0 - توظيف التكنولوجيا الجديدة للمعلومات و الاتصال ، للمساعدة على تحقيق أهداف التعليم للجميع - توطيع 7 - المتابعة المنتظمة لما يحرز من تقدم فئ تحقيق الأهداف ، و و في تنفيذ الاستراتيجيات في مجال التعليم للجميع ، و للاستراتيجيات على الصعيد القطري

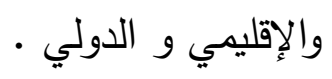


V - الاعتماد على الآليات القائمة لتعجيل التقدم نحو تحقيق التعليم للجميع

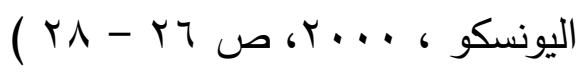

و أدت المنظمات الدولية و الإقليمية و العربية العاملة في مجال تعليم

الكبار ، دورا أساسيا في التحضير و التنفيذ لوقائع هذه المؤتمرات السياسية التي ولي ارتأت في مؤسسات المجتمع المدني شريكا حقيقيا لها ، ليس هذا فحسب ، بل هل إن كثيرا من المتابعين نظروا إلى هذه المؤتمرات الدولية ، كمؤتمرات خاصة بتعليم الكبار ، لأن ما يطرح فيها شديد الالتصاق بمؤسسات تعليم الكبار ، و بالقضايا التي يشتغل بها المتخصصين فيه ، فالقضايا التي تتاولتها هذه المؤتمرات مثل البطالة و الفقر و وتحسين البيئة و تفعيل دور المرأة' و العدل و المساواة و احترام حقوق

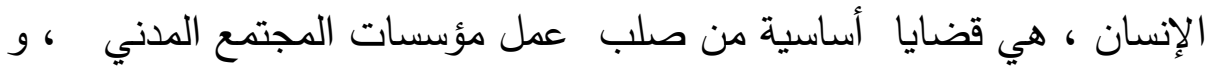
مؤسسات تعليم الكبار على وجه الخصوص • و إذا كانت المؤتمرات سالفة الذكر ذات ارتباط بتعليم الكبار ، فان المؤتمر الدولي الخامس لتعليم الكبار المنعقد في هامبورج 99 ام ، قد أولى جل عنايته بمسألة تعليم الكبار في إطار العولمة ، و غلبت عليه التوجهات السياسية ، اتضح ذلك من خلال الأوراق الأساسية التي قدمت من المجموعات الآسيوية ، و اللاتينية الأوربية ، والأقريقية و العربية ـ و ناقش الحضور في المؤتمر قضايا هامة للغاية ، من بينها دور تعليم الكبار في رعاية المواطنين ذوى الحاجات الخاصة ، و و القاطنين في المناطق النائية ، و أساليب النهوض بالتعاون الدولي، و تحديات العصر و المستقبل ( العولمة ، الثورة التكنولوجية ، التغييرات الاجتماعية ، معضلة

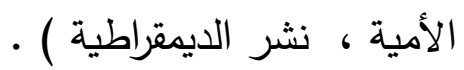

و شكلت هذه القضايا ذات الصبغة السياسية المباشرة الأجندة التي ينبغي ان ان النئ ينشغل بها المتخصصين في مجال تعليم الكبار ، خلال عقدين من الزمن .و أتت 
موقف المجلات التربوية العربية من بعض القضايا الخاصة ا..م. دـ ـ محمد أحمد محمد اسماعيل

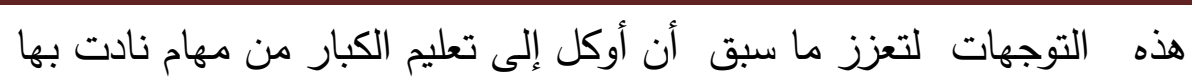

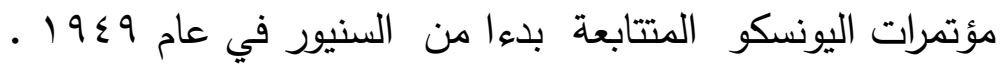

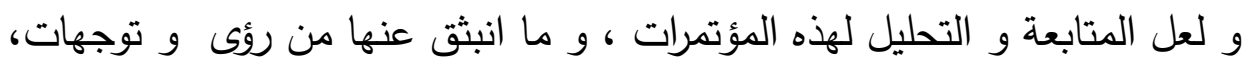

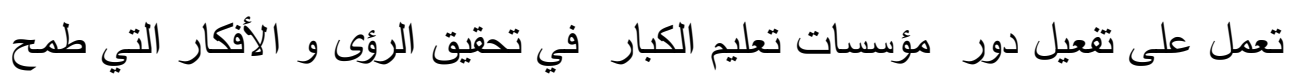
إليها المجتمع الدولي ، كما يعبر عن ذللك جوهر التوجهات المتبناة في المؤتمرات

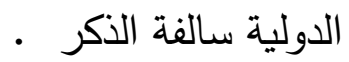

و لم تهمل استراتيجية تعليم الكبار في الوطن العربي الصادرة عام ... ب ، البعد

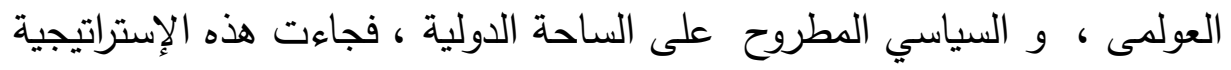

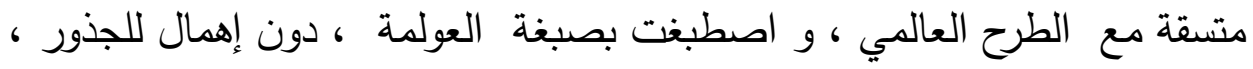

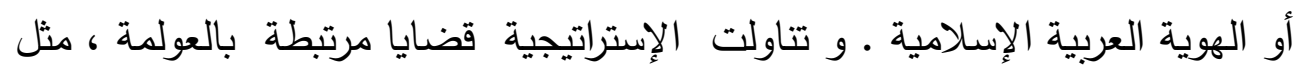

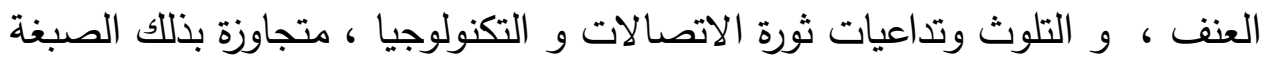

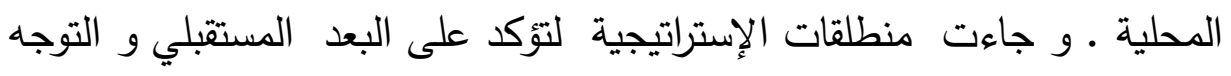

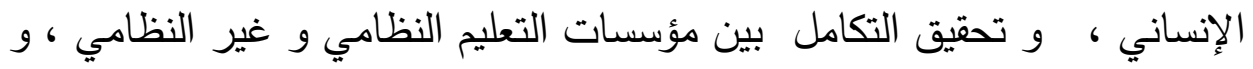

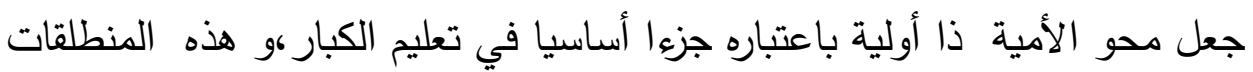

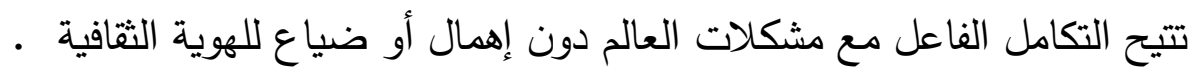

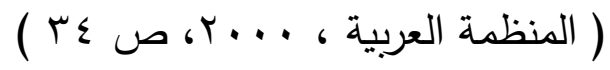

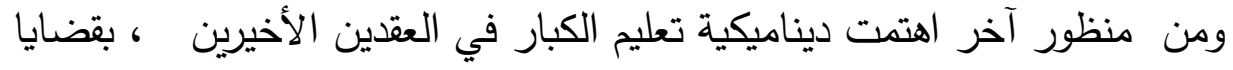

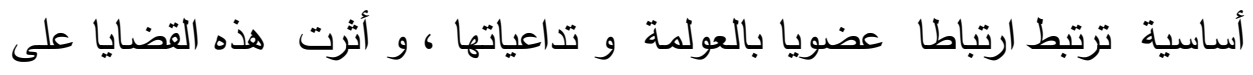

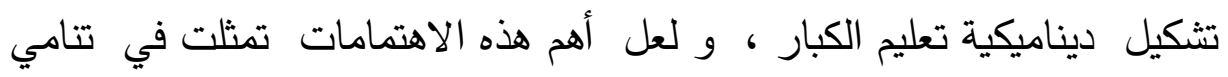

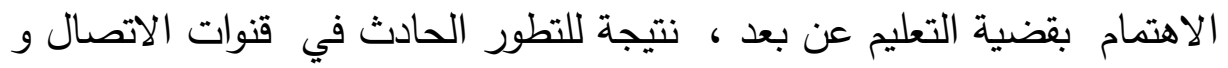

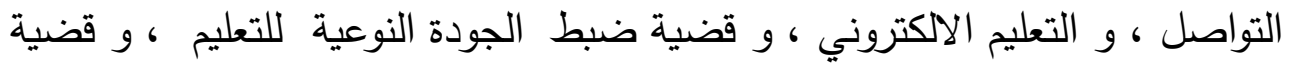
تطوير التعاون الدولي لتعزيز التفاهم بين الثعوب ، و الرؤية الموسعة لتعليم الكبار 
كوسيلة لتحسين جودة الحياة ، و تحقيق الرفاهة للمواطنين ، ولعله من البديهي إذن أن تكون هذه القضايا آنفة الذكر ، تشكل الأولويات التي ينبغي للمتخصصين في القطاع التعليمي بصفة عامة ، و في تعليم الكبار بصفة خاصة ، أن ينشغلوا و يسترشدوا بموجهاتها لاختيار بحوثهم ، إذا أرادوا لهذه البحوث أن ترتبط بالسياق - العالمي ثالثا - العوامل و المتغيرات المجتمعية التي أدت إلى زيادة الاهتمام بلور كليات التربية في مجال محو الأمية و تعليم الكبار: أ - تتامي الحركة العلمية الواعدة التي انطلقت منذ أوائل الثلاثينيات من القرن الماضي في مجال البحث العلمي لتعليم الكبار و ارتباطها بالتنمية البشرية المستدامة. فلقد تطورت حركة تعليم الكبار في بعديها التطبيقي و العلمي ، في إطار المؤتمرات الدولية التي تبنتها اليونسكو .وفي إطار التمويل الكبير الذي وفرته المؤسسات التمويلية العالمية ، مثل الكارنجى وفورد وغيرهما ، وتأدية الجامعات الأمريكية والأوروبية و

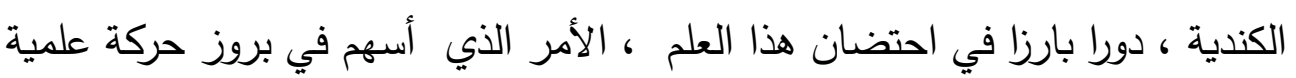
واعدة .

حيث انطلقت الأبحاث العلمية في مجال تعليم الكبار بصورة منتظمة منذ عام 194 ، عندما افتتح أول قسم لمنح الدكتوراه في الولايات المتحدة الأمريكية ، و أسهم هذا البرنامج والبرامج التي توالت بعده ، في توسيع نطاق حدوث تقدم من نوعيته وكم الأبحاث في هذا المجال ، سواء ما أرتبط بها من فكر فلسفي، أو توجهات استراتيجية

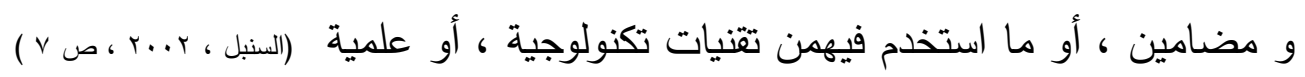


موقق المجلات التربوية العربية من بعض القضايا الخاصة ا.م. دـ ـ محمد أحمد محمد اسماعيل

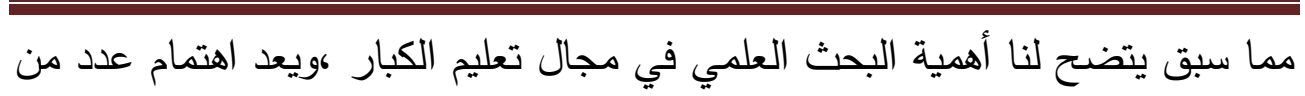

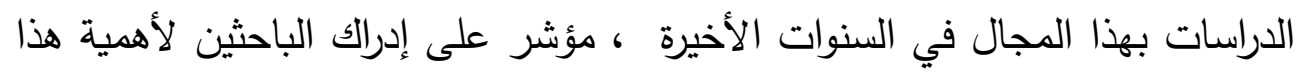

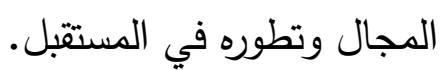
وهذه الحركة أصبحت أكثر من أي فترة أخرى ، مرتبطة ارتباطا وثيقا بحركة التتمية

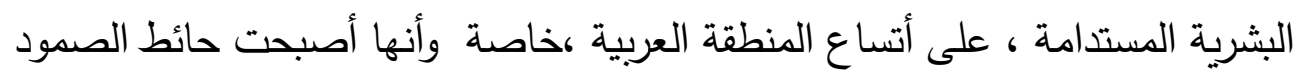

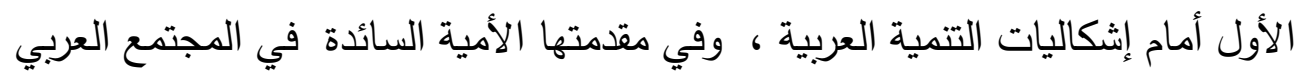

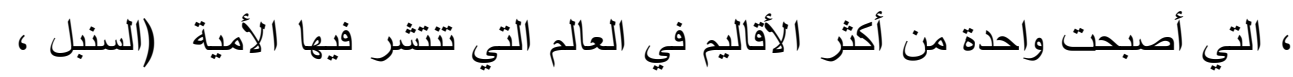
• ( V r r...r ب - عامل ظهور مواقف ومبادرات دولية لتدويل إثكالية بعض القضايا الخاصة بالتعليم المستمر و تحويلها إلى شأن عالمي من مظاهر الاهتمام الملحوظ بقضايا التعليم المستمر على المستوى الدولي و الإقليمي

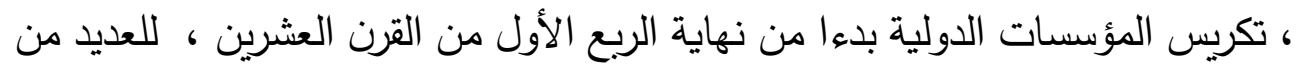
الندوات و المؤتمرات التي تتاولت ودعمت تعليم الكبار وشرعت لقيام مؤسسات ترعاه

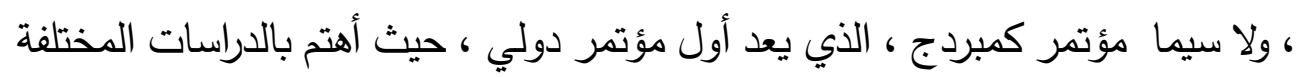

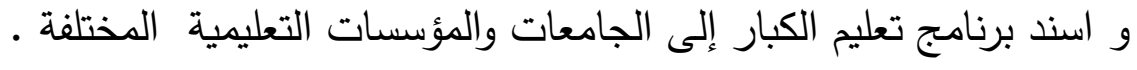

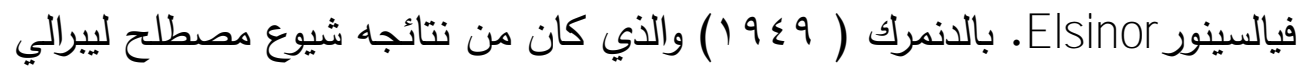

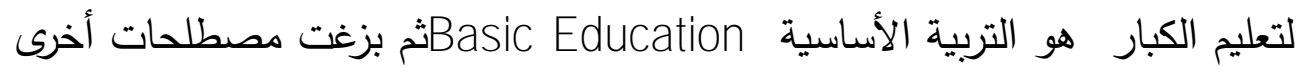

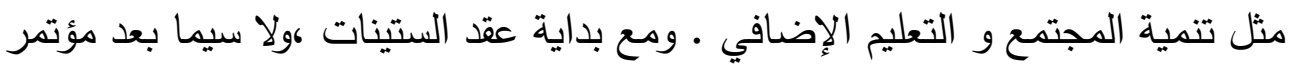
مونتريال في كندا ـ 197 تطور مفهوم تعليم الجماهير ، ليشمل التعليم الوظيفي للكبار

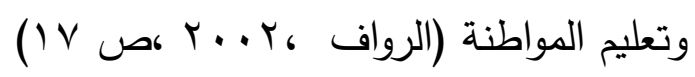

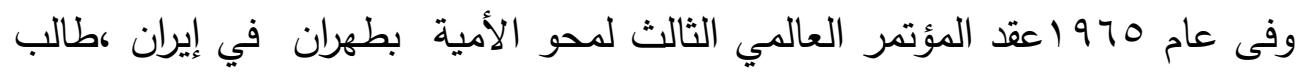
فيه الحاضرون بالاهتمام بالتعلم الذاتي و انتشار المراكز العلمية و الثقافية و التربوية 
و الاجتماعية للمساعدة في محو الأمية ، وساهم مؤتمر طوكيو باليابان عام $19 V Y$ ثم مؤتمر نيروبي 19V7 في بلورة توجه جديد لتعليم الكبار يتمحور حول "التعليم المستمر" الذي سرعان ما تحول إلى "التعليم المتواصل مدى الحياة "هع عقد مؤتمر

باريس عام 1910 ( مجلس النشر العلمي 991 ( )

كذلك هنالك الموقف الرسمي المعلن للمجلس العالي لتعليم الكبار والذي يتخذ من تورنتو *

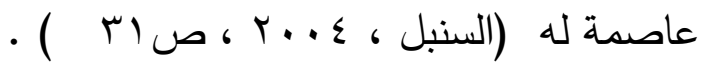
*المجلس العالي لتعليم الكبار يضم في عضويته . 19 منظمة قاعدته تمثل ائتلافا دوليا متعدد الاهتمامات و الأغراض . مالميل كذلك جاءت مبادرة التعليم للجميع ـ199 م الرامية إلى تدويل إشكالية الأمية وتحويلها إلى شأن عالمي بعد ما كانت لقرون من الزمن مسألة محلية هامشية ، ويوضح دخول مؤسسات مالية كبرى مثل البنك الدولي و برنامج الأمم المتحدة للإنماء في مثل هذه

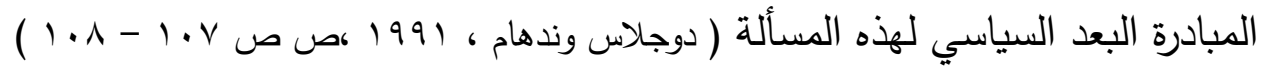
وركز الإعلان العالمي حول التعليم للجميع ،على الرؤية الموسعة للتعليم التي أكدت

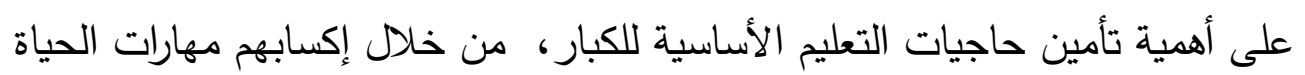

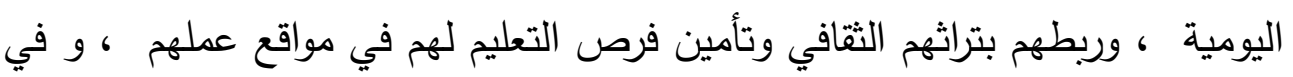
المدارس .كما ركزت الرؤية الموسعة للتعليم ، على المسائل المرتبطة بتعميم الالتحاق بالتعليم للصغار و الكبار، ومنح أولوية قصوى لضمان توفير التربية للفتيات والنساء كما أولى المؤتمر الدولي الخامس لتعليم الكبار الذي انعقد في هامبورغ 199 الجل عنايته بمسألة تعليم الكبار في إطار العولمة ، و غلبت عيه التوجهات السياسية، و اتضح

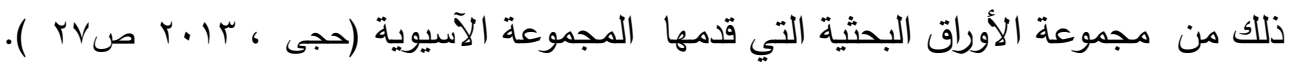

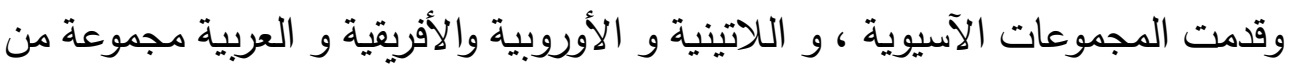
الأوراق البحثية ،التي ناقثت بعض القضايا الجوهرية الهامة ، مثل دور تعليم الكبار في رعاية المواطنين ذوي الاحتياجات الخاصة ، و القاطنين في المناطق النائية ، و 


\section{موقف المجلات التربوية العربية من بعض القضايا الخاصة أ.م. دـ ـ محمد أحمد محمد اسماعيل}

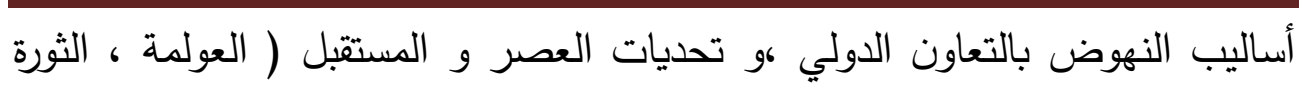

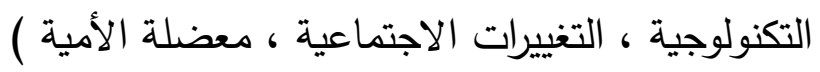

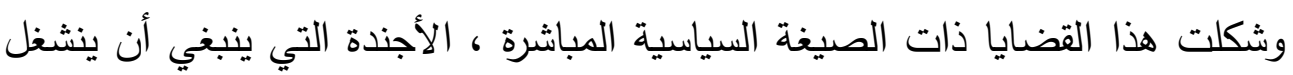

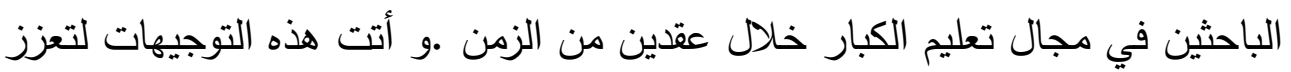
ما سبق أن أوكل إلى تعليم الكبار من مهام نادت بها مؤتمرات اليونسكو المتتابعة بدأ

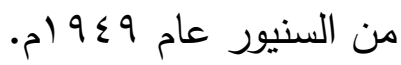

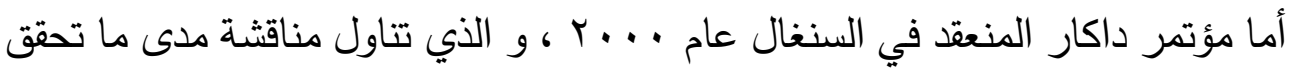
من إنجازات في إطار مبادرة جومتين، و سجل مدى التزام الحكومات بتحقيق التعليم

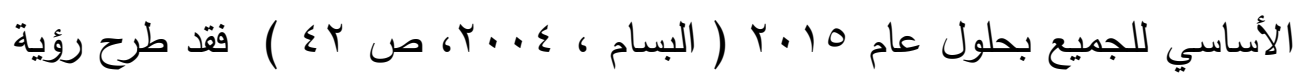

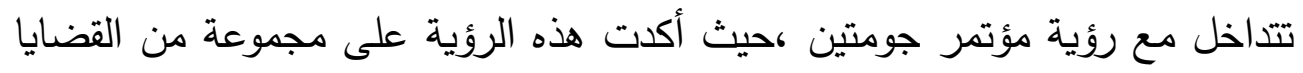

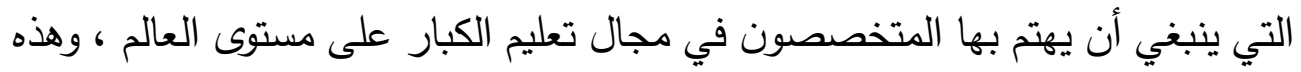

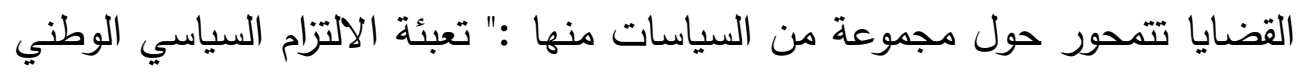

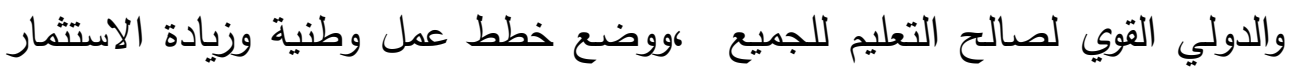

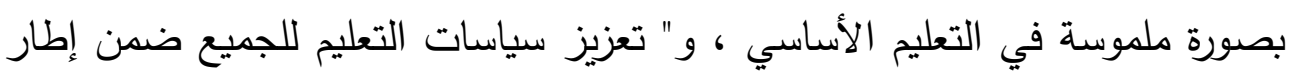
قطاع تعليمي مستديم ، و متكامل حقا ومرتبط بشكل واضح بالاستراتيجيات الخاصة الاصني

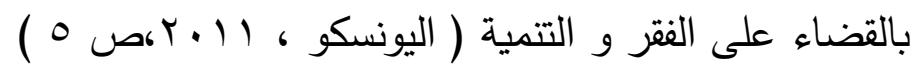
وبناء على ذلك تم استضافة المزيد من المؤتمرات والندوات من قبل الكليات

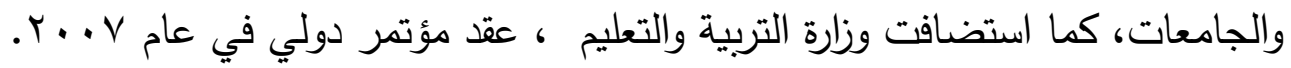
وقد تواصلت ندوات ومؤتمرات تعليم الكبار التي انتظمت بالدول العربية ،

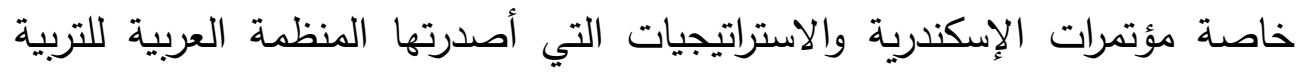

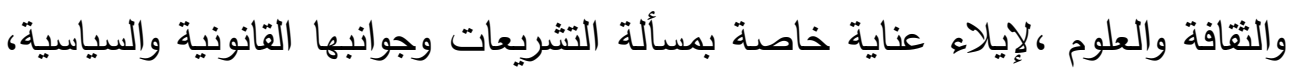


ولضبط الجوانب الإجرائية والقانونية لتسيير برامج محو الأمية وتعليم الكبار .( السنبل،

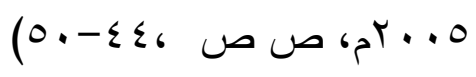

ج - عامل تزايد الرغبة على مستوى العالم بحركة البحث العلمي في مجال محو الأمية وتعليم الكبار -

تشهد بحوث تعليم الكبار على الساحة العربية و الدولية ، تطورا من حيث العمق و الاتساع ، وذلك على الرغم من كل الإشكاليات الفنية و المنهجية التي تشهدها ، بل أنها في حالة تزايد من حيث التتوع و الكم على حد سواء ، و أصبحت أكثر تقدما و تعقيدا ، ومن المتوقع أن يستمر هذا التطور بسبب الاهتمام الاجتماعي المتزيد بتعليم الكبار و التعلم مدى الحياة ، و الحاجة الثديدة إلى التعلم المستمر ، و اكتثاف الكثير من مؤسسات التعليم العالي للكبير بصفته متعلما ، وذللك لانعكاس الحاجة للإسهام الجاد من تغيير المجتمعات ، فالجوانب النظرية والمنهجية لمشكلات تعليم الكبار تعنى بها الدائرة العلمية للتربية وعلم النفس في معهد الثقافة في كل من موسكو و لننجراد . و الجوانب الاجتماعية و الاقتصادية تعنى بها الجامعات ، وترتبط الجوانب الاجتماعية بالأسس النغسية ( البسام ، 911 (، ص ح^) ، كما ترتبط البحوث من أمريكا اللاتينية من مجال تعليم الكبار بالجوانب المجتمعية ، وهي قي الأغلب معنية بالفئات المحرومة من الأميين ، و تتطلق من تفسير أحوالهم بردها إلى معاناتهم للظلم في مجتمعاتهم وضرورة أن يقرر تعليمهم بتوعيتهم بما هم عليه من الظلم و الحرمان ، وبإسهامهز في تغيير البنية الاجتماعية في تلك المجتمعات. ولقد دفعت هذه الرغبة الأكاديمية الباحثين في مجال تعليم الكبار إلى التطلع

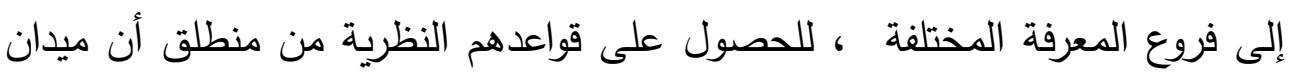
تعليم الكبار - ميدان متذاخل التخصصات 
موقف المجلات التربوية العربية من بعض القضايا الخاصة أ.م. د ـ محمد أحمد محمد اسماعيل ومن أبرز مظاهر تزايد الرغبة الأكاديمية بحركة البحث العلمي ، في مجال تعليم الكبار تبنى عدد من الجامعات الأمريكية و الأوروبية تعليم الكبار كعلم قائم بذاته

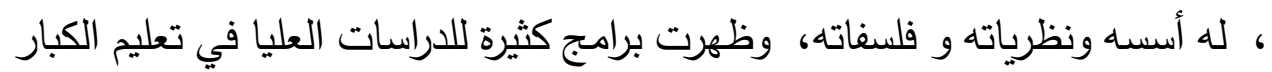

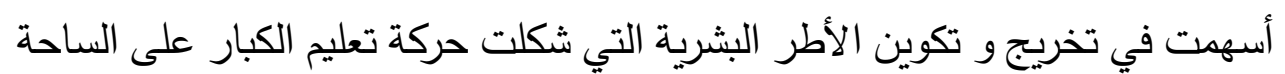
الدولية ، و لولا هذا التكوين الذي أحدثته الجامعات الأمريكية و الكندية و الأوروبية

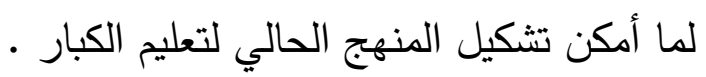
- قيام الكثير من الجامعات في استراليا، و آسيا ، و أفريقيا ، وفى أنحاء الوطن العربي ، باستحداث هياكل وبرامج تعنى بإعداد المتخصصين في هذا المجال ، وإعداد الدراسات العلمية المتمحورة حول قضايا الكبار • - امي البحث العلمي التربوي في تعليم الكبار منذ الستينيات و لا سيما في البلاد الاسكندنافية ،و ألمانيا ، و بريطانيا ،و فرنسا ، كما أن الكثير من تلأك البحوث وثيق الصلة بالتطبيق ، بل إن منه مشروعات تجريبية معنية بتتمية مشاركة الكبار في برامج التعليم المعدة لهم في انجلترا و السويد و فرنسا ، و ازدياد البحوث ذات الأسس النظرية العلمية منذ عقد الثمانينات.

د - نشوء مناخ دولي يساهم في دفع حركة تعليم الكبار على الساحة الدولية تمثل في كثير من الأفكار و القيم و الاتجاهات التي تضع تعليم الكبار في موقع عالمي لم يتبوأ من قبل ، فمن أهم إفرازات العولمة ، تتامي دور المجتمع المدني ، وتتامي دور تعليم الكبار في الخطط التربوية الهادفة إلى تحقيق مبدأ التربية المستمرة للجميع ، هذا من ناحية ومن ناحية أخرى ، فإن التغيرات المصاحبة للعولمة ساهمت إلى حد كبير في تتامي الوعي بأهمية تعليم الكبار كشأن سياسي يتم من خلاله بث القيم 
الإنسانية ، والمبادئ الحضارية وتوعية الجماهير ، ليتم إدماجهم دمجا فاعلا في صلب

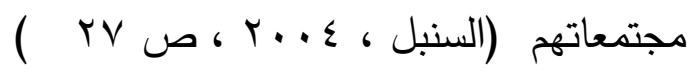

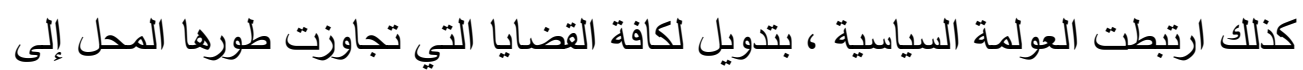
الطور العالمي ، و أخذت تبحث عن الحلول العالمية ، مثل قضايا البيئة و الفقر و الانفجار السكاني و المرأة و محو الأمية .ووجد تعليم الكبار نفسه منغمسا بهذه الانشغالات ، مما أعطاه بعدا سياسيا ،و متسع في مفهومه و أدواره ، فالمتخصصين في تعليم الكبار كانوا مشاركين فاعلين ، في المؤتمرات الدولية لحقوق الإنسان،و المرأة و التتمية الاجتماعية و السكان و البيئة ، الأمر الذي أدى إلى نشوء مناخ عالمي عزز من دور مؤسسات تعليم الكبار ،و أضاف إليها أدوارا لم تكن ضمن اختصاصاتها .

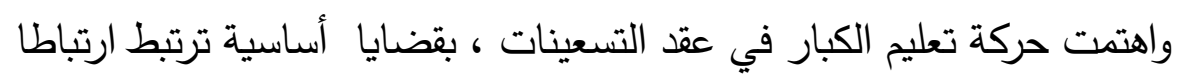
عضويا بالعولمة وتداعياتها ،و أثرت هذه القضايا على تشكيل حركة تعليم الكبار، و لعل أهم هذه الاششغالات ، تمثلت في تتامي الاهتمام بمسألة التعليم عن بعد، نتيجة

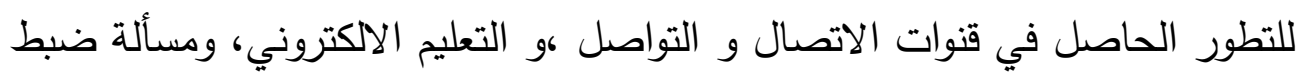
الجودة النوعية للتعليم ، ومسألة تطوير التعاون الدولي لتعزيز التفاهم بين الشعوب ،و النظرة المؤسسة لتعليم الكبار كوسيلة لتحسين جودة الحياة ،وتحقيق الرفاهة للمواطنين هـ - تبنى المؤسسات الدولية لحركة البحث العلمي في مجال محو الأمية وتعليم

$$
\text { الكبار و تمويله . }
$$

حيث ساهمت عدة متغيرات مجتمعية عالمية في زيادة الاهتمام بحركة البحث العلمي التربوي في مجال محو الأمية وتعليم الكبار في مستوياتها البرامجية والعلمية و البحثية العلمية التربوية ، و يأتي في مقدمتها الاهتمام السياسي الذي حظيت به حركة تعليم الكبار من المنظمة الدولية للتربية و العلوم و الثقافة "اليونسكو " ،وما تبع ذلك من اهتمام لاى الدول خاصة بعد الحرب العالمية الثانية ، وتبنت حركة البحث العلمي 


\section{موقف المجلات التربوية العربية من بعض القضايا الخاصة أ.م. دـ ـ محمد أحمد محمد اسماعيل}

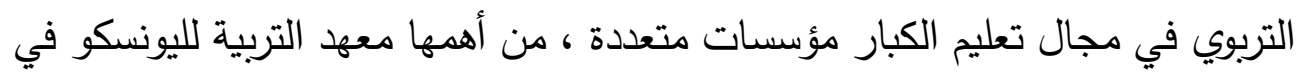

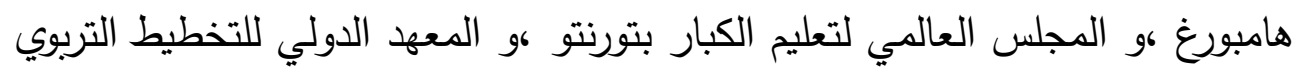
بباريس ،ومكتب التربية الدولي بجنيف ، ومركز سرس الليان لتعليم الكبار ، و الدنظمة التئي

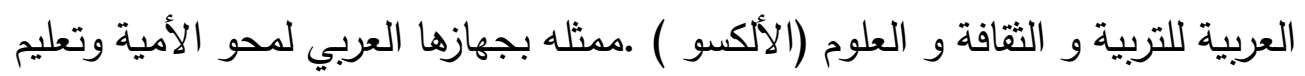
الكبار ،و الذي اشرف على إصدار مجلة تعليم الجماهير •

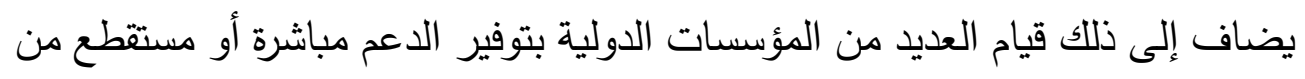
ضرائبها المستحقة دعما لحركة تعليم الكبار ، وتعد مؤسسات الكارنجي ، وفورد

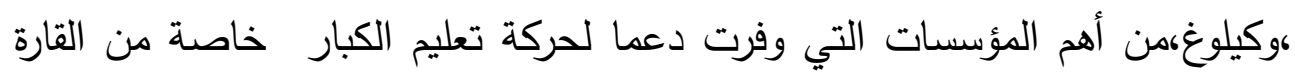

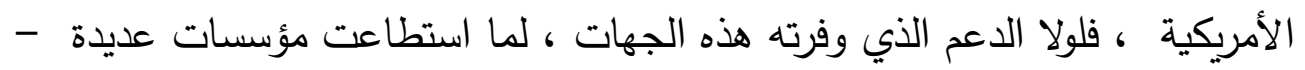

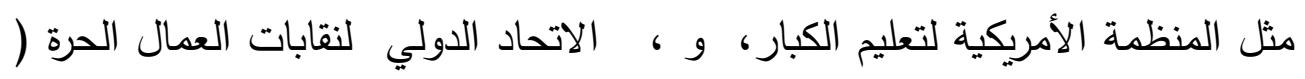
(ICFTO

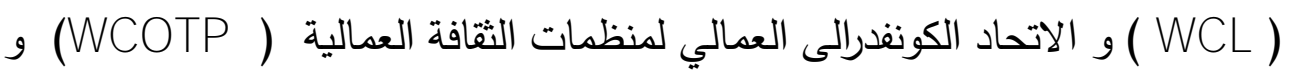

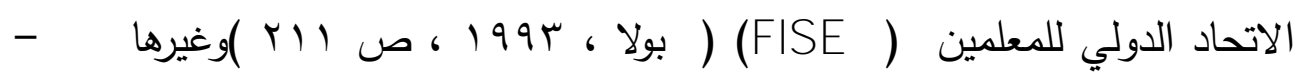

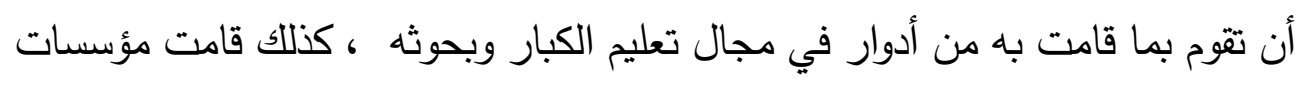

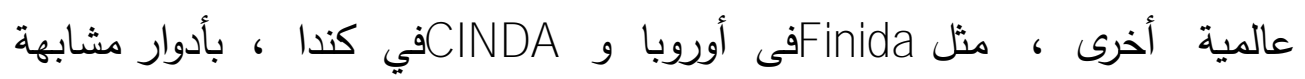

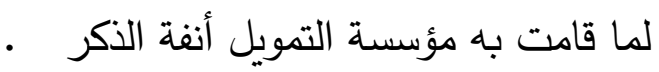

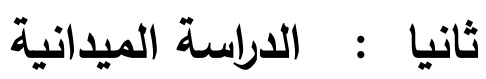
إجراءات الدراسة الميدانية

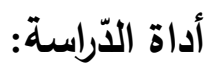

تم تصميم استمارة تحليل المضمون لاستيفاء عناصر التحليل ولتحقيق أكبر قدر

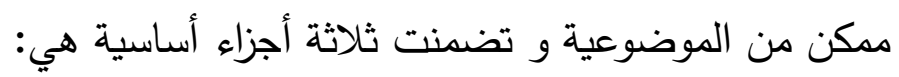

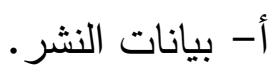


ب- بيانات المادة العلمية المنشورة.

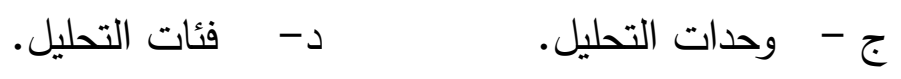

وقام الباحث بعرض بعض هذه الاستبانة على (V) محكمين أوردوا عدداً من الملاحظات، و التغييرات عليها حتى استقرت الاستبانة على شكلها النهائي الوارد في

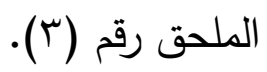

\section{مجتمع الدّراسة وعينتها:}

يشتمل مجتمع الدراسة على جميع الأبحاث التي تتاولت دور كليات التربية في مجال

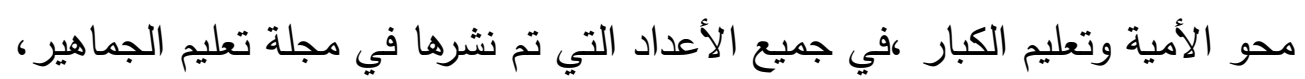
ورسالة الخليج العربي، واتحاد الجامعات العربية، ورسالة التربية وعلم النفس، خلال

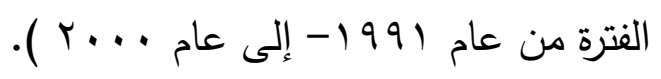

صدق الأداة:

تم عرض استمارة التحليل على مجموعة من ذوي الخبرة والاختصاص في المجال التربوي بصفة عامة، وفي مجال تعليم الكبار بصفة خاصة، وذللك للتأكد من صلاحيتها لقياس دور كليات التربية في مجال محو الأمية وتعليم الكبار و علم تعلم الثيخوخة

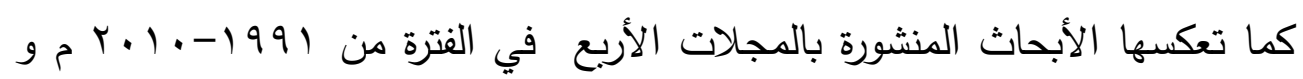
قدرتها على ترجمة الأفكار، والقضايا، والفئات التي يتضمنها المضمون بدقة وأمانة. المعادلة

باستخدام وذلك الآتية:

N P

$$
P=
$$

$\mathrm{NP}+\mathrm{N} \mathrm{Np}$

P = يعني مقابل الاتفاق. P 
موقف المجلات التربوية العربية من بعض القضايا الخاصة أ.م. دـ ـ محمد أحمد محمد اسماعيل NP يعني عدد مرات الاتفاق، أو عدد الفقرات المتفق عليها. NNP يعني عدد مرات عدم الاتفاق، أو البنود التي لم يتفق عليها. ثبات الأداة:

لتحقيق الثبات لاستمارة التحليل وضبط العوامل الذاتية التي يمكن أن تئثر في نواتج البحث، وثبات أداء التحليل، فقد تم حساب ثبات التحليل عن طريق سحب عينة من المحتوى، وقام الباحث بتحليلها، كما قامت الدكتورة عزة ياقوت الأستاذ المساعد بكلية التربية، جامعة تبوك بالتحليل لنفس العينة. ثم تم حساب معامل الاتفاق بين تحليل كل منا على فقرات أداة التحليل، وتم استخدام معادلة هولستي.

$$
\begin{aligned}
& C R=\quad 2 M \\
& \mathrm{~N} 1+\mathrm{N} 2 \\
& \text { حيث إن:- } \\
& \text { C R }
\end{aligned}
$$

يعني عدد الفئات التي تم اتفاق عليها بين الباحث ونفسه، أو بينه وبين =M =M

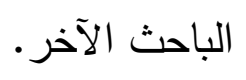

N1 = مجموع الفئات التي حللها الباحث.

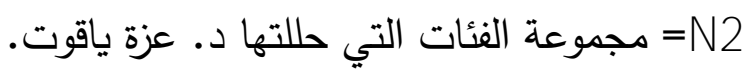
مجموع الفئات التي حللها الباحث والباحثة ووصلت المقارنة على معامل $=N 1+N 2$ الثبات (^^ی,). وهي نسبة تكفي لصلاحية التحليل. التحليل الكمي و الكيفي لبعض قضايا تعليم الكبار أولا -وحدة القائم بإجراء البحث ( الباحث ) بالبحوث التي تتاولت دور كليات التربية في مجال محو الأمية وتعليم الكبار ، بالمجلات الأربع - تعليم الجماهير - رسالة 
التربية وعلم النفس - رسالة الخليج العربي - اتحاد الجامعات العربية - في الفترة من / التحليل الكمي و الكيفي لوحدة القائم بإجراء البحث ( الباحث ) بالبحوث التي تتاولت دور كليات التربية في مجال محو الأمية و تعليم الكبار، بالمجلات الأربع - تعليم الجماهير - رسالة التربية وعلم النفس - رسالة الخليج العربي - اتحاد الجامعات

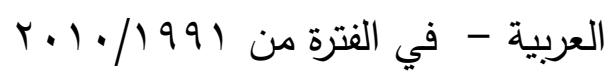
أ - التحليل الكمي لوحدة القائم بإجراء البحث ( الباحث ) بالبحوث التي تتاولت دور كليات التربية في مجال محو الأمية وتعليم الكبار ، بالمجلاتالأربع - تعليم الجماهير - رسالة التربية وعلم النفس - رسالة الخليج العربي - اتحاد الجامعات العربية - في

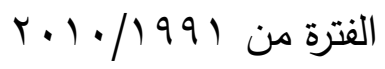

جدول (1)

\begin{tabular}{|c|c|c|c|c|c|c|}
\hline 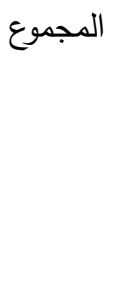 & الجاد العجاد & الخليج & رلتمالة & تعليم & القائم بالبحث & 5 \\
\hline 1. & 1 & & & 9 & فردي & 1 \\
\hline 1 & 1 & & & & مشترك & $r$ \\
\hline & & & & & مؤسسة / هيئة & $r$ \\
\hline 1 & & & & 1 & جهة دولية & $\varepsilon$ \\
\hline & & & & & جهة حكومية & $\circ$ \\
\hline & & & & & التخصص (تربوي / غير تربوي) & 7 \\
\hline & & & & & النوع (باحث، باحثة) & $\vee$ \\
\hline & & & & & أخرى & \\
\hline
\end{tabular}


موقف المجلات التربوية العربية من بعض القضايا الخاصة أ.م. دـ ـ محمد أحمد محمد اسماعيل

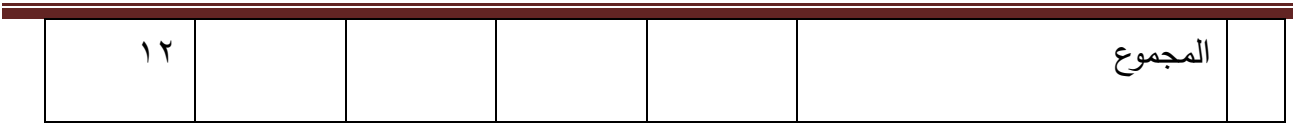

ب - التحليل الكيفي لوحدة القائم بإجراء البحث ( الباحث ) بالبحوث التي تتاولت دور كليات التربية في مجال محو الأمية وتعليم الكبار ، بالمجلاتالأربع - تعليم الجماهير - رسالة التربية وعلم النفس - رسالة الخليج العربي - اتحاد الجامعات

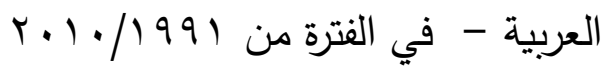

$$
\begin{aligned}
& \text { يتضح من الجدول (1) ما يلى : }
\end{aligned}
$$

- أن جل القائمين بعمل الأبحاث العلمية التربوية التي تتاولت دور كليات التربية في مجال محو الأمية والتعليم المستمر بالمجلات العلمية موضع الدراسة ، باحث فردي ، فهنالك غياب شبه تام للبحوث المشتركة ، أو المؤسساتية ، باستثناء بحثين فقط وهما بحث " التأهيل التربوي للمدرس الجامعي دراسة ميدانية بجامعة الملك فيصل لعمرو

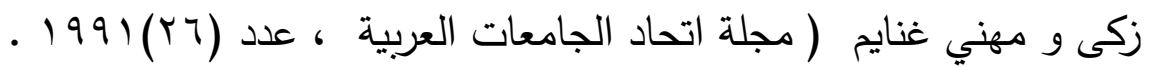
و بحث " نموذج مقترح لمنهج إعداد معلمي المرحلة الابتدائية للقيام بدور تعليمي مزدوج للكبار والصغار "من إعداد مكتب اليونسكو الإقليمي للتربية في البلاد العربية ،( مجلة

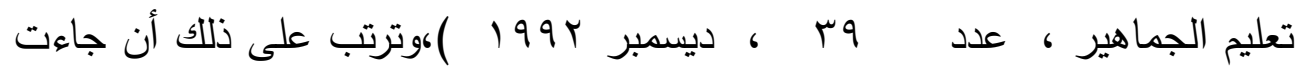
هذه البحوث مجزئة ، ومحدودة المعالجة ، وتعبر عن اهتمام الباحث ذاته ، وبالتالي

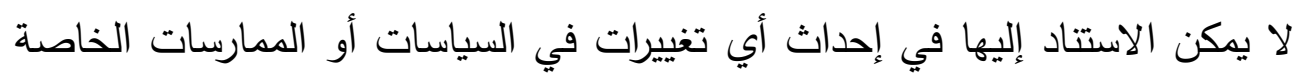
بدور كليات التربية في مجال محو الأمية وتعليم الكبار إلا من خلال منظور ، المناهج والمقررات الدراسية ،، والتربية الميدانية و إعداد المدرس الجامعي • - أن القائمين بإجراء هذه البحوث كلهم تربويين من أهل الاختصاص التربوي ، كما أن بعضهم متخصص في مجال تعليم الكبار من مثل خليل السعادات ، أستاذ تعليم الكبار بقسم السياسات التربوية بجامعة الملك سعود ،مما انعكس على وعيهم بالمجال 
- أن القائمين بالبحث، باحثين ذكور ، وغياب الباحثات الإناث مما يطرح التساؤل عن سبب إحجامهن عن طرق هذا المجال خاصة ، وأن المرأة تحتل مكاناً كبيراً فيما يتعلق بالأمية بالمجتمع العربي بصفة عامة هذا من جهة ، ومن جهة ثانية أن هناك عضوات هيئة تدريس بالجامعات العربية تخصصن في مجال تعليم الكبار، و و بالتاليفهنعلى أعلى مستوى من الكفاءة في تتاول مثل هذه الموضوعات ، خاصة ما يرتبط بتعليم المرأة ، وبدورها في إحداث التنمية المجتمعية بالمجتمع العربي ، خاصاقفي ظل حرص الدول المتقدمة على مساندة و مؤازرة برامج التعليم المستمر ذات التوجهات التموية الجذرية ، و الموجهة لتفعيل دور المرأة و دمجها في النسيج المجتمي، و محو أمية التعليم المهني للطبقات المهشة ، ، و برامج التثقيف بالديمقراطية و حقوق

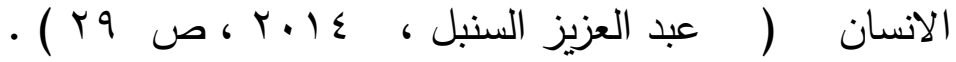
- لم تتناول مؤسسة أو هيئة حكومية في اى دولة عربية بنشر بحث في المجلات موضوع الدراسة مما يطرح التساؤل عن سبب هذا الغياب - لم تتناول هيئة دولية متخصصة في تعليم الكبار بنشر بحث في المجلات موضوع الدراسة على الرغم من انعقاد العديد من المؤتمرات الخاصة بتعليم الكبار ثانيا - وحدة القضايا الخاصة بدور كليات التربية في مجال محو الأمية وتعليم الكبار ، بالمجلاتالأربع - تعليم الجماهير - رسالة التربية وعلم النفس - رسالة الخليج

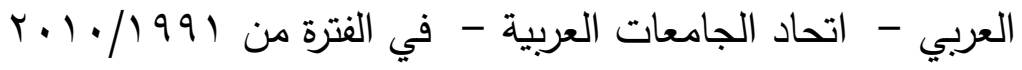
التحليل الكمي و الكيفي للقضايا الخاصة بدور كليات التربية في مجال محو الأمية وتعليم الكبار ، بالمجلاتالأربع - تعليم الجماهير - رسالة التربية وعلم النفس - رسالة

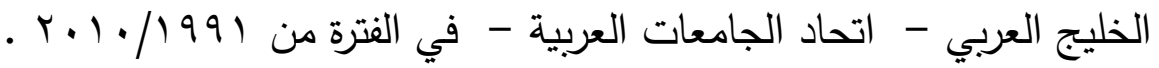
أ - التحليل الكمي لوحدة القضايا الخاصة بالبحوث التي تتاولت دور كليات التربية في مجال محو الأمية وتعليم الكبار بالمجلات الاربع - تعليم الجماهير - رسالة 
موقف المجلات التربوية العربية من بعض القضايا الخاصة أ.م. دـ ـ محمد أحمد محمد اسماعيل

التربية وعلم النفس - رسالة الخليج العربي - اتحاد الجامعات العربية - في الفترة

من

جدول (ז)

\begin{tabular}{|c|c|c|c|c|c|c|c|c|c|}
\hline تحاد & الجا & & رسا & & رجا & ير & مجل & فئات التحليل & 5 \\
\hline$\%$ & ك5 & $\%$ & ك & $\%$ & ك5 & $\%$ & ك & & \\
\hline & & & & & & & r & قالخية إعداد المقررات & 1 \\
\hline & r & & & & & & r & قضية إعداد معلم محو & r \\
\hline & & & & & & & & التشتراك طلاب كليات التربية والمعلمين في & r \\
\hline & & & & & & & & تعليم الكبار في مجام التدريب قيادات & $\varepsilon$ \\
\hline
\end{tabular}


مجلة دراسات في التعليم الجامعى

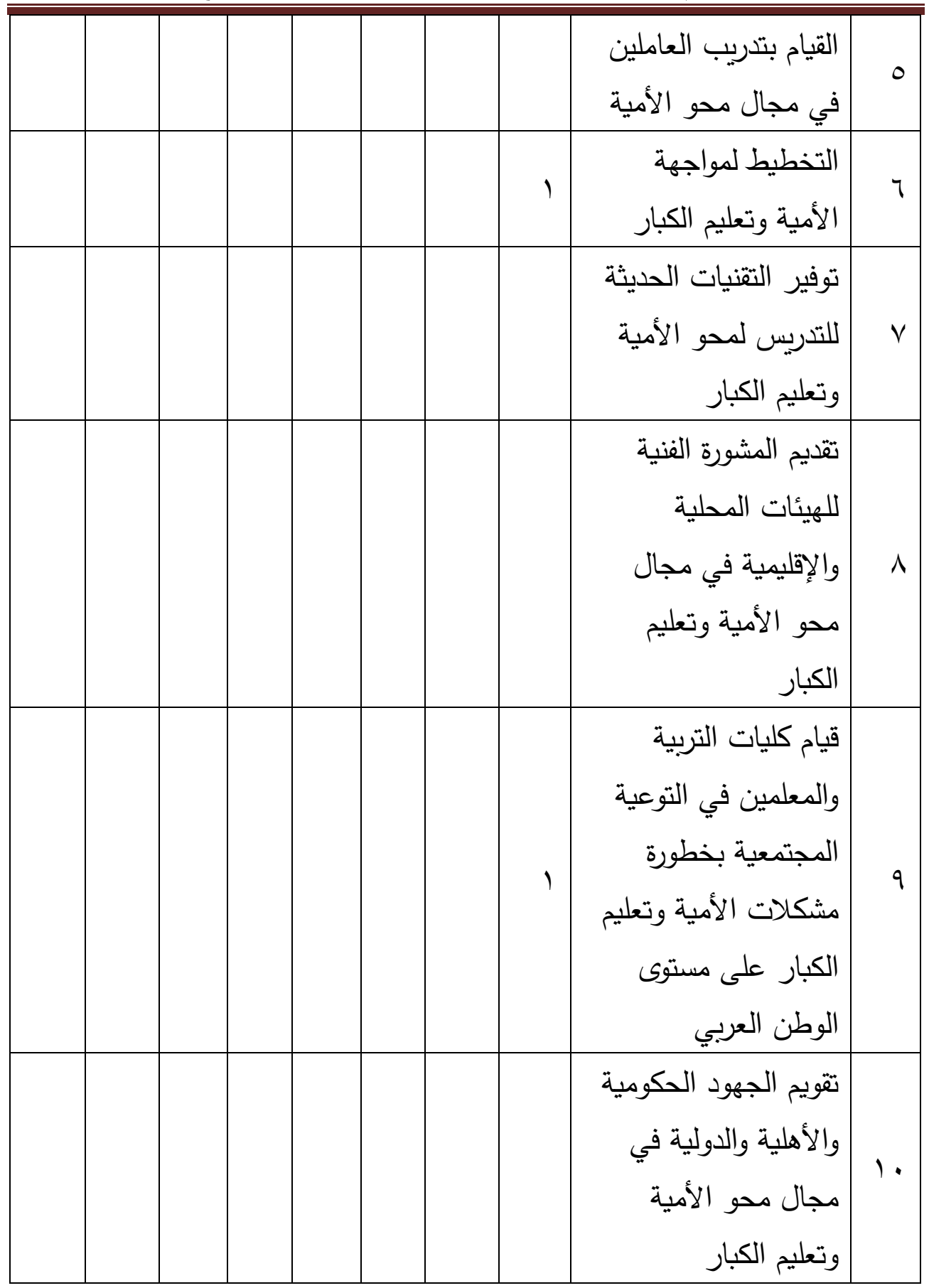


موقف المجلات التربوية العربية من بعض القضايا الخاصة أ.م. دـ ـ محمد أحمد محمد اسماعيل

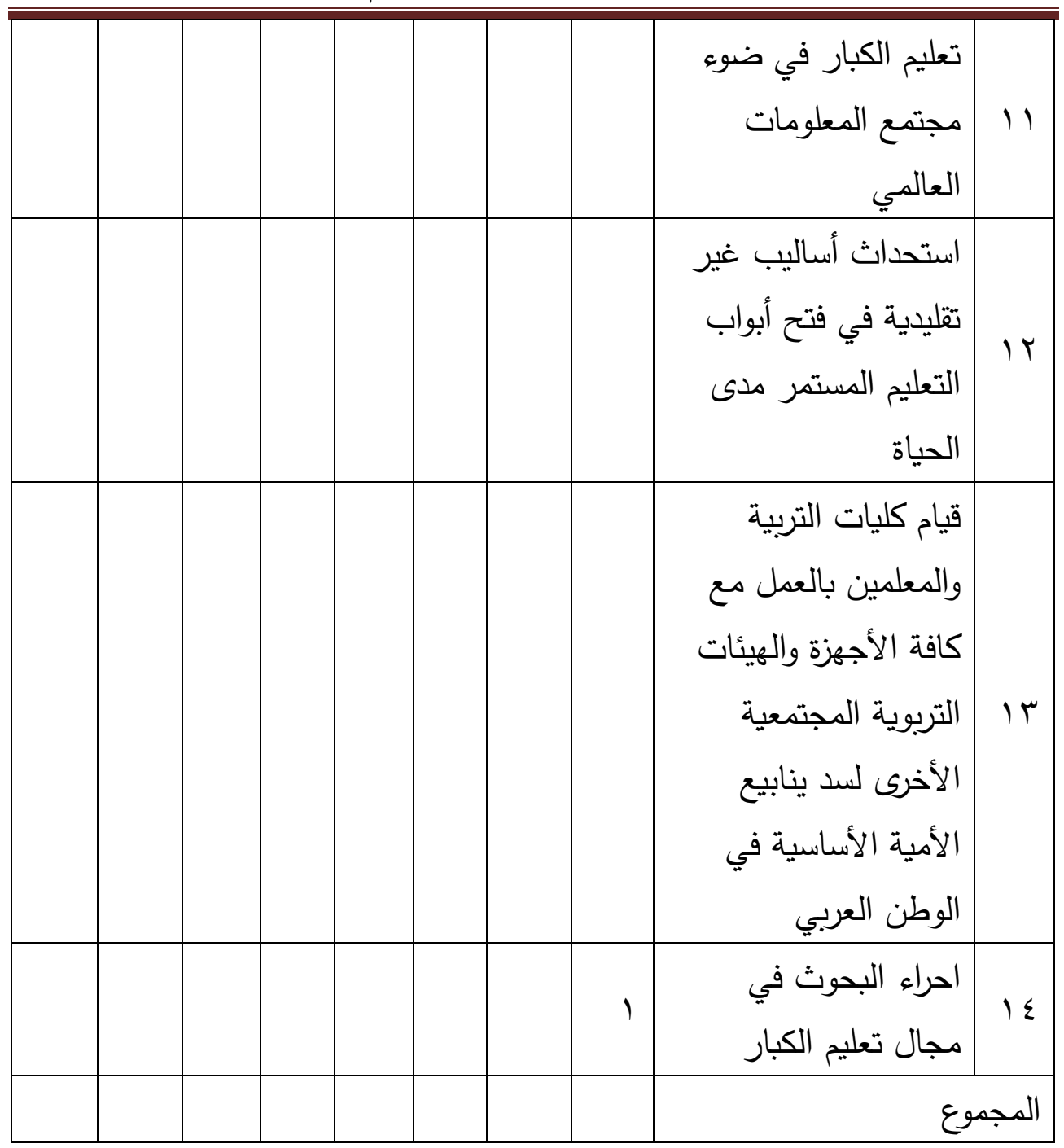

ب - التحليل الكيفي لوحدة القضايا الخاصة بالبحوث التي تتاولت دور

كليات التزبية في مجال محو الأمية وتعليم الكبار ، بالمجلاتالأربع - تعليم الجماهير

- رسالة التربية وعلم النفس - رسالة الخليج العربي - اتحاد الجامعات العربية -

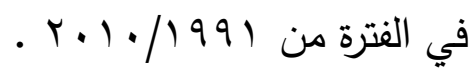


يتضح من جدول ( r r r أن إجمالي الأبحاث المنشورة التي تتاولت دور كليات التربية في مجال محو الأمية و تعليم الكبار بالمجلات الأربع في الفترة من 199 19 ـ

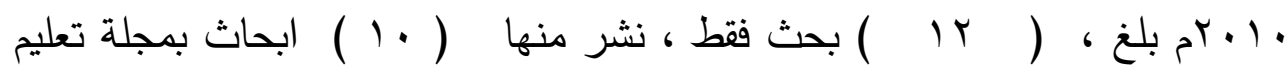
الجماهير ، و جاء بحثين فقط بمجلة اتحاد الجامعات العربية *''، بينما خلت مجلات "رسالة الخليج العربي" ورسالة التربية وعلم النفس ، من تناول أي بحث عن دور كليات التربية في مجال محو الأمية وتعليم الكبار بصفة خاصة ، بل لم تتناول مجلتي رسالة الخليج العربية ، ومجلة رسالة التربية، وعلم النفس أي بحث في مجال تعليم الكبار بصفة عامة!! مما يطرح التساؤل عن سبب الإحجام عن نشر مثل هذه البحوث في المجلتين ، خاصة وأن مجلة رسالة التربية وعلم النفس تصدر عن الجمعية السعودية للعلوم والتربية والنفسية "جستن" بكلية التربية ، جامعة الملك سعود، و التيبها قسم السياسات التربوية الذي يضمبدورهمسار لتعليم الكبار ، و به برنامجين ماجستير ودكتوراه لتعليم الكبار ! !.وإن كانت مجلة رسالة الخليج العربي قد تتاولت عرض مختصر لبعض الكتب في مجال تعليم الكبار في باب مخصص لنشر ملخصات الكتب الحديثة الكنة 
موقق المجلات التريوية العربية من بعض القضايا الخاصة ا.م. دـ ـ محمد أحمد محد اسماعيل

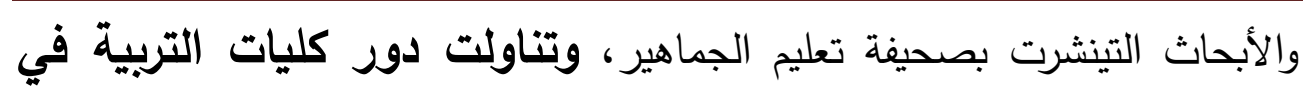
مجال محو الأمية وتعليم الكبار هي:

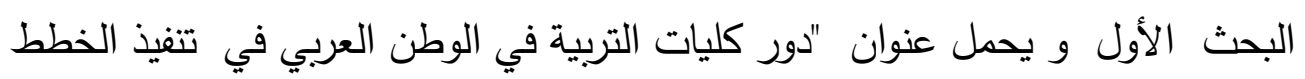

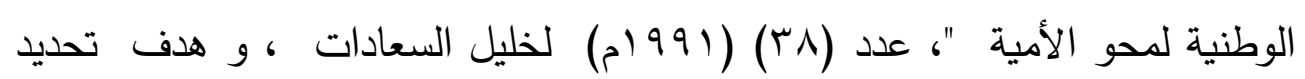

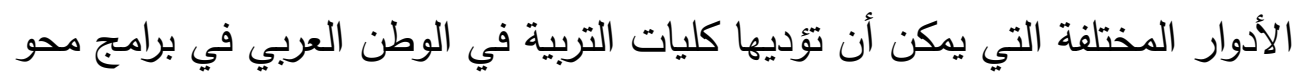

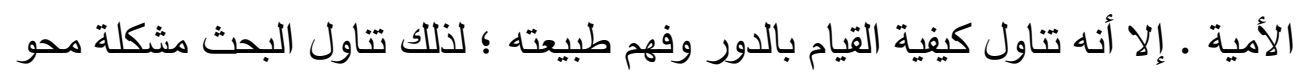

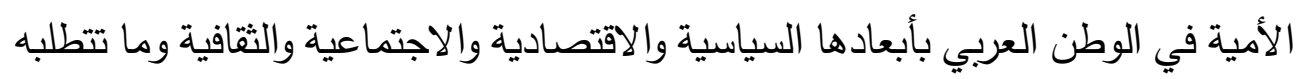

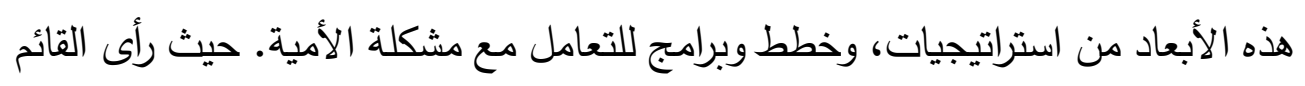

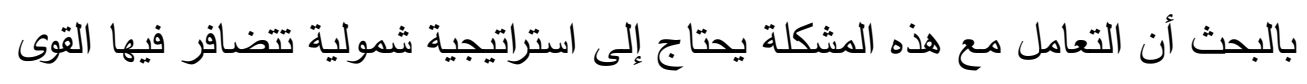

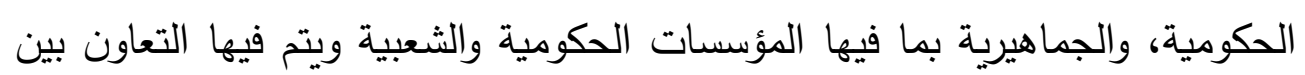

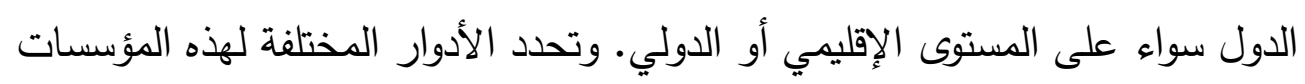

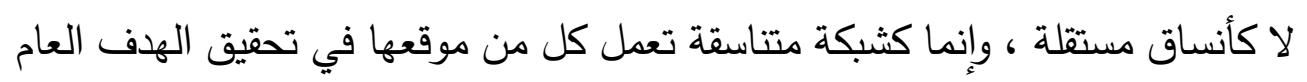
، وضمن المنظور المحدد لها في هذا التتظيم الثبكي.

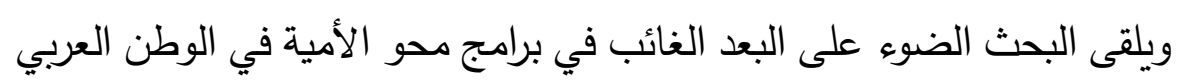

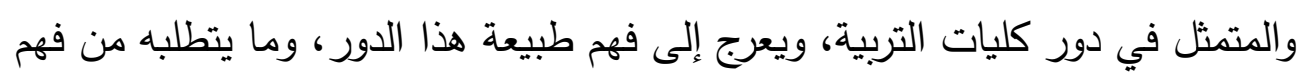

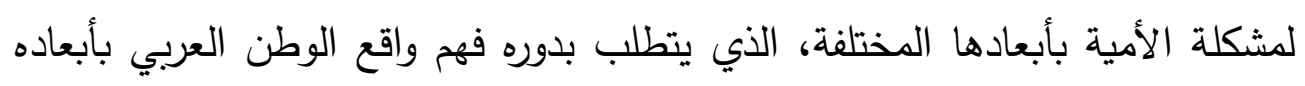

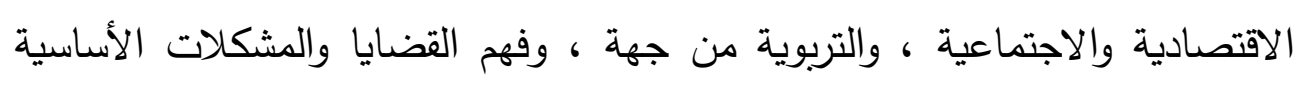
للتربية في الوطن العربي من جهة ثانية. لذلك يطرح البحث صورة موجزة لبعض المؤشرات الاقتصادية والاجتماعية

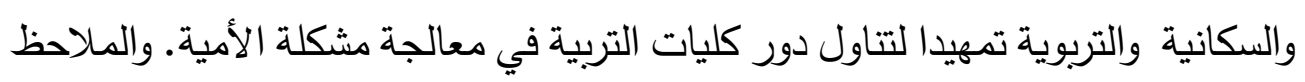

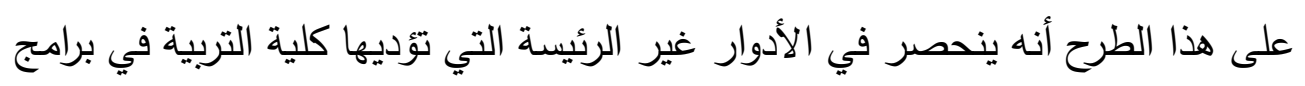

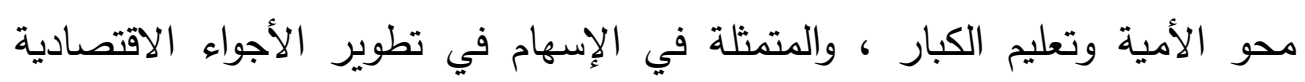


والاجتماعية والتربوية السليمة التي تؤدي إلى مجتمع متناسق ومتوازن ومتماسك في بنيته الملائم لمطالب الحاضر ، والمستقبل.

لذا فعلى كليات التربية أن تعمل مع كافة الأجهزة التربوية ، والمجتمعية على إيجاد بنية هيكلية سليمة للاقتصاد العربي عن طريق إعداد القوى البشرية اللازمة لمختلف القضايا الاقتصادية ، والمساعدة في محو أمية الفلاحين ، والعمال والنساء الذين يشكلون غالبية

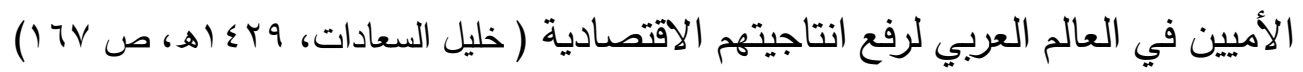
كذلك يطرح البحث العناصر الاساسية المكونة لاستراتيجية محو الأمية في البلاد العربية والمتمثلة في الوثيقة التي أقرها مؤتمر الإسكندرية الثالث لمحو الأمية في الفترة من | (-7 | ديسمبر 9V7 ام والمبادئ والاتجاهات الاساسية التي تحكم هذه الاستراتيجية. كما عرض لقضية علاقة المؤسسات الجامعية الأكاديمية بقضايا التنمية المجتمعية ، ونظر لها ، مبينا وجهتي النظر تجاه هذه القضية ، الأولى التي تتمثل في ضرورة اشراك المؤسسة الأكاديمية في كل مراحل، وجوانب القضية التتموية التي تتصدى لها سواء على مستوى التخطيط أم التنفيذ، والثانية التي تتمثل في التأكيد على ضرورة تجنب المؤسسة الأكاديمية الخوض في تتفيذ البرامج، وأن يقتصر دورها على التخطيط فقط. ويسوق أنصار كل اتجاه حججه القوية الى الدرجة التي لم تمكن الاتحاد الدولي للجامعات في اجتماعه المنعقد في مانيلا ، 191 من حسم هذه القضية. ويطرح البحث الأدوار المباشرة ، وغير المباشرة لكليات التربية في برامج محو الأمية ماتهية مبينا أن تنفيذ هذه الأدوار يتطلب الدعم المادي والمعنوي من رأس السلطة أولا، ومن كافة المؤسسات المجتمعية ثانيا، وأن توضع التربية كأولى الأولويات المجتمعية ثالثا. وجاء البحث الثاني بعنوان "أولويات البحث التربوي في تعليم الكبار في الدول

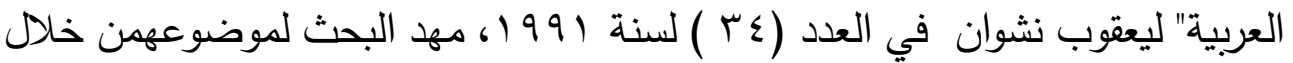
مناقشة عامة حول التربية المستمرة وتعليم الكبار ونظام التربية وأنظمته الفرعية ، والتربية 


\section{موقف المجلات التريوية العربية من بعض القضايا الخاصة أ.م. دـ ـ محمد أحمد محمد اسماعيل}

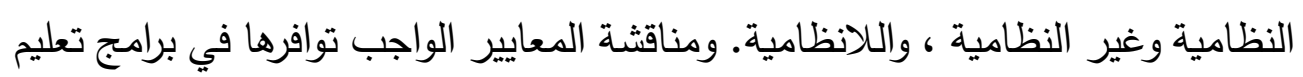

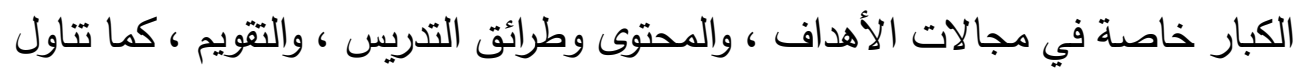
أهمية البحث التربوي في ميدان التربية المستمرة.

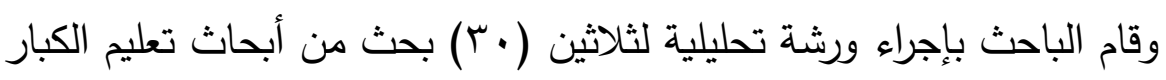

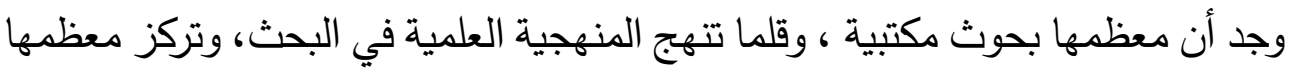
على مسألة محو الأمية ، بمفهومها الضيق. وفي ضوء النتائج قدم الباحث توصيات من بينها الإثارة إلى أهمية دراسة برامج تعليم

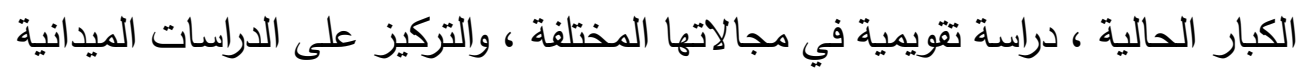

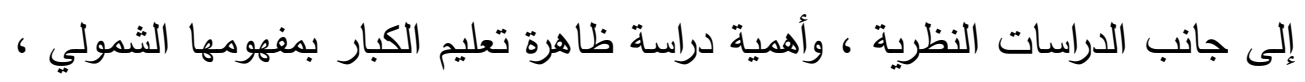
بحيث لا تقتصر على ميدان محو الأمية. ويلاحظ على هذه الدراسة أنها لجأت إلى معالجات ميدانية لأنية تمخضت عن نتائج هامة وأساسية.

وجاء البحث الثالث بعنوان " نموذج مقترح لمنهج إعداد معلمي المرحلة الابتدائية للقيام

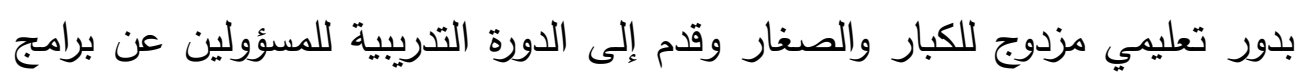

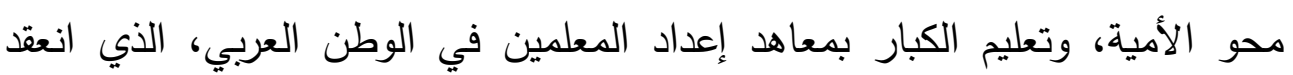

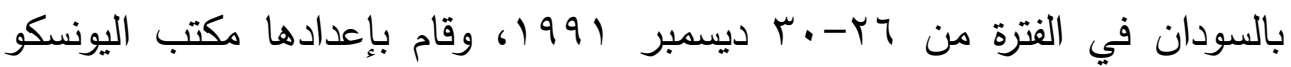
الإقليمي للتربية في البلاد العربية. وقدمت هذه الورقة البحثية نموذجا لمنهج إعداد معلمي المرحلة الابتدائية من أجل القيام

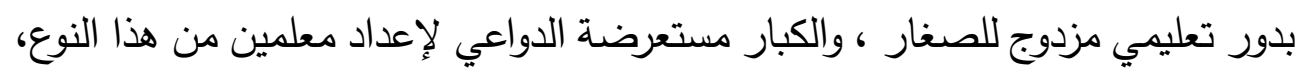

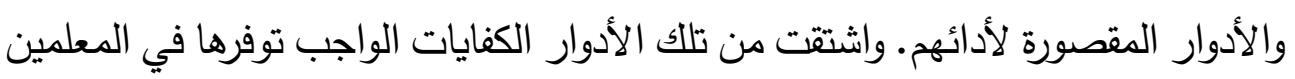
وبنت المنهج المقترح ليكسب المعلم تلك الكفايات ، ثم اقترحت طرادرائق تلتفيذ المنهج. 
والورقة و هي تقدم ذلك، لا تهمل تجارب الدول العربية في إعداد معلمي المرحلة الابتدائية ، والخبرات العميقة المكتسبة، والمؤسسات التي قامت لهذه الغايات كدور المعلمين ، ومعاهد التربية وكلياتها. فالنموذج المقترح ينفذ في هذا الإطار، فهو استكمال وتطوير وتجديد لما هو قائم ، وليس بديلا له. إلا أن ما طرحه البحث من الاستعانة بفئات مختلفة من المعلمين ليقوموا بتعليم الأميين ، وذلك بإشراكهم في دورات تدرببية قصيرة في مجال محو الأمية ، و تدريب المعلمين لتعليم الكبار عن طريق التدريب المناسبيطرح مجموعة من التساؤلات عن طبيعة هذه الدورات التدريبية القصيرة من حيث مدتها الزمنية ، وطبيعتها ودورها في التعريف بنظريات و فلسفاتتعليم الكبار ومراحل تطوره ، ونتائج مؤتمراته، وخصائص الكبار الفسيولوجية والسيكولوجية وكذلك بعض الخصائص التي يتميز بها الدارسون الكبار، وتحديد احتياجات الدارسين سواء الاحتياجات البشرية وتتمية الجماعة ام تحديد الاحتياجات التعليمية للدراسين ، وعرض للنماذج سواء من دول العالم المتقدم او النامي، وذللك حتى يستطيعوا القيام بالدور الذي طرحته الدراسة .

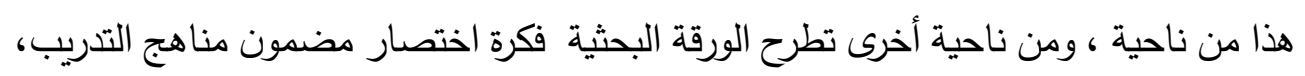

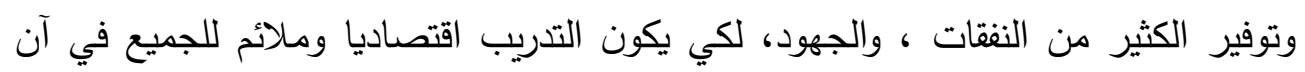

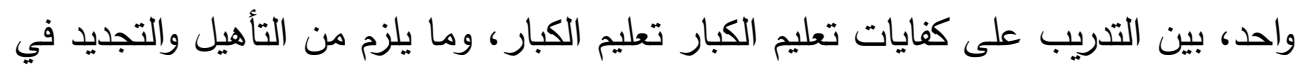
كفايات تعليم الصغار دون أن يوضح كيفية الاختصار في مضمون مناهج التدريب بدون الاخلال بعملية التدريب، خاصة وأن البحث يرى أن اختيار معلم التعليم الابتدائي للعمل في دئي التعليم الأساسي للكبار وتأهيله لهذا التعليم عن طريق التدريب يوفر لحملات محو الأمية أكفأ المواد البشرية القابلة للعمل من هذه الحملات، تحت ادعاء أن طبيعة العالم المتغير الذي يقدم المعلم عليه يتطلب إعداد المعلم للقيام بأدوار متعددة في عالم تتواصل فيه التجارب لنماذج متعددة من المناهج والأساليب والطرق. 


\section{موقف المجلات التربوية العربية من بعض القضايا الخاصة أ.م. د ـ محمد أحمد محمد اسماعيل}

مما يطرح التساؤل عن مدى كفاءة معلم التعليم الابتدائي للعمل في مجال التعليم الأساسي للكبار خاصة في ظل اختصار مضمون مناهج التدريب . وجاء البحث الرابع بعنوان : المحتوى التعليمي لمناهج إعداد معلمي الكبار في كليات

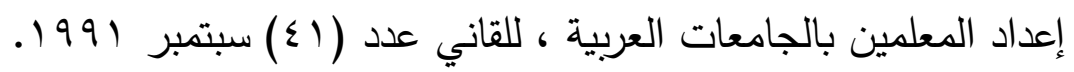
يطرح البحث المبررات التي تدفع البلدان العربية إلى اعتبار تعليم الكبار مهمة قومية ، كذلك يطرح بعض التساؤلات الجوهرية المتصلة بقضية الإعداد ، والتدريب للمعلمين في هذا المجال، ولعل ابرزها . كيفية إعداد معلمي تعليم الكبار ، ونوع الإعداد اللززم لهم، ومن الذي يقوم بتوفير ، وتتظيم برامج الاعداد والتدريب، وما الخطط الاساسية لمحتوى هذه البرامج على كافة المستويات.

وعلى الرغم من أن البحث طرح هذه التساؤلات ، إلا إنها قد اقتصرت على الإجابة عن

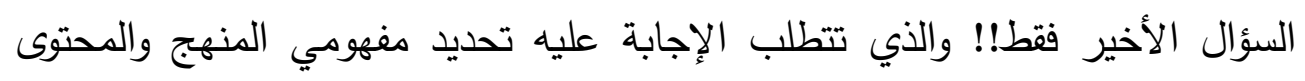
وتحديد المعايير العلمية للمحتوى التعليمي للمناهج وتحديد الأسس العلمية للمحتوى العلمي لمناهج إعداد وتدريب المعلمين بالجامعات العربية ، مع عرض لبعض الاسس اللازمة لتحديد المحتوى لتعليم الكبار وكذا بعض التجارب، والنماذج المؤثرة في مجال

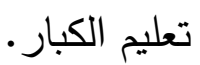
كذا نجد البحث يعرض لبعض الفلسفات ، ولبعض المدارس الفلسفية والفكرية التي لا بد من تدريسها للعاملين في مجال تعليم الكبار والتي يجب على معلمي الكبار الاطلاع عليها لكونها تمثل الاطار الفكري لكثير من التجارب ، والممارسات الحديثة في هذا

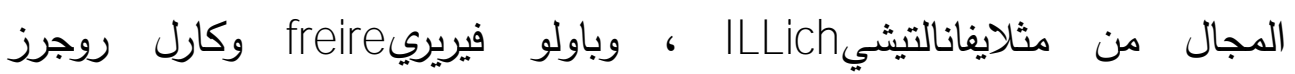
R ojers 
الواجب تضمينها في مناهج إعداد معلمي الكبار على مستوى مساقدارسيالدبلوم ، والماجستير والدكتوراه.

وجاء البحث الخامس بعنوان، التجارب العالمية في تدريس مناهج تعليم الكبار في

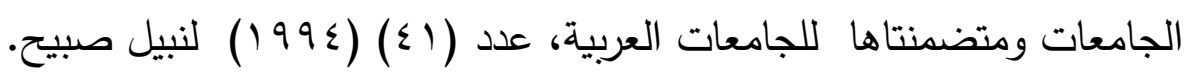
وهو عبارة عن محاولة تمهيدية تستهدف عرض وتحليل ومناقشة قضية تطوير مناهج تعليم الكبار في الجامعات ومتضمناتهاللجامعات العربية، وذللك في ضوء الدراسة التحليلية المقارنة بعض تجارب الدول الاجنبية في هذا المجال بغرض تقديم توصيات ومقترحات توضح امام المسئولين عن الجامعات في الدول العربية من منطلق ان النظرة المستقبلية لدور الجامعات بالمنطقة العربية في تطوير مناهج تعليم الكبار لابد ، وأن تستند على رؤية ، تتناول دراسة ، وتحليل التجارب العالمية في بـاني تدريس مناهج الكبار بالجامعات في الدول المتقدمة. بيد أن الرؤية الاستشرافية لدور الجامعات بالمنطقة العربية في تطوير مناهج تعليم الكبار يجب الا تقتصر على نماذج من بعض الجامعات بالدول المتقدمة فقط، بل يجب أن تستند على رؤية أوسع وأثمل تتتاول دراسة أو تحليل التجارب العالمية في عديد من دول العالم المتقدم ، والنامي على السواء وذللك لكي نستفيد من الخبرات ، وإمكان تعميم الفائدة ، ومن جهة ثانية تحذرنا من الوقوع في اخطاء غيرنا بل وتزودنا بالاستفادة

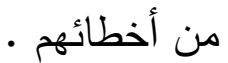
فالبحث في طبيعة النظم والتجارب التربوية يحتاج إلى دراسة ، وتحليل نواح كثيرة ، تتناول الاسس التاريخية و العوامل الجغرافية ، والسياسية ، والدينية والثقافية ، وكذلك طبيعية القيم والفلسفة التربوية التي تتناول طريقة الحياة التي يختارها المجتمع ، والمبادئ

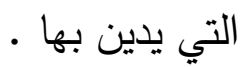




\section{موقف المجلات التربوية العربية من بعض القضايا الخاصة أ.م. دـ ـ محمد أحمد محمد اسماعيل}

كذلك يعرض البحث لحالة الخلل، في العلاقات بين معاهد التعليم العالي، وتعليم الكبار إذ تدل الصورة العامة للجامعات العربية على ان الاتجاه الغالب على نشاطها هو التركيز على تعليم الطلاب النظاميين ، والقيام ببعض البحوث الأكاديمية ، دون أن تحظي مشكلات تعليم الكبار، ومحو الأمية من هذه الجامعات بما تستحق من عناية ،على لونى الرغم مما تتطوي عليه هذه المشكلات من آثار بالغة الخطورة على حياة الفرد وتقدم المجتمعات العربية على السواء كذلك يطرح البحث حاجة المنطقة العربية ـ إلى تأصيل علم جديد " اندراجوجيا " بحيث يصبح هنالك اطر مرجعية له وان يقوم على اسس وأصول علمية تساهم الجامعات العربية في وضعها وإخضاعها للبحث المستمر ، والمراجعة الدائمة في ضوء الأساليب

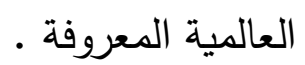
وجاءالبحث السادس بعنوان : واقع مناهج تعليم الكبار في معهد التربية التابع للأونروا عدد (1§) (§99 (19) لمحي الدين شعبان توق وعبد اللطيف خيري. وهو عبارة عن ورقة تعريفية بمعه التربية التابع للأونروا وعرض البحث جوانب ومحتويات المناهج التابعة للأونروا، وفقا لمنهية وصفية تحليله ناقشت طبيعة الدورات التي ينظمها معهد التربية ، والمنحى التدربي المستخدم، وبرامج التدريب ، والتطبيقات العملية وتقويم المتدربين، والجهاز الفني العامل بالمعهد. واختتم البحث بتناول اهمية تطوير هذه البرامج التدريبية ، والارتقاء بنوعيتها لتكون قادرة على الاستجابة الحقيقية بشكل جاد لكل التحديات ، والتحولات القائمة والمتوقعة بشكل

وأشار البحث إلى أن الأولوية سوف تعطي إلى تطوير برامج التدريب الاساسية وبشكل خاص دورات المعلمين الجامعيين الاساسية ، والتوجه نحو تتظيم دورات قصيرة تدور حول محاور تدربيية محددة، وبخاصة في مجال تدريب القادة التربوين ، بحيث 
يتم تنظيم دورات لمدة أسبوع أو اسبوعين أو شهر والتوجه نحو تتظيم برامج تدريبية لأعداد المعلمين القادرين على رعاية التلاميذ الموهوبين، والمتفوقين. وكذلك التوجه نحو تتظيم برامج تدريب في البحوث التربوية والتقويم بأشكاله المتعددة، وتنشيط عمليات البحث التربوي من خلال تدريب الكوادر البحثية القادرة على بلى قيادة عمليات البحث التربوي ميدانيا أو الاسهام الفعال في عمليات إثراء ، وإغناء المناهج الدراسية ، وذلك من خلال تدريب المشرفين التربويين، ومديري المدارس على قيادة عمليات الاثراء، والاغناء للمناهج الدراسية بصورة تطبيقية، وعملية ، ثم مراجعة ولثن المواد والوسائط التدرببية المقروهة والمرئية ، والعمل على تحديثها وتجديدها وخاصة تلك التي مضى على إنتاجها واستخدامها أكثر من خمس سنوات. وأخيرا التخطيط لإعادة تأهيل ، وتدريب العاملين التربويين ممن مضى على تأهيلهم أكثر من خمس سنوات، وفق برنامج تدريبي يقوم على اعتماد أسلوب التدريب قصير المدى وبدء برنامج مكيف يهدف إلى تدريب الميدانيين أو العمل على النهوض بنوعية كفاياتهم التدريبية بصورة شاملة. وجاء البحث السابع بعنوان: الجذع المشترك كمدخل لتعليم الكبار بالعدد (1) لعام § 9 ام لعبد الفتاح حجاج. وهو عبارة عن بحث وصفيتحليلي يهدف إلى ترسيخ مفهوم الجزع المشترك، كمدخل لإعداد وتكوين العاملين في مجال تعليم الكبار و من خلال معالجة تحليلية عامة ، ارتكزت على التعريف بمفهوم نشاط محو الأمية ، وبرامج التقافة العمالية والتعليم الموازي، والارشاد الزراعي ، والتدريب وإعادة التدريب ، وبرامج التقافة الاسرية، والثقافية العامة، وبرامج الخدمة العامة التابعة للجامعات. ومن خلال ما تم عرضه تم تحديد مفهوم الجزع المشترك، والفلسفة التي ينطلق منها ، وقدم مقترح عام لتعليم الكبار في ضوء مدخل الجزع المشترك مع تحديد ادوار الجامعات، وكليات التربية في هذا المجال. 
موقف المجلات التربوية العربية من بعض القضايا الخاصة ا..م. دـ ـ محمد أحمد محمد اسماعيل

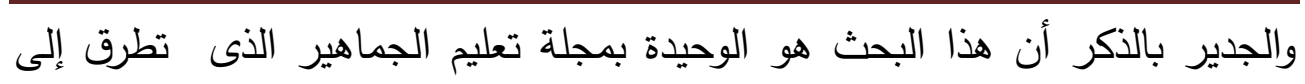

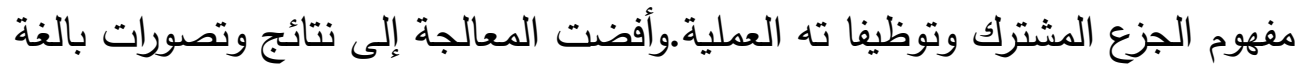

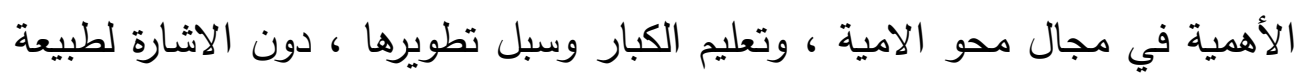
السياقات المجتمعية، والتتموية التي تستند إليها. وجاء البحث الثامن بعنوان: تطبيق التربية الميدانية في مدارس تعليم الكبار الليلية مجلة التها: تعليم الجماهير عدد (20) 991 ام لخليل السعادات.

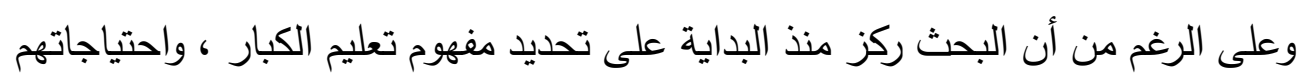

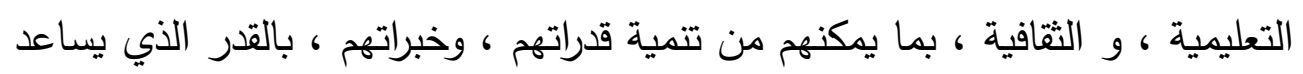

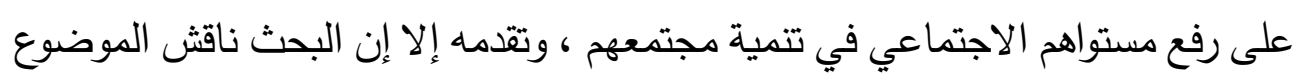

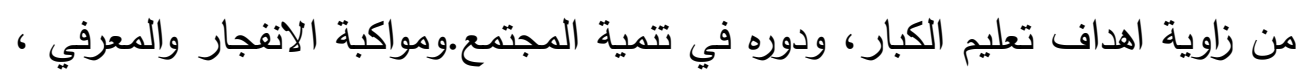
وسد جوانب النقص في التعليم النظامي و تثثيف المجتمع ، واستغلال اوقات الفراغ.

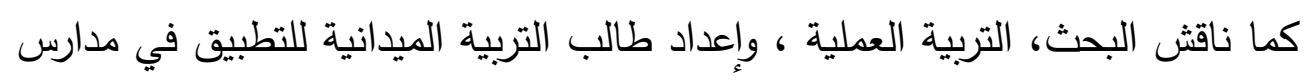
تعليم الكبار الليلية. وبصفة عامة يلاحظ أن هذا البحث اعتمد على منهجية وصفية دقيقة بعض الشيء

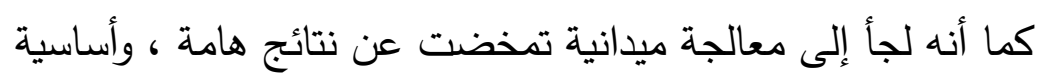

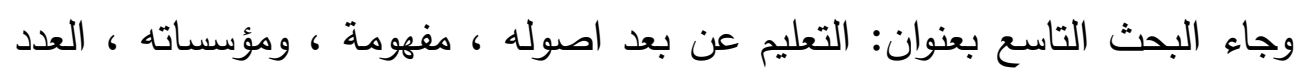

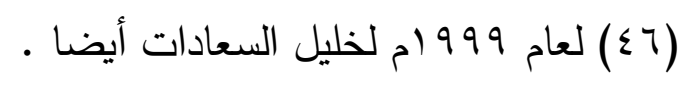
تتاول التمعيد للبحث عرضا لأهمية التعليم عن بعد تعليميا واقتصاديا وتكنولوجيا ومعرفيا

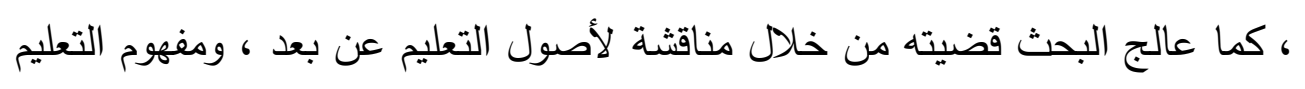
التفاعلي عن بعد ، وانواع مؤسساته.

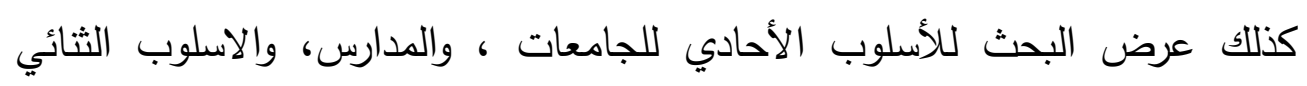
والمزدوج للجامعات ، ومؤسسات الخدمة العامة والثبكات. 
كذلك قام البحث بعرض بعض التجارب العالمية في التعليم عن بعد ، .وأكد في خاتمته على أهمية إنشاء جامعة عربية دفتوحة ، ودراسة اصول ، وجذور التعليم عن بن بعري بعد ، مع إدخال مفاهيم التعليم عن بعد، وتقنياته في برامج التدريب وإعداد المعلمين ،

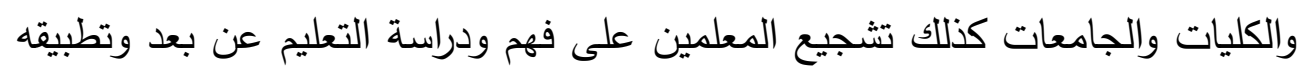
في مواقعهم التعليمية وإزالة بعض العراقيل التي تواجه مؤسسات التعليم المفتوح ، والتعليم عن بعد، والاستفادة من التجارب العالمية الناجحة في هذا المجال. كما قام البحث بمناقشة الاسس الفلسفية والاستراتيجية لتعليم الكبار ومحو الأمية بقدر لهن عال من المنهجية بما يمكن الاستفادة منها لتطوير الواقع العربي. وجاء البحث العاشر بعنوان : إعداد معلم الكبار ، وتدربيه لمواجهة متطلبات مجتمع معايع

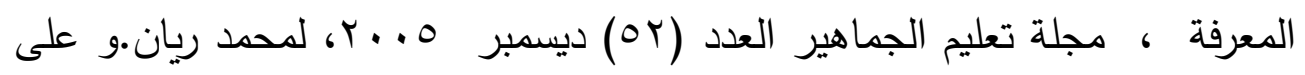
الرغم من أن عنوان البحث اعداد معلم الكبار ، الا ان الباحث لم يتناول اعداد معلم

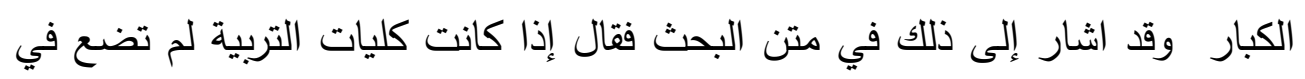
خططها حتى الآن برامج لتخريج هذا المعلم الذي يتعامل مع الكبار ، فلا أقل من تحسين نوعية التدريب، وتجويده للوصول بهذا المعلم إلى مستوى الدور الذي تؤهله له به

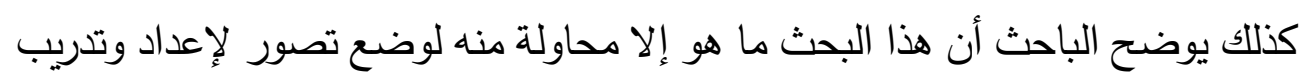

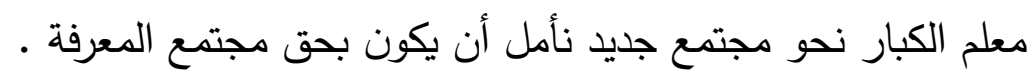

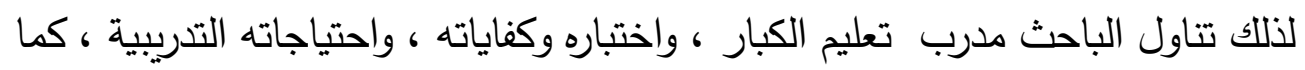
تتاول أهم الخصائص التي ينبغي أن تتوفر في شخصية المعلم بصفة عامة .وفيمن

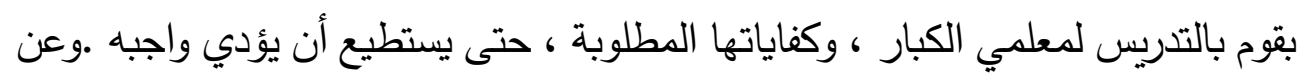

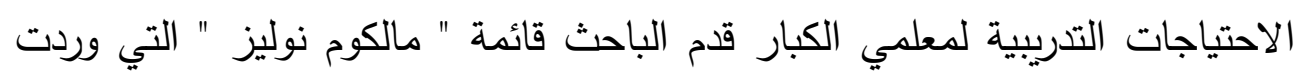
The modem practice of adult education بكتابه 


\section{موقف المجلات التربوية العربية من بعض القضايا الخاصة أ.م. دـ ـ محمد أحمد محمد اسماعيل}

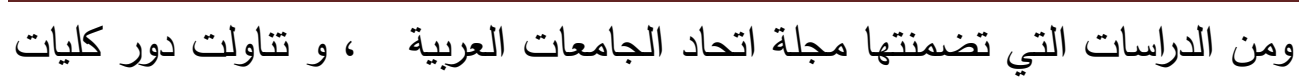

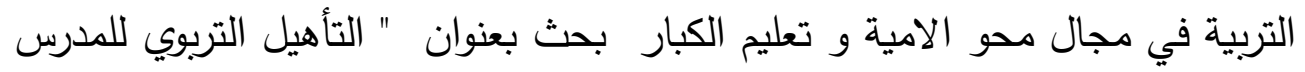

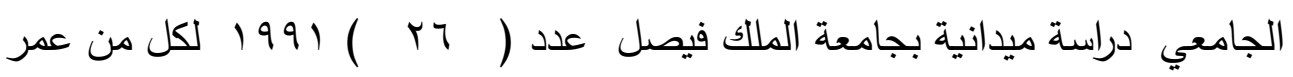

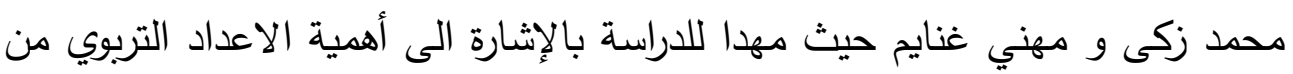

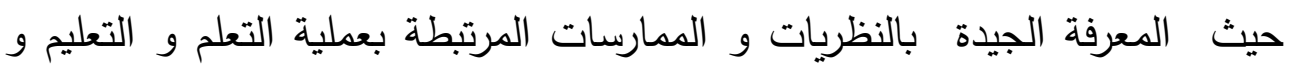
قدرات و مهارات استخدام التتنيات التعليمية المخافة بالجانب التخطيطي و التنفيذي قاعة الدراسة وطرح الباحثان مجموعة من التساؤلات منها:

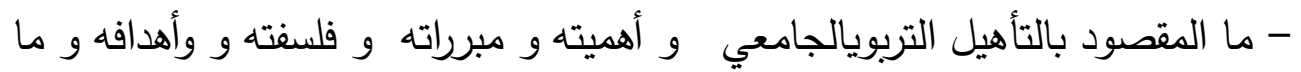

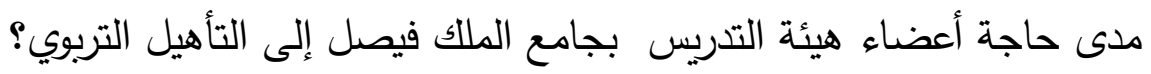
- ماهي المجالات التربوية التي يحتاجون فيه الى التدريب؟ - ما علاقة اختلاف مجالات التأهيل التربوي ببعض المتغيرات من مثل الكلية و

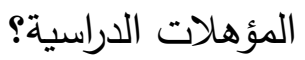

ويلاحظمن جدول ( r ) أن الأدوار الأساسية التي تمت مناقشتها في الأبحاث

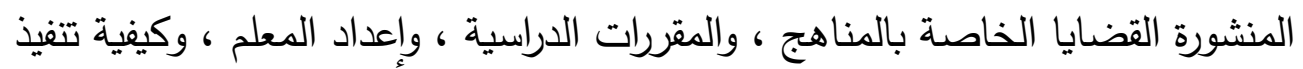

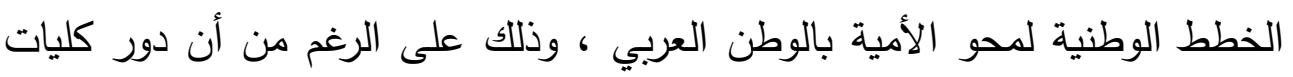

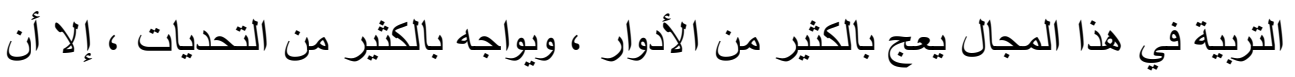
هذه الأدوار والتحديات الكبرى لم تتاقش بصورة منتظمة ، وجادة .

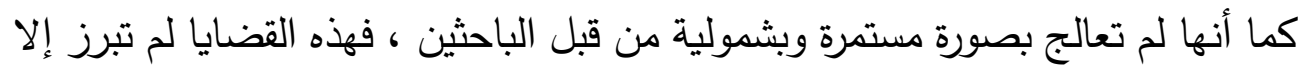

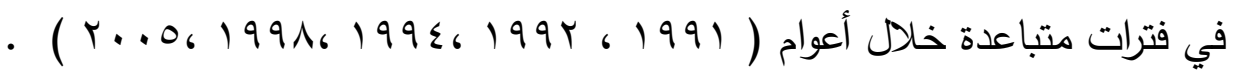

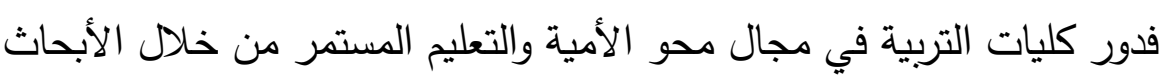

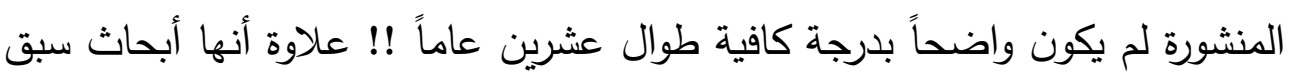

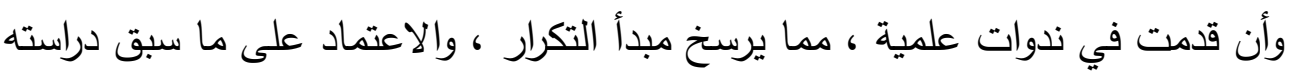


دون تكلف عناء البحث عن الدراسات التي تطرح قضايا جديدة ، كما يفعل مبدأ الحداثة في طبيعة الأبحاث المنشورة .

كذللك يلاحظ غياب الكثير من القضايا الأساسية التي تتعلق بدور كليات التربية في مجال محو الأمية ، وتعليم الكبار ، والتي عبرت عنها العديد من المؤتمرات الإقليمية والدولية .. فلم تلق مثل هذه القضايا نصيبا من الاهتمام من قبل الباحثين لتتاولها

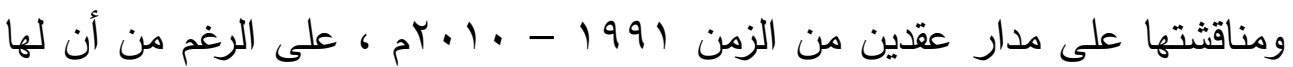
أبعاد متعددة معرفية ومجتمعية من ذلك على سبيل المثال لا الحصر : - الدراسات المستقبلية المرتبطة بدور كليات التربية تجاه قضية الأمية وتعليم الكبار ، كقضية مجتمعية هامة في الوطن العربي • - إشراك طلاب كليات التربية ، وكذللك المعلين في التدريب ببرامج محو الأمية وتعليم الكبار ، وقيام كليات التربية بتدريب قيادات تعليم الكبار ، والعاملين في

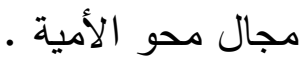
- تقديم المشورة الفنية للهيئات المحلية ، والإقليمية ، والدولية فيما يتعلق بمحو الأمية • وتعليم الكبار - التوعية المجتمعية بأهمية التعليم المستمر وإثارة الوعي المجتمعي بخطورة مشكلة الأمية ، وتعليم الكبار على مستوى الوطن العربي • - استخدام أساليب التدريب المستمر عن بعد لتوفير فرص التعليم المستمر للجميع • - العمل مع كافة الأجهزة المجتمعية ، والهيئات التربوية المجتمعية لسد منابع الأمية الأساسية في الوطن العربي ل 
موقف المجلات التربوية العربية من بعض القضايا الخاصة أ.م. دـ ـ محمد أحمد محمد اسماعيل

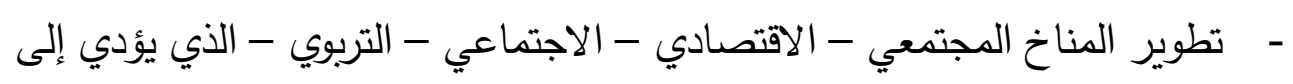
ايجاد مجتمع متناسق ، ومتوازن ومتماسك في بنيته وملاعم لمطالب الحاضر يلري

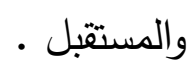

- تقويم الجهود الحكومية ، والأهلية ، والدولية في مجال محو الأمية وتعليم الكبار

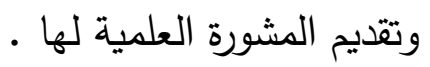

فكل هذه القضايا النوعية ، كانت محور اهتمام العالم أجمع خلال العقد الأخير من

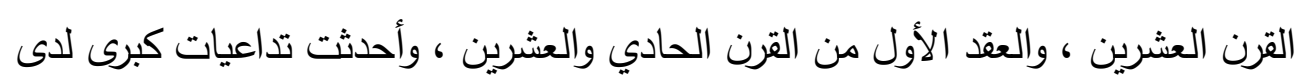
المنظمات العاملة في مجال محو الأمية ، وتعليم الكبار • بيد أن احجام الباحثين عن طرق مثل هذا النوع من الأبحاث لم يسهم في توضيح دور كليات التربية في مجال محو الأمية ، وتعليم الكبار ، ويكرس النظر إليه على أنه متبلور حول إعداد المعلم بصفة عامة ، ويخفى دورها فيما يتعلق بقضية الأمية

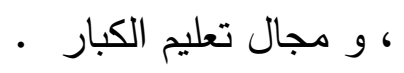

r - وحدة الإطار النظري ، والدراسات السابقة بالأبحاث التي تتاولت دور كليات التربية في مجال محو الأميةوتعليم الكبار ، بالمجلات الأربع تعليم الجماهير - رسالة التربية وعلم النفس - رسالة الخليج العربي - اتحاد

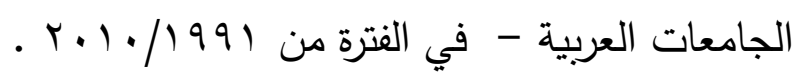

جدول (r)

أ - - التحليل الكمي لوحدة الإطار النظري ، والدراسات السابقة بالأبحاث التي تتاولت دور كليات التربية في مجال محو الأمية وتعليم الكبار ، بالمجلات الأربع - بالإل تعليم الجماهير - رسالة التربية وعلم النفس - رسالة الخليج العربي - اتحاد

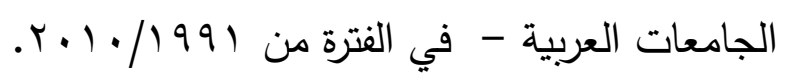


العدد التاسع والعشرون 10 ـ الت

مجلة دراسات فى التعليم الجامعى

\begin{tabular}{|c|c|c|c|c|c|}
\hline $\begin{array}{r}\text { العربية الجامعات } \\
\text { العربية }\end{array}$ & الخليجالعربي & 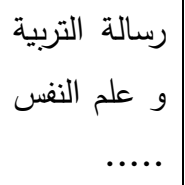 & مجلةتعليم & السإطار النظري ، والدراسات & م \\
\hline- & - & - & 1 & العربية & 1 \\
\hline- & - & - & - & $\begin{array}{r}\text { الأجنبية الداجد السابقة } \\
\end{array}$ & $r$ \\
\hline- & - & - & - & توظيف الإطار النظري في & $r$ \\
\hline- & - & - & - & بأهداف البحث الإطار النظري & $\varepsilon$ \\
\hline- & - & - & - & علموضة الدراسات السابقة & 0 \\
\hline- & - & - & - & بأسئلة البحث الداسات السابقة & 7 \\
\hline- & - & - & - & الدراسات السابقة $\quad$ البحث من & v \\
\hline- & - & - & - & أللهية الدراسات السابقة & $\wedge$ \\
\hline- & - & -- & - & أخرى & 9 \\
\hline & & & & المجموع & \\
\hline
\end{tabular}

ب - التحليل الكيفي لوحدة الإطار النظري ، والدراسات السابقة بالأبحاث التي تناولت دور كليات التربية في مجال محو الأمية وتعليم الكبار ، بالمجلات الاربع تعليم الجماهير - رسالة التربية وعلم النفس - رسالة الخليج العربي - اتحاد الجامعات

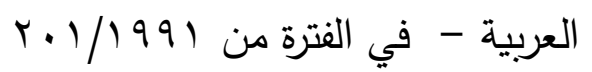

تبين من التحليل الكمي والكيفي لوحدة الإطار النظري ، والدراسات السابقة للأبحاث

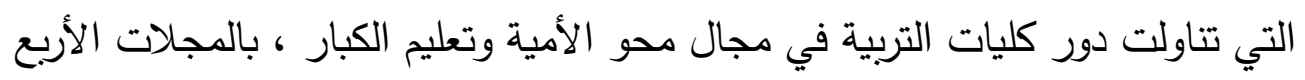




\section{موقف المجلات التربوية العربية من بعض القضايا الخاصة أ.م. دـ ـ محمد أحمد محمد اسماعيل}

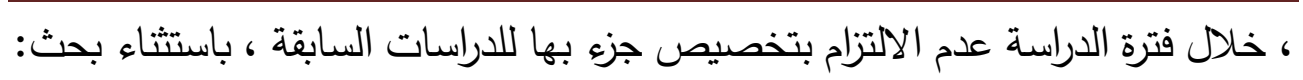

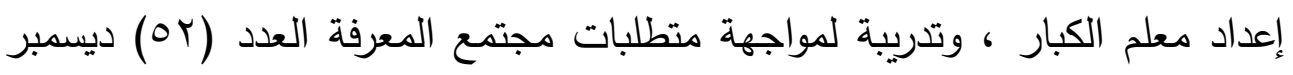

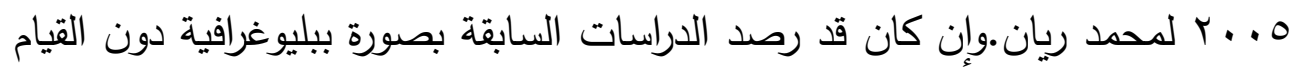

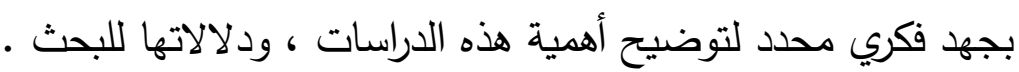

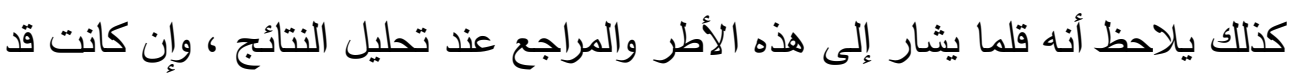
تناولت الأطر النظرية بصورة أقرب إلى المقالة منها إلى الدراسات العلمية المنهجية في

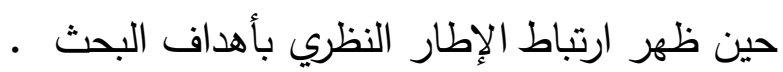
ونتيجة لذلك ضعفت معرفة الباحثين بنقاط القوة ، والضعف بالدراسات السابقة بما

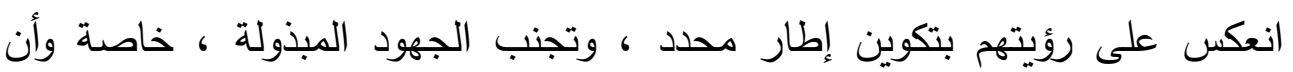

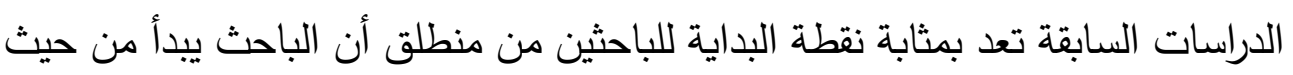

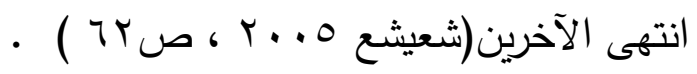
رابعا -وحدة مناهج البحث المستخدمة في الابحاث التي تناولت دات دور كليات التربية

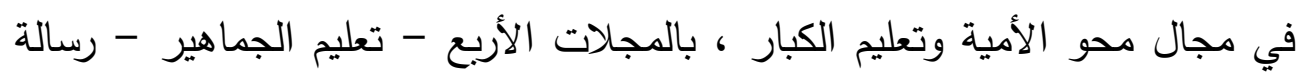

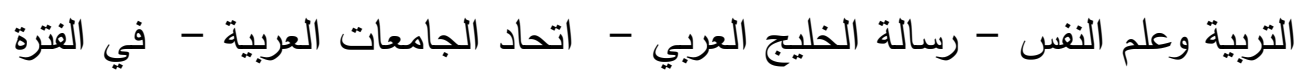
r.1./1991 من

المنهج هو عبارة عن تلك الطريقة التي يسلكها الباحث من دراسة للمشكلة ليتعرف على التى

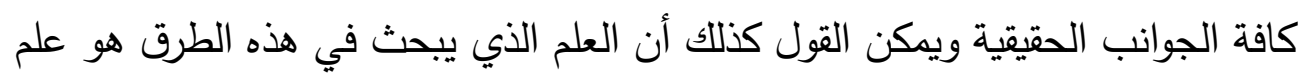

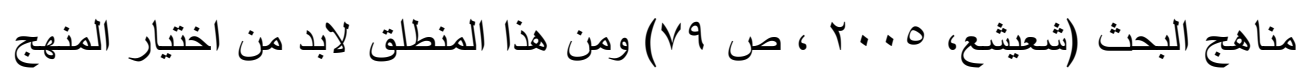
المناسب للمشكلة التي حلها هو هدف البحث.

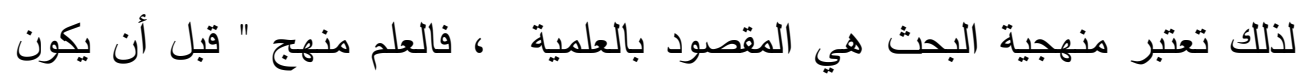

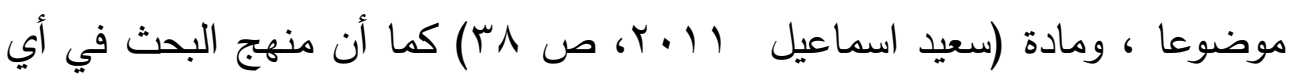

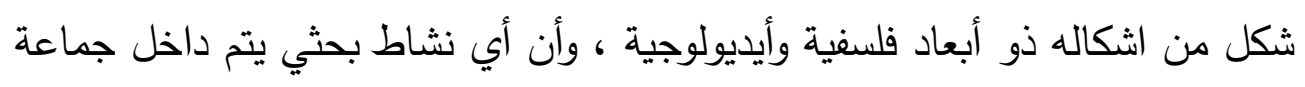


علمية يعمل من خلالها الباحث ويستمد شرعية وجوده العلمي ممن خلالها في إطار

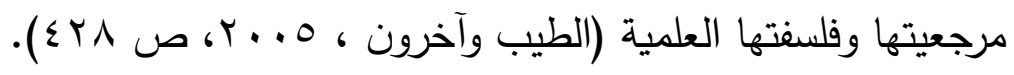
وبناء على ذلك فإن تناول مناهج البحث الكمية أو الكيفية يتطرق إلى مجموعة مترابطة من القواعد ، والمسلمات الفلسفية ، والأيديولوجية والايستمولوجية ،وهذا يعني أن قضية المنهج اكبر من كونها مسألة فنية تتعلق بجمع بيانات أو معلومات عن ظاهرة ما تدرسها بأنها فإشكالية المناهج ضرورة معرفية ففي كل زمان ترتبط المعرفة العلمية بمستوى المناهج المطبقة لذا فإن المعرفة المستقبلية تتعلق بتطور مناهج اليوم (سالم ،

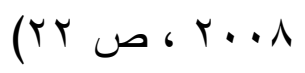

$$
\text { جدول ( ) }
$$

أ - - التحليل الكمي لوحدة مناهج البحث المستخدمة في الابحاث التي تتاولت دور كليات التربية في مجال محو الأمية وتعليم الكبار بالمجلات الاربع - تعليم الجماهير - رسالة التربية وعلم النفس - رسالة الخليج العربي - اتحاد الجامعات العربية - في

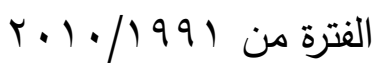

\begin{tabular}{|c|c|c|c|c|}
\hline $\begin{array}{r}\text { مجلة } \\
\text { اتحاد العربية } \\
\text { الجادات }\end{array}$ & |الخليج & | رجلة & تجلية & البحثية المنهجية العلمية المستخدمة في \\
\hline$r$ & - & - & 7 & المنهج الوصفي \\
\hline- & - & - & - & المنهج التجريبي \\
\hline- & - & - & - & المنهج التاريخي \\
\hline- & - & - & - & المنهج الاثتوجرافي \\
\hline
\end{tabular}


موقف المجلات التربوية العربية من بعض القضايا الخاصة أ.م. دـ ـ محمد أحمد محمد اسماعيل

\begin{tabular}{|c|c|c|c|c|}
\hline- & - & - & 1 & المنهج المقارن \\
\hline- & - & - & - & الالتزام بالمنهجي العلمي المستخدمة \\
\hline- & - & - & - & استباق المنهجية مع اسئلة البحث ارتباط \\
\hline- & - & - & $V$ & البحث المنطقة العلمية التي بنت عليها \\
\hline & & & $r$ & أخرى \\
\hline & & & & المجموع \\
\hline
\end{tabular}

ب - التحليل الكيفي لوحدة مناهج البحث المستخدمة في الابحاث التي تتاولت دور

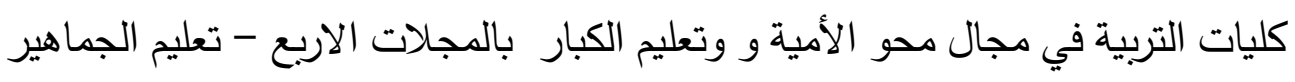
- رسالة التربية وعلم النفس - رسالة الخليج العربي - اتحاد الجامعات العربية - في

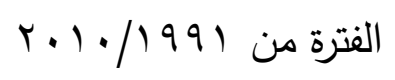

يلاحظ من الجدول لوحدة مناهج البحث المستخدمة في الابحاث التي تتاولت دور كليات التربية في مجال محو الأمية ، وتعليم الكبار بالمجلات الأبع خلال الفترة من $\cdot r^{r} \cdot 1 \cdot-1991$

أنها استخدمت المنهج الوصفي الذي يرتبط منذ بدايته بدراسة مجموعة المشكلات

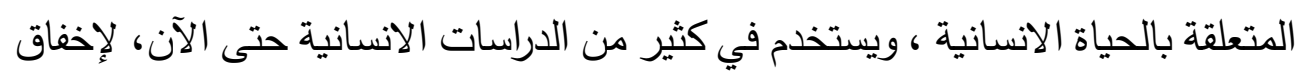

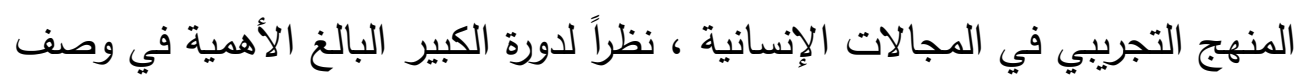
الظاهرة وجمع ، وتتظيم كافة البيانات ، والمعلومات والتعبير عنها تعبيرا كميا وكيفيا

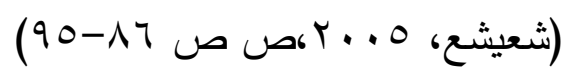


وتبرز أهمية المنهج الوصفي في كونه المنهج المناسب لدراسة بعض الموضوعات الإنسانية ، وخاصة في مجال البحوث التربوية حيث يتطلب اكثر من مجرد عملية وصف الوضع القائم للأشياء و الظواهر ، وجمع المعلومات والبيانات عنها ، بل لابد من تصنيفها وتتظيمها والتعبير عنها كميا ، وكيفيا بحيث تؤدي إلى فهم لعلاقات هذه الظواهر مع غيرها من الظواهر الأخرى ، وذلك على اختلاف أنماطه

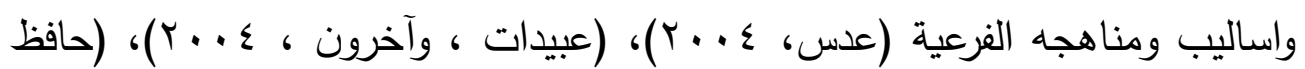

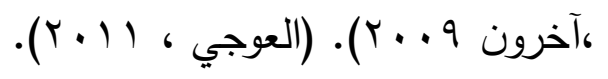

والابحاث التي استخدمت المنهج الوصفي هي ، بحث اولويات البحث التربوي في تعليم الكبار في الدول العربية، مجلة تعليم الجماهير عدد(ی) (1991 ) ) ، حيث قام الباحث بتحليل مضمون ثلاثين بحث من ابحاث تعليم الكبار ، والملاحظ على المنهج الوصفي المتمثل في تحليل المضمون ، انه منهج وصفي دقيقة بعض الشيء، الا ان الباحث لم يستخدم فئات أو وحدات تحليل ، ولم يتناول إجراءات الصدق ، أو الثبات لعملية التحليل التي قام بها وإن كانت المعالجة التحليلية تمخض عنها نتائج هامة ، واساسية

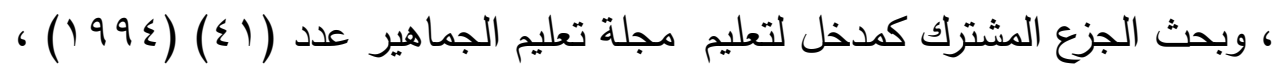
قام فيه الباحث بمعالجة تحليلية عامة، ارتكزت على التعريف بمفهوم نشاط محو الامية، وبرامج الثقافة العمالية ، والتعليم الموازي . • وبحث واقع مناهج تعليم الكبار من معهد التربية التابع للأونروا مجلة تعليم الجماهير عدد (1) (؟9 (1) حيث استخدم الباحث المنهج الوصفي التحليلي لمناقثة طبيعة الدورات التي ينظمها معهد الأونروا التابع لليونسكو ، المنحى التدريبي المستخدم ، وبرامج التدريب ، والتطبيقات العملية ، وتقويم المتدربين ، والجهاز الفني العامل في 
موقف المجلات التربوية العربية من بعض القضايا الخاصة أ.م. دـ ـ محمد أحمد محمد اسماعيل وبحث تطبيق التربية الميدانية في مدارس تعليم الكبار والليلية." مجلة اتحاد الجامعات

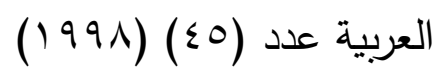

وبحث التعليم عن بعدأصوله، مفهومه ، مؤسساته، مجلة تعليم الجماهير عدد (T؛) (999 (199) حيث ناقش الباحث بقدر عال من المنهجية الأسس الفلسفية والاستراتيجية لتعليم الكبار ومحو الأمية والتي يمكن الاستفادة منها لتطوير الواقع العربي •وبحث " إعداد معلم الكبار وتدريبه لمواجهه متطلبات مجتمع المعرفة " مجلة تعليم الجماهير

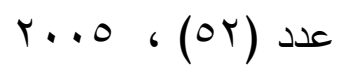
وجاء استخدام المنهج المقارن في بحث واحد فقط هو " التجارب العالمية في تدريس مناهج تعليم الكبار في الجامعات ومتضمنتاها ، مجلة تعليم الجماهير عدد إي عام §9 9 الدراسة وتحليل الوضع القائم في المنطقة العربية من حيث طبيعة الدور الذي تؤديه الجامعات العربية في مجال مناهج تعليم الكبار مستندا على الواقع الثقافي الذي عايثه الباحث بالفعل إحساسا وخبرة ودراسة وتفاعل زمني مع الماضي ، ومكاني مع

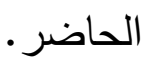

وجاءت ثلاثة ابحاث بدون استخدام منهج بحث !! مما يطرح التساؤل عن سبب غياب مناهج البحث الأخرى ، خاصة وأن هناك بهن مناهج بحث تستخدم في مجال تعليم الكبار وهي منهج تف Tough الذي يستتد على دراسة مشروعات التعلم لدى الكبار Adult learning projects و منهج بحوث المشاركة participatoryResearch التي اسهم المجلس العالمي لتعليم الكبار في تطويرها!. والجديد بالذكر أن لهذين المنهجين اصولهما الفلسفية العميقة الضاربة في عمق حركة تعليم الكبار كما إنهما يستندان إلى مفاهيم التعلم الذاتي ، ومناهج إثارة الوعي التي

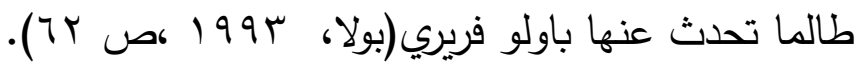


كذلك يلاحظ غياب المناهج الاستشرافية ، من مثل اسلوب دلفاي الذى يعد من أشهر الاساليب الاستشرافية و التتبؤ في الدراسات المستقبلية كما يعتبر منهجا للوصول الى هي لئي ) رسم السياسات و البدائل أو الوصول الى اتفاق على موضوع ما ليس فقط للتنبؤ

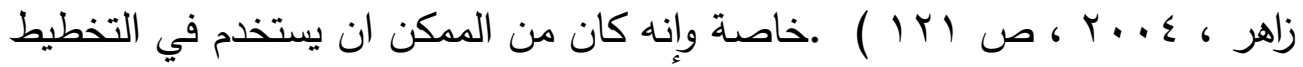
لدور كليات التربية تجاه مشكلة الامية ، أو في أي مجال من مجالات تعليم الكبار !! بيد أن ما يثير التساؤل أيضا وبدرجة كبيرة غياب المنهج الاثوجرافي في هذه الأبحاث على الرغم من إن مجال تعليم الكبار من المجالات التي يستخدم فيه المنهج الاثثوجرافي

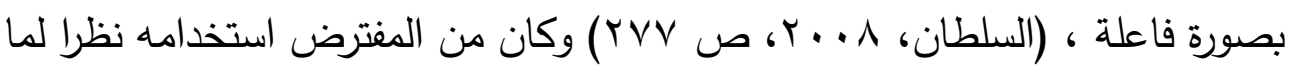
يحققه من معلومات نوعية تحليلية تعتمد على التعمق والتبصر ، والوصف المكثف، وتقسير الظواهر الاجتماعية من خلال ربطها بسياقها المحلي ( Miles\&Hublman $(, 1999$, p. 15 وربما يرجع انعدام استخدامه في هذه الأبحاث الى ضعف الاهتمام به ، بوصفه أحد

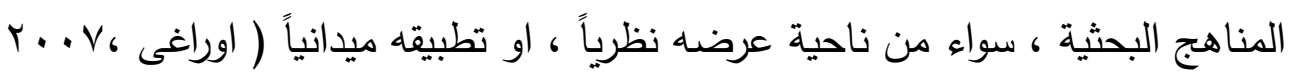
(0) 0 ص وما يثير التساؤل أيضا غياب استخدام المنهج التاريخي سواء بالطريقة الطولية او العرضية ، لدراسة " محو الأمية ، وتعليم الكبار " ودور كليات التربية تجاههم حيث باله يقوم الباحث بتتبع مراحل تطور هذا الدور حتى يومنا هذا أو يتتاوله بنظره كلية داخل السياق الثقافي بشتى أبعاده في مجتمعنا الحالي " مجتمع المعلومات العالمي " ويحاول رسم المعالم الرئيسة ، أو الخصائص التي تميزه، ثم يتأمل اثر هذا السياق الثقافي في

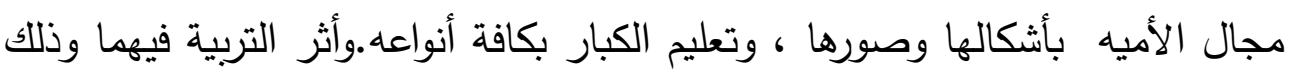

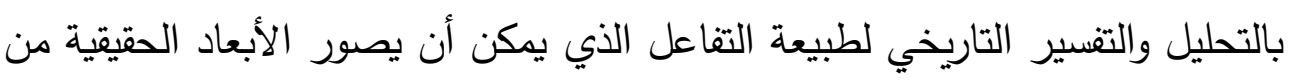




\section{موقف المجلات التربوية العربية من بعض القضايا الخاصة أ.م. دـ ـ محمد أحمد محمد اسماعيل} ثقافة المجتمع ، والحياة الفكرية فيه ، ومن ثم يمكن رصد دور كليات التربية في مجال

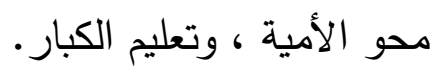
وكان من الطبيعي والمنطقي غياب المنهج التجريبي الذي يعمل على استخدام التجربة في تحقيق وأثبات الفروض ، وذلك عن طريق التجريب في هذه الأبحاث ، ذلك لان طبيعتها لا تتاسبها القيام بالتجربة العلمية التي يتم عن طريقها التأكد من صحة الفروض وله وبصفه عامة ، يلاحظ على مناهج البحث المستخدمة في هذه البحوث انها جاءت

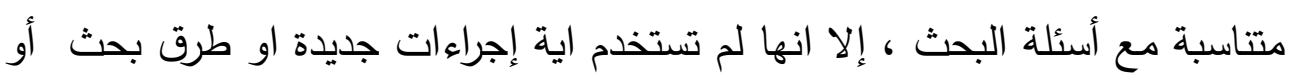
منهجية جدية ، بحيث تقدم مفاهيم جديدة للفكرة التي بصدد بحثها متحدية الطرح النظري

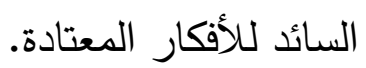
كذلك يلاحظ ان بعضها قد قدم مبررات كافية لاختيار المنهج المناسب لأهدافه وقدمت

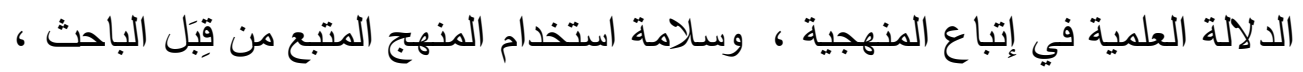
كذللك كانت المنهجية واضحة ومفصلة ، ومتدرجة ، وقابلة للفحص والتقييم في كافة

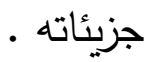
خامسا -وحدة نوعية المعلومات المتضمنة في الأبحاث التي تتاولت دور كليات التربية في مجال محو الأمية وتعليم الكبار بالمجلات الاربع - تعليم الجماهير رسالة التربية وعلم النفس - رسالة الخليج العربي - اتحاد الجامعات العربية - في

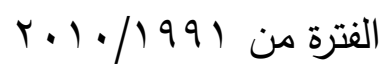

$$
\text { جدول (0) }
$$

أ - التحليل الكمي لوحدة نوعية المعلومات المتضمنة في الابحاث التي تتاولت دور كليات التربية في مجال محو الأمية وتعليم الكبار بالمجلات الاربع - تعليم الجماهير - رسالة التربية وعلم النفس - رسالة الخليج العربي - اتحاد الجامعات

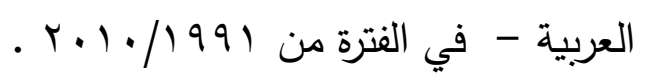




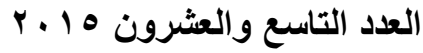
مجلة دراسات فى التعليم الجامعى

\begin{tabular}{|c|c|c|c|c|c|}
\hline 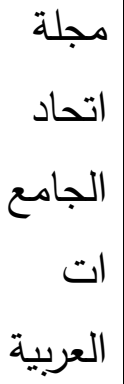 & رجلة الخليج & مجلة & تعلة & 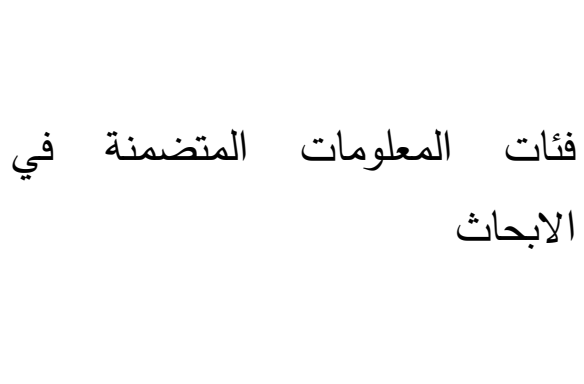 & r \\
\hline$r$ & & & 1. & كمجال محو ارتباط المعلومات المتوافرة في البحوث & 1 \\
\hline$r$ & & & r & مع التوجهات المعلومات المتضمنة في البحث & $r$ \\
\hline & & & $\varepsilon$ & إضافة أفكار ورؤى حديثة مبتكرة & r \\
\hline & & & 1 & في البحثة المراجع ، والمعلومات المتضمنة & $\varepsilon$ \\
\hline & & & & أخرى & \\
\hline & & & & المجموع & \\
\hline
\end{tabular}

التحليل الكيفي لوحدة نوعية المعلومات المتضمنة في الابحاث التي تتاولت دور

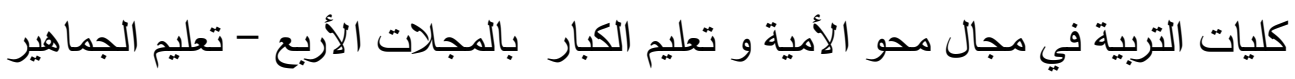
- رسالة التربية وعلم النفس - رسالة الخليج العربي - اتحاد الجامعات العربية - في

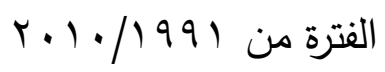

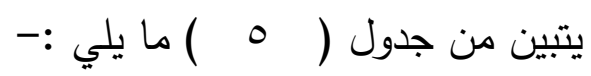
أ- فئة ارتباط المعلومات المتوافرة في البحث بمجال محو الأمية وتعليم الكبار كمجال متداخل التخصصات . 
موقف المجلات التريوية العربية من بعض القضايا الخاصة . أ.م. د. ـ محمد أحمد محمد اسماعيل

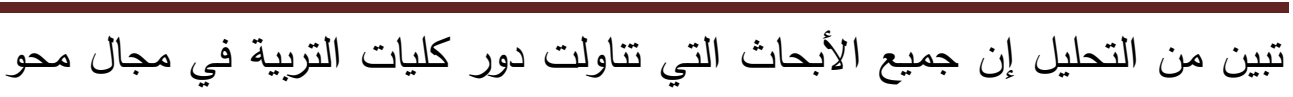

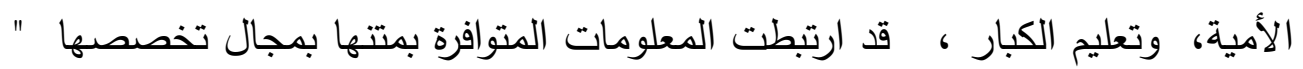

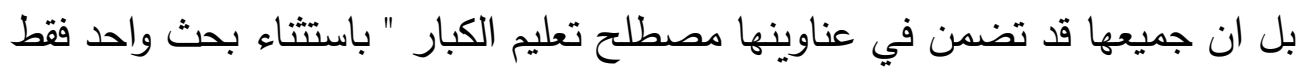

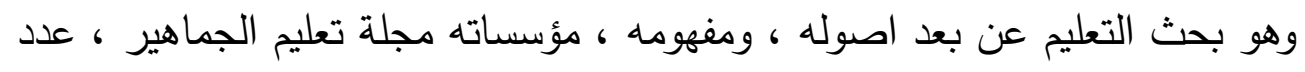

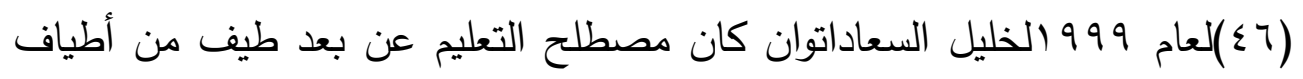

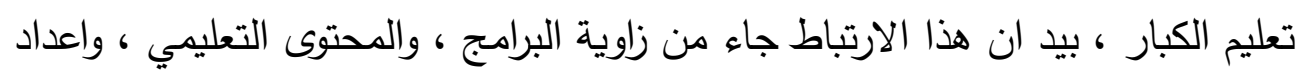

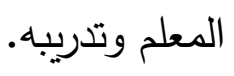
ب-فئة اتساق المعلومات المتضمنة في البحث مع التوجهات العالمية المعاصره

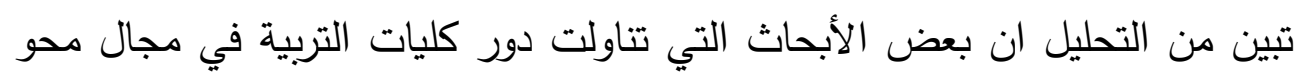

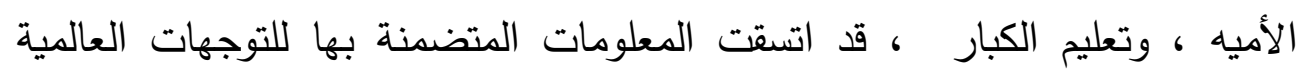

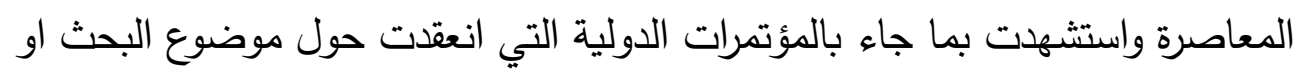

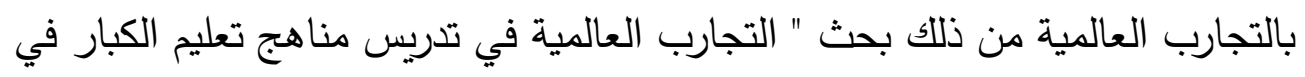

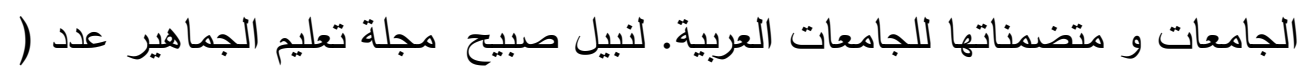

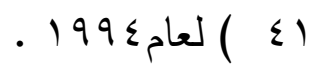
كذلكتدم نشوان في بحثه اولويات البحث التربوي في تعليم الكبار في الدول العربية

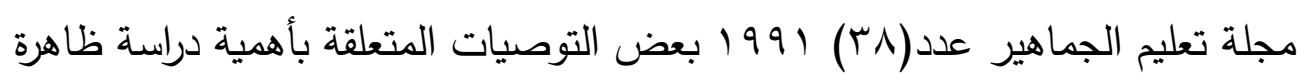

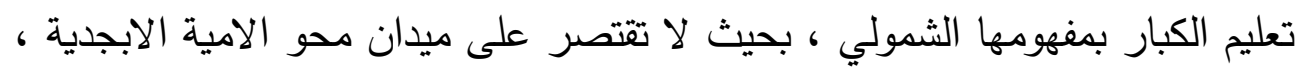

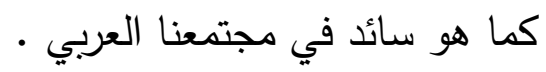
ونجد هذا الاتساق أيضا عند محمد ريان فيبحثه ،" اعداد معلم الكبار وتدريبه لمواجهة

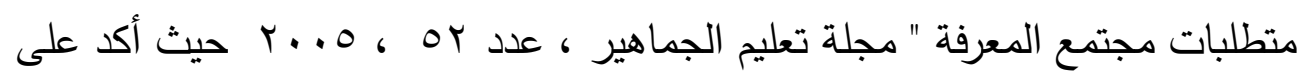

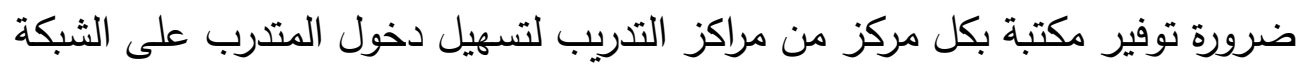

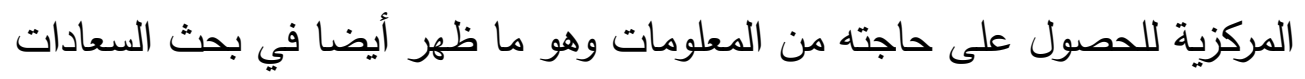


" ، بحث التعليم عن بعد اصوله ، ومفهومه ، مؤسساته " مجلة تعليم الجماهير ، عدد

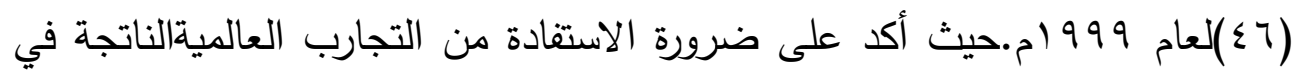
مجال التعليم عن بعد.

ج - فئة - إضافة أفكار ، ورؤى حديثة مبتكرة . تبين من التحليل الكيفي ان جل الأبحاث التي تناولت دور كليات التربية في مجال محو الأميةوتعليم الكبار ، قد عرضت أفكار ورؤى جديدة عند وقت نشرها بالمجلة ، كما

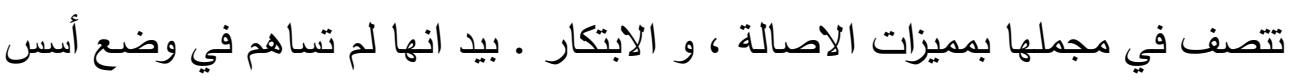
لبناء نظرية عربية للتعليم المستمر ، كذللك لم تفتح الطريق لبحوث جديدة تستخدم التفكير

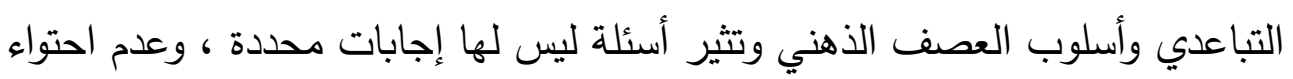
مشكلة البحث علو أسئلة يجيب عليها من نوع ماذا لو ؟ وربما يرجع ذلك الى عدم الانبثاق من الاطار العربي !! وضعف بيئة الابداع في الساحة الأكاديمية ، والبحثية العربية . الابنية

ومن الأبحاث التي قدمت رؤى مبتكرة وأصيلة بحثحي الدين شعبان توق وعبد اللطيف خيري" بعنوان : " دور كليات التربية في الوطن العربيفي تنفيذ الخطط الوطنية لمحو

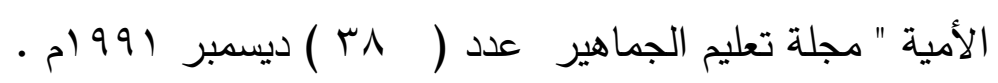
حيث القيا الضوء على البعد الغائب في برامج محو الأميه في الوطن العربي متمثلاً في دور كليات التربية في تنفيذ خطط محو الامية . كما قدمت ورقة اليونسكو " .. نموذج مقترح لمنهج إعداد معلمي المرحلة الابتدائية للقيام بدور تعليمي مزدوج للكبار والصغار • " مجلة تعليم الجماهير، عدد ( وب إع ) ب99 ام قيام معلم المرحلة الابتدائية بدور تعليمي مزدوج للصغار والكبار 


\section{موقف المجلات التربوية العربية من بعض القضايا الخاصة أ.م. د ـ محمد أحمد محمد اسماعيل}

وطرحعبد الفتاح حجاج مفهوم الجذع المشترك كمدخل لتعليم الكبار في بحثه " الجذع لعان

$$
\text { المشترك كمدخل لتعليم الكبار" بالعدد (1) (ع) لعام ع } 99 \text { ام. }
$$

وقدم اللقاني في بحثه " المحتوى التعليمي لمناهج إعداد معلمي الكبار في كليات

إعداد المعلمة بالجامعات العربية ، عدد (1) سبتمبر، عام §99 ام تصور حول

المفردات الواجب تضمينها في مناهج اعداد معلمي الكبار على مستوى مساق دراسي

ومستوى الدبلوم ، والماجستير ، و الدكتوراه.

$$
\text { و الملاحظ على هذه البحوث أنها : - }
$$

- لم تختبر او تطور نظرية ، او فلسفة لتعليم الكبار ، أو للتوصل الى مبادئ وقوانين علمية فيما يتعلق بمحو الأمية و تعليم الكبار ـ كذلك لم تجرى محاكاه نظرية للواقع معتمده على التجارب والدراسات الميدانية للتأكد من إمكانية تطبيق النتائج على لهي

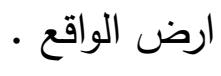

- لم نجد بينها بحوث من نوع التقييم او التقويم التي تهدف لتطوير نتاجات فاعلة يمكن استخدامها في مجال محو الأمية و تعليم الكبار لتلبية احتياجات مجتمعية في هذا المجال وفق مواصفات دقيقه ثم اختبار هذه النتائج ميدانيا للتحقق من مدى فاعليتها وقد يرجع ذللك لارتفاع تكلفة هذا النوع من البحوث على الرغم من مردوده

$$
\text { الإيجابي على العملية التربوية. }
$$

- غياب فكرة تقييم العوامل ، والمتغيرات الخاصة بموضوع البحث ، أو توضيح

المتغيرات التي تؤثر في قضية محو الأمية ، والتعليم المستمر أو اختيار وسيلة لقياس المقدرة ،أو المعلومات التي تعبرعن القياس بدرجات متفاوتة دفئة حداثة المراجع ،المعلومات ، المتضمنة في البحث . فيما تتعلق بحداثة المراجع المستخدمة من الأبحاث التي تناولت دور كليات التربية

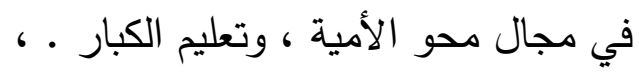


أظهر التحليل تأرجح المراجع المستخدمة في الأبحاث ما بين المراجع الحديثة التي لم يمض عليها أكثر من خمس سنوات ،والمراجع القديمة ، سواء ما مضى عليها عشر سنوات أو تلك التي مضى عليها أكثر من عشر سنوات أو خمسة عشر عام

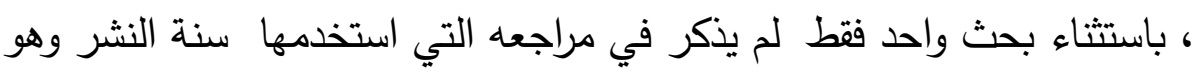
بحث "نموذج مقترح لمنهج إعداد معلمي المرحلة الابتدائية للقيام بدور تعليمي مزدوج للكبار والصغار ،، من إعداد مكتب اليونسكو الإقليمي للتربية في البلاد العربية ، حيث لم يشر إلى سنة النشر بالمراجع التي استخدمها وهي ثلاث مراجع إلا في مرجع واحد فقط ، وهو مرجع ،عبدالواحد عبدالله يوسف ، خلاصة أعمال وتوصيات الندوة الإقليمية حول الأساليب المبتكرة لإعداد معلم المرحلة الابتدائية

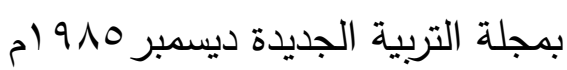
بيد أن الملاحظ بصفة عامة أن جل الأبحاث رجعت إلى مراجع قديمة بنسب كبيرة من ذلكعلى سبيل المثال أن بحث محمد حسين" المحتوى التعليمي لمناهج إعداد معلمي الكبار في كليات إعداد المعلمين ، بالجامعات العربية قد استخدم (9 ب) مرجع ، ثلاث منهم حديثة لم يمض عليها ( 0) سنوات ، بينما كان عدد المراجع القديمة التي مضى عليها أكثر من (0) عام (1) (1) مرجع ، وجاءت (9) مراجع

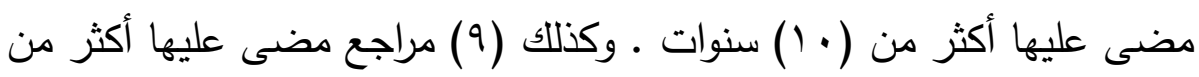

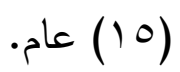

واستخدم بحث " التجارب العالمية في تدريب مناهج تعليم الكبار في الجامعات

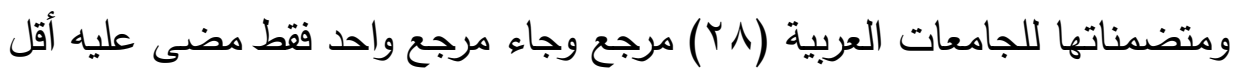

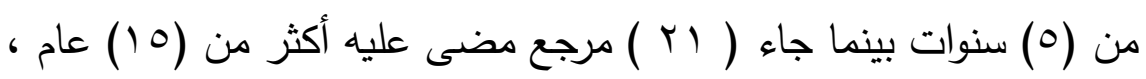

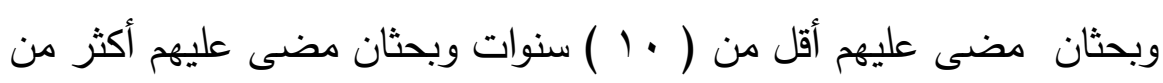
عشر سنوات . 
موقف المجلات التربوية العربية من بعض القضايا الخاصة أ.م. دـ ـ محمد أحمد محمد اسماعيل

واستخدم بحث " إعداد معلم الكبار وتدرببه لمواجهة متطلبات مجتمع المعرفة لمحمد علي الريان (Tr) مرجع كان منهم (T) مراجع فقط حديثة لم يمض عليها أكثر من (0) سنوات و (7 (1) مرجع مضى عليهم أكثر من ( • ( ) سنوات ، أما باقي المراجع فمضى عليها أكثر من ( 10 (1) عام

كذلك رجع بحث " التأهيل التربوي للمدرس الجامعي دراسة ميدانية بجامعة الملك فيصل لعمر زكى و مهني غنايم مجلة اتحاد الجامعات العربية عدد ( جr ) يناير (991 الى (10 ) مرجع باللغة العربية و (V) ) مراجع بلغة اجنبية ل لايوجد بينهم مرجع حديث مضى عليه اقل من خمس سنوات اما المراجع العربية فبه (7 ) مراجع

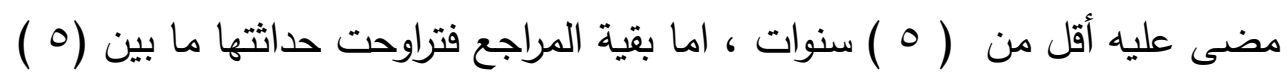
الى ( • ( ) ) عام.

سادسا - وحدة مصادر المعرفة العلمية المتضمنة في الأبحاث التي تتاولت ، دور كليات التربية في مجال محو الأمية وتعليم الكبار ، بالمجلات الاربع - تعليم الجماهير - رسالة التربية وعلم النفس - رسالة الخليج العربي - اتحاد الجامعات

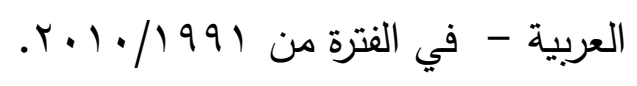

جدول (7)

أ - التحليل الكمي لوحدة مصادر المعرفة العلمية المتضمنة في الأبحاث التي تتاولت ، دور كليات التربية في مجال محو الأمية وتعليم الكبار ، بالمجلات الأربع تعليم الجماهير - رسالة التربية وعلم النفس - رسالة الخليج العربي - اتحاد الجامعات

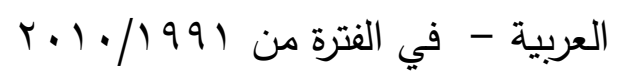

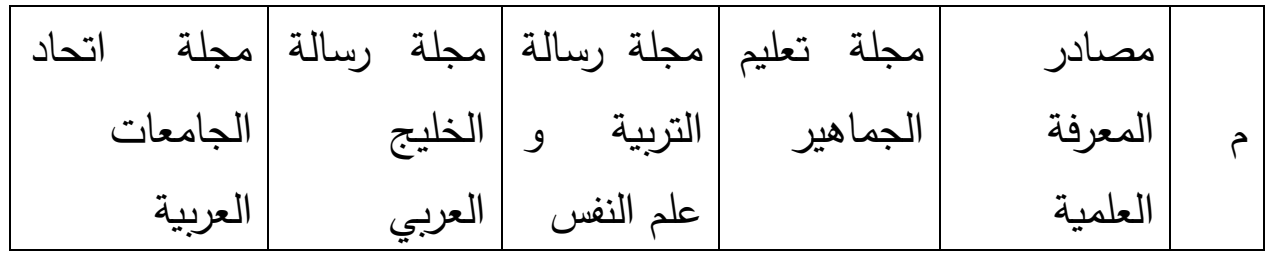




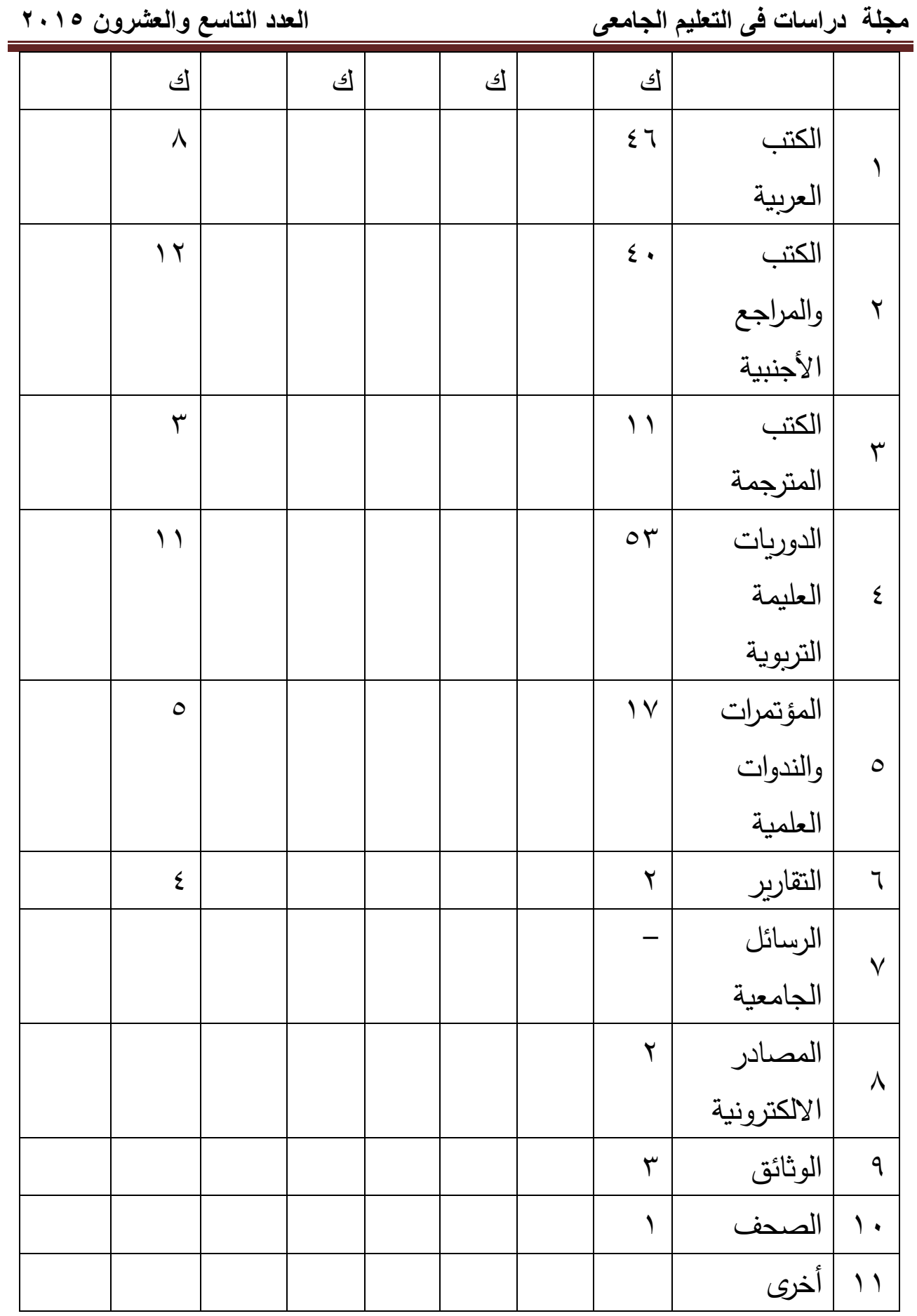


موقف المجلات التربوية العربية من بعض القضايا الخاصة أ.م. دـ ـ محمد أحمد محمد اسماعيل \begin{tabular}{|l|l|l|l|l|l|l|l|l|}
\hline \hline & & & & & & & & \\
\hline
\end{tabular}

ب - - التحليل الكيفي لوحدة مصادر المعرفة العلمية المتضمنة في الأبحاث التي

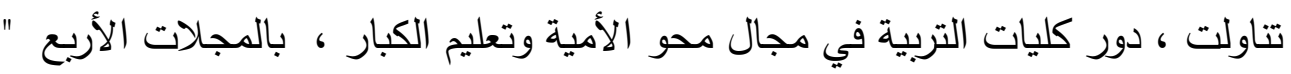
تعليم الجماهير - رسالة التربية وعلم النفس - رسالة الخليج العربي - اتحاد الجامعات

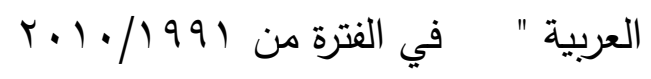

يبين جدول ( 1 ( ) تتوع مصادر المعلومات المتضمنة في البحوث التي تناولت دور الجامعات في مجال محو الأمية وتعليم الكبار ، بالمجلات الأربع في الفترة

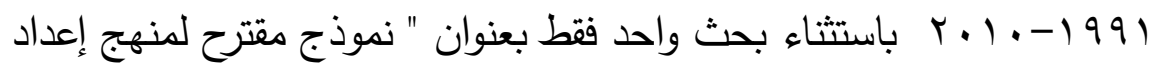
معلمي المرحلة الابتدائية للقيام بدور تعليمي مزدوج للكبار والصغار ، وهو من إعداد مكتب اليونسكو الإقليمي للتربية في البلاد العربية ،حيث استخدم مصدر واحد

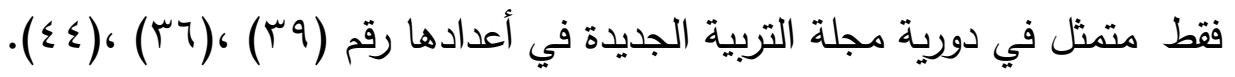
فئة الكتب العربية

مثلت فئة "الكتب العربية" - كمصدر للمعرفة للأبحاث التي تتاولتدور

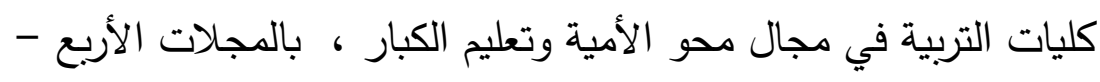
تعليم الجماهير - رسالة التربية وعلم النفس - رسالة الخليج العربي - اتحاد

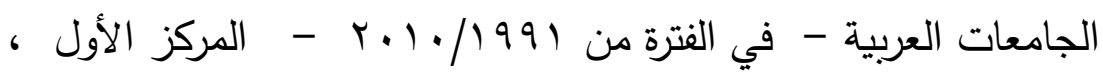

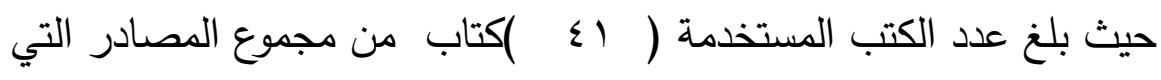
اعتمدت عليها الأبحاث بمجلة تعليم الجماهير حيث مثل ركن أساس بالنسبة للباحثين ،خاصة وهو يمثل الوعاء الذي يضم نتاج ما أبدعته عقول

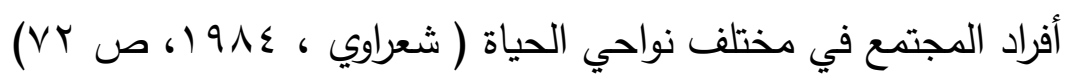
واختلفت نسبة استخدام الكتب العربية في الأبحاث من بحث لآخر ، فجاءت 
في بحث ( المحتوى التعليمي لمناهج اعداد معلمي الكبار في كليات المعلمين

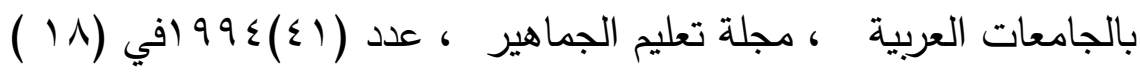
تكرار و في بحث التجارب العالمية في تدري مناهج تعليم الكبار في الجامعات و متضمنتاها للجامعات العربية في (r ) تكرارات بينما جاءت في بحث اعداد معلم الكبار و تدريبه لمواجهة متطلبات مجتمع المعرفة مجلة

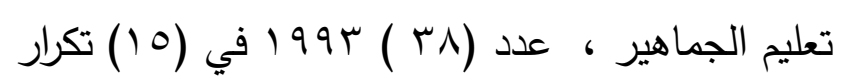

كذلك جاءت الكتب في بحث التأهيل التربوي للمدرس الجامعي دراسة ميدانية

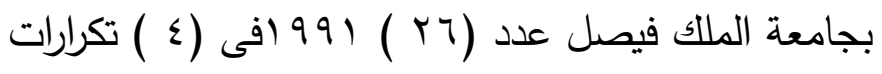

\section{فئة " لأكتب والمراجع الأجنبية}

تساعد الكتب والمراجع الأجنبية في إفادة الباحث من الخبرات الأجنبية المستحدثة في تحليله لمشكلة بحثه ، والوقوف على آخر التطورات العلمية الحادثة في مجال بحثه

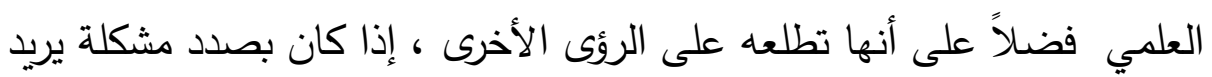

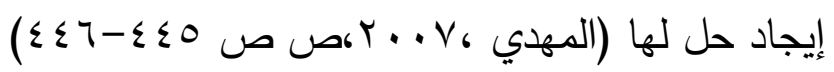

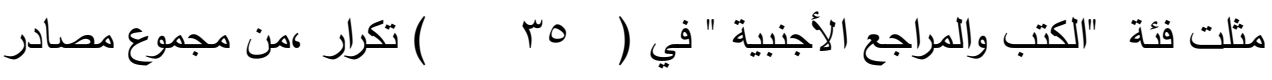
المعلومات بالأبحاث المنشورة بمجلة تعليم الجماهير التي تتاولت دور كليات التربية في مجال محو الأمية ، وتعليم الكبار ، إلا إن استخدام المراجع الأجنبية كأحد

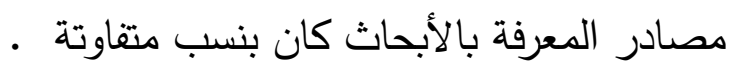
فجاءت بحث ( المحتوى التعليمي لمناهج اعداد معلمي الكبار في كليات المعلين بالجامعات العربية في ( T ال ) تكرار كانت مجموع تكرارا تها في بحث الجذع المشترك كمدخل لتعليم الكبار في(11) ) تكرار وفي بحث التجارب العالمية في تدريس مناهج تعليم الكبار في الجامعات و متضمنتاها للجامعات العربية في ( ب ) تكرارات وخلت تماماً في بحث أولويات البحث التربوي في تعليم الكبار في الدول العربية عدد $1991(r \wedge)$ 
موقف المجلات التربوية العربية من بعض القضايا الخاصة أ.م. دـ ـ محمد أحمد محمد اسماعيل و جاءت الكتب الاجنبية ببحث التأهيل التربوي للمدرس الجامعي دراسة ميدانية

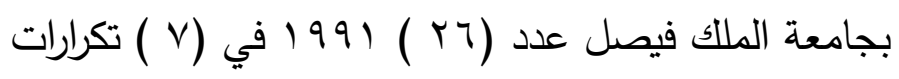
فئة "الكتب المترجمة "

استخدمت البحوث فئة "الكتب المترجمة " في ( c ) تكرارات من مجموع المصادر التي استخدمتها الأبحاث التي بصدد دراستها. وقد انعكست هذه المصادر -الكتب المترجمة - على أبحاثهم ، حيث مثلت هذه "الكتب المترجمة " مصدر استفادة الهات للباحثين ، خاصة وأن مؤلفه الأجنبي له رؤية نابعة من خلفية ثقافية مختلفة ، ومغايرة

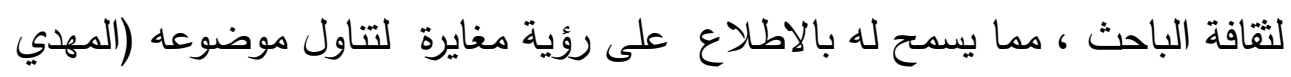

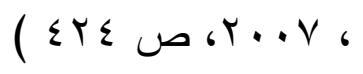

و قد اختلفت نسبة استخدامها كمصدر للمعلومات من بحث لآخر ، فبينما جاءت في (7) تكرارات ببحث المحتوى التعليمي لمناهج اعداد معلمي الكبار في كليات المعلمين بالجامعات العربية ، كانت في بحث إعداد معلم الكبار

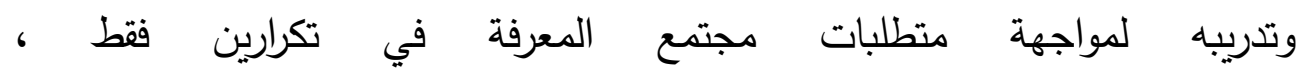
وجاءت في تكرار واحد فقط في كل من بحث أولويات البحث التربوي في تعليم

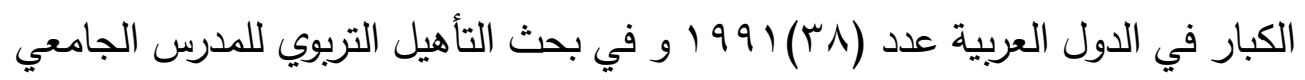

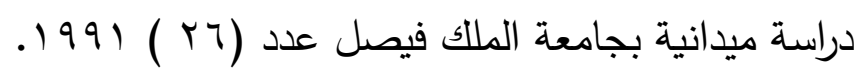
- فئة " الدوريات العلمية " تعد الدوريات العلمية التربوية مكون هام من مكونات العقل التربوي ، خاصة وأن الجمعيات التربوية ، والنفسية وكليات التربية في الوطن العربي ، تصدر عدداً كبيرا من هن

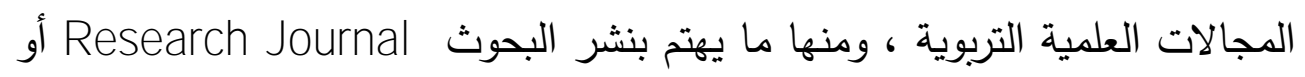

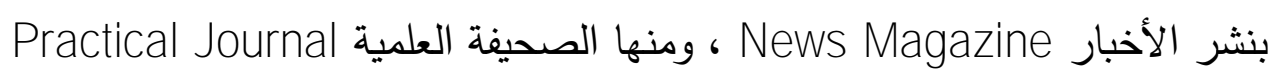


مثلت فئة " الدوريات العلمية " كأحد مصادر المعلومات التي اعتمدت عليها المجلات الأربع في ( ז ع ) تكرار ، واختلفت نسبة الاعتماد عليها كمصدر للمعلومات

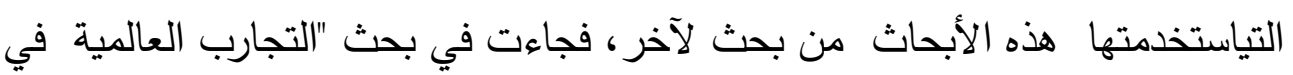
تدريس مناهج تعليم الكبار في الجامعات و متضمنتاها للجامعات العربية " في(10) تكرارو كانت في "بحث أولويات البحث التربوي في تعليم الكبار في الدول العربية" عدد $1991(r \wedge)$

في(• (1) تكرارات.وفي بحث"إعداد معلم الكبار و تدريبه لمواجهة متطلبات مجتمع المعرفة " في(9) تكرارات

وفى بحث التأهيل التربوي للمدرس الجامعي دراسة ميدانية بجامعة الملك فيصل بمجلة

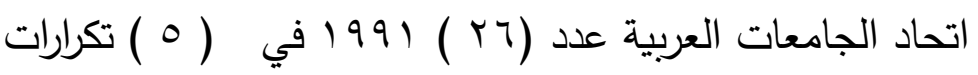

$$
\begin{aligned}
& \text { - }
\end{aligned}
$$

تعد الندوات ، والمؤتمرات العلمية التربوية أحد الطرق الهامة في تغذية العقل التربوي بما ينميه ، ويجدده ، وذللك إذا اتسمت بالجدة ، والمتابعة للمستجدات التربوية حيث

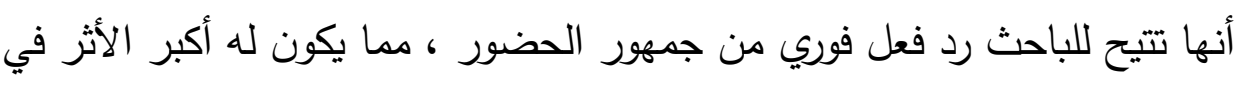
أن يعيد النظر في أدائه ، أو يعززه ، أو يعدله ، أو يبحث عن أسلوب هن آخر (إسماعيل

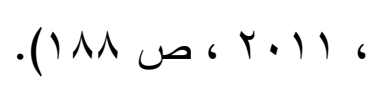

كما أن الندوات العلمية تطر ح فيها رؤى فكرية من المفكرين ، وكبار الأستاذة ممن

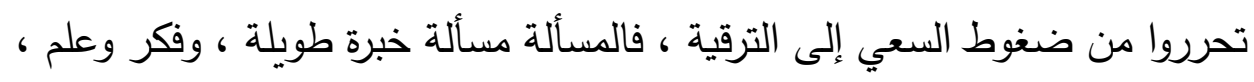
وعقول قادرة على العطاء ، وبذلك تكون الندوات ذات قوة فاعلة مغذية للعقل التربوي

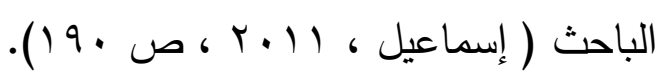

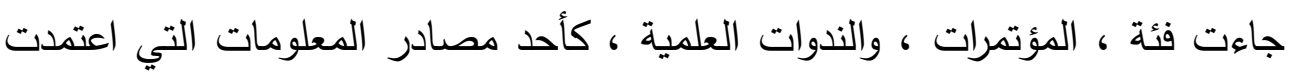
عليها الأبحاث المنشورة التي تتاولت دور كليات التربية في مجال محو الأمية ، و و 
موقف المجلات التربوية العربية من بعض القضايا الخاصة ا..م. دـ ـ محمد أحمد محمد اسماعيل

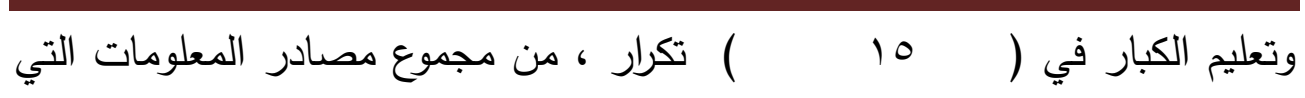
اعتدت عليها البحوث قيد الدراسة ، وجاءت بنسب مختلفة من بحث لآخر فجاءت

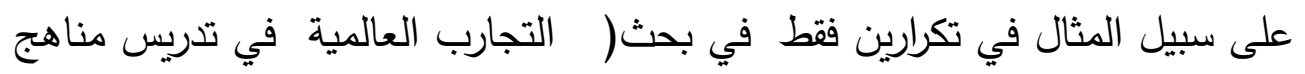

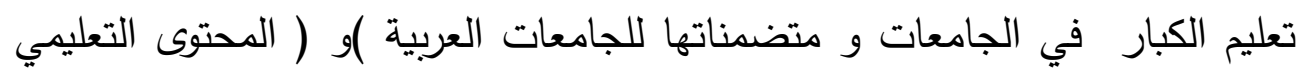

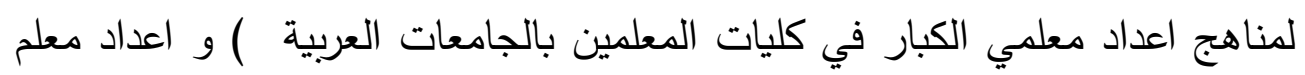

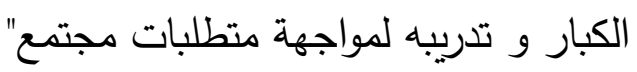
بينما جاءت في (^) تكرارات في بحث أولويات البحث التربوي في تعليم الكبار في

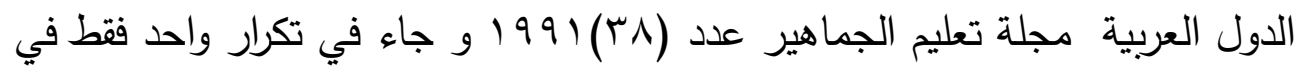

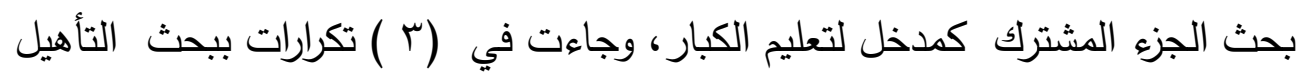

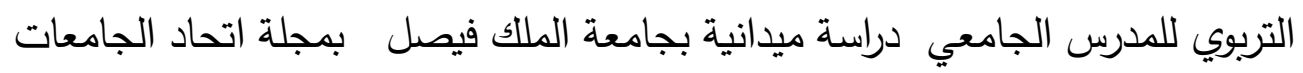

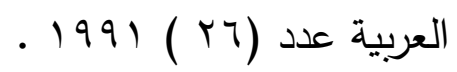

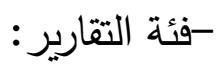
تعد التقارير نوعاً خاصاً من الكتب أو الكتيات وهي تتضمن محاضر جلسات

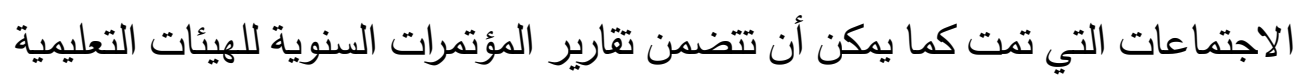

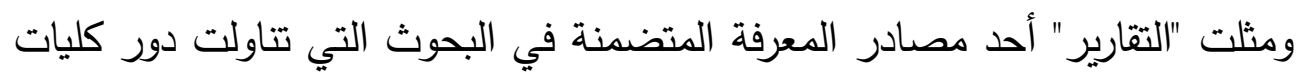

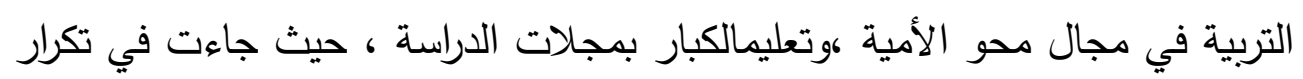
واحد فقط من مجموع مصادر المعلومات التي اعتمدت عليها البحوث .

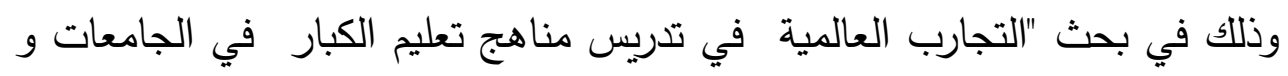

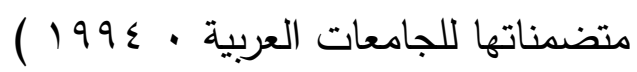
بينما خلت باقي البحوث من الاعتماد على "التقارير" وذلك على الرغم من ان ان التعليم

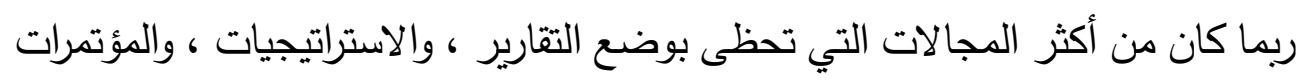


، وظهور الدوريات المتخصصة مما يوفر زاداً رائعاً للفكر التربوي العربي ( اسماعيل ،

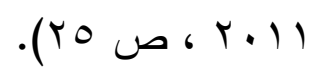

\section{فئة الرسيائل الجامعية}

لم يستخدم أي بحث من الأبحاث المنشورة بالمجلات الأربع ، الرسائل الجامعية " الماجستير والدكتوراه " كمصدر من مصادر المعرفة ، على الرغم مما تتسم به الرسالة الجامعية من كونها ذات منهج علمي دقيق في الغالب وتقدم مسحاً للدراسات السابقة في مجال البحث ، وتقترح كثير من المشكلات التي تتطلب مزيد من الدراسة ، والبحث

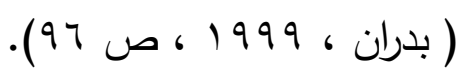

وقد يرجع عزوف الباحثين عن استخدام رسائل الماجستير والدكتوراه في ابحاثهم لكونهم

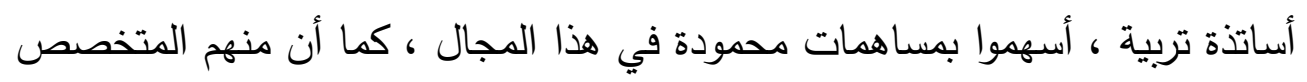

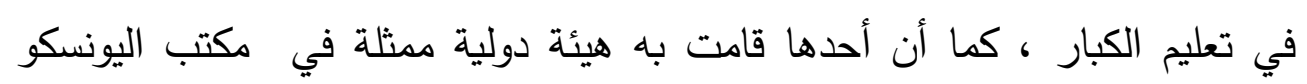
الإقليمي للتربية في البلاد العربية ، إلا أن ذلك يطرح التساؤل عن جدوى رسائل

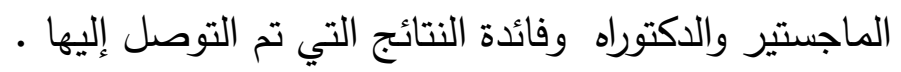

\section{فئة المصادر الإلكترونية}

وجاءت المصادر الإلكترونية ، كأحد مصادر المعرفة المتضمنة من الأبحاث

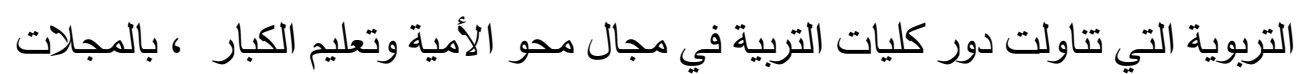
الأربع - تعليم الجماهير - رسالة التربية وعلم النفس - رسالة الخليج العربي - اتحاد

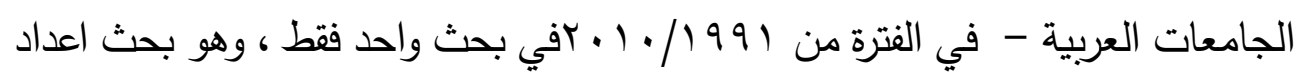

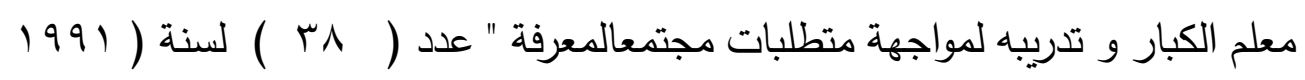
) حيث استخدم مرجع " تكنولوجيا الاتصالات وآثارها التربوية والاجتماعية ، لحلمي 


\section{موقف المجلات التريوية العربية من بعض القضايا الخاصة أ.م. دـ ـ محمد أحمد محمد اسماعيل}

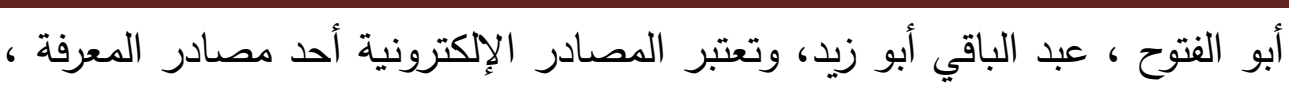

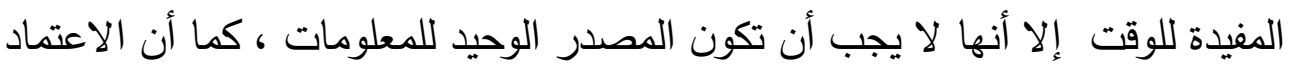

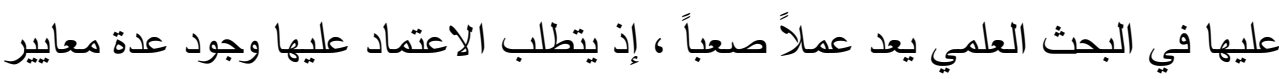

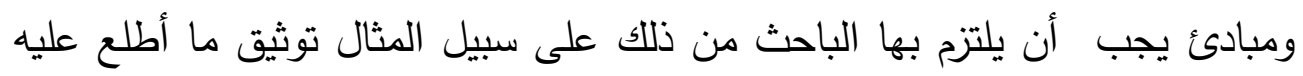

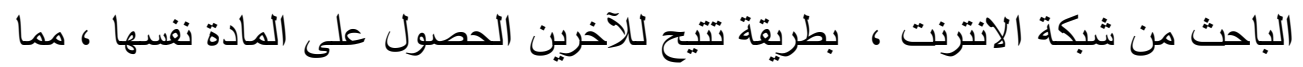

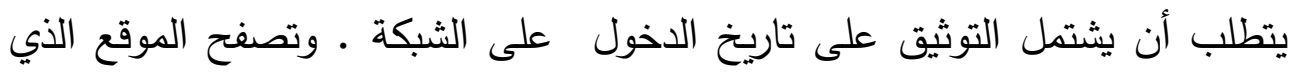

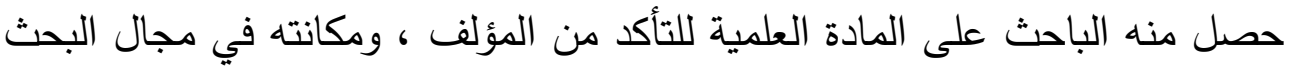

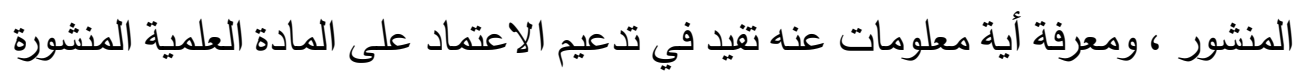
، ومعرفة الجهة المسؤولة عن المادة العلمية المنشورة .

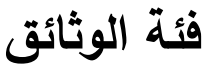

جاءت الوثائق -كأحد مصادر المعرفة المتضمنة في الأبحاث التربوية التي تناولت

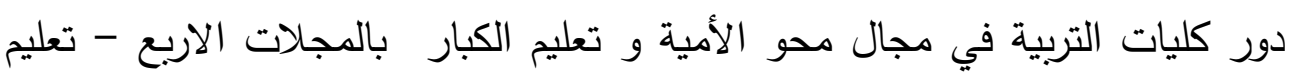
الجماهير - رسالة التربية وعلم النفس - رسالة الخليج العربي - اتحاد الجامعات

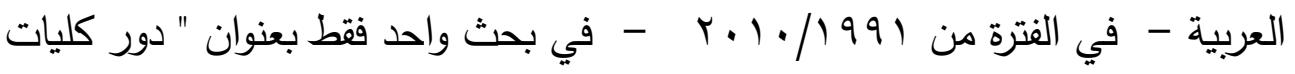

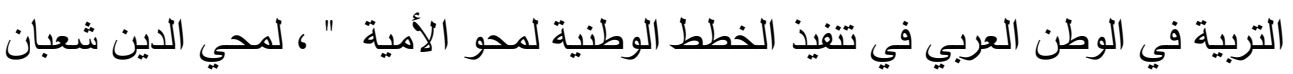

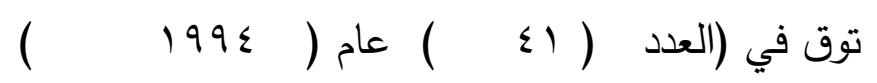

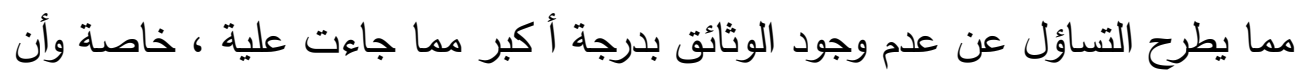

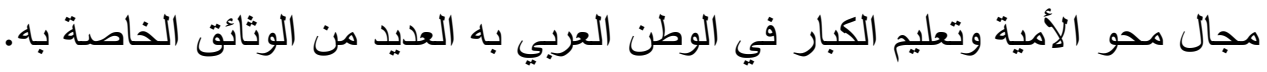

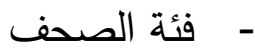

جاءت الصحف - كأحد المصادر المعرفة المتضمنة في الأبحاث التربوية التي

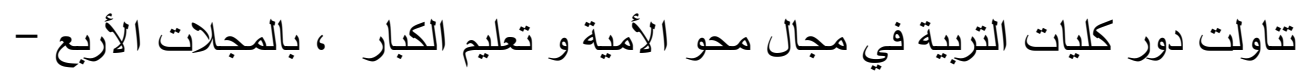

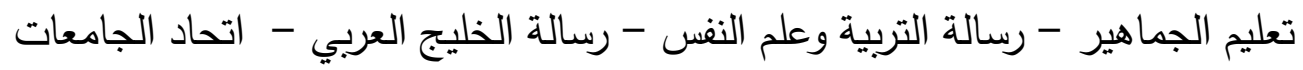




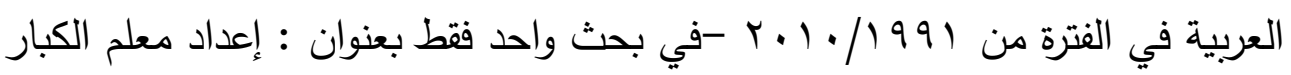

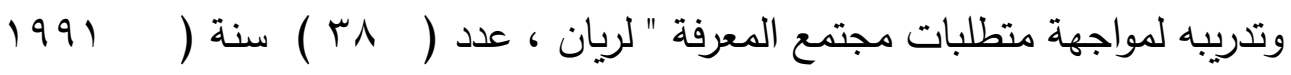

حيث استخدام مقال بعنوان " مركز البحوث ودورها في النهضة والإصلاح " بصحيفة

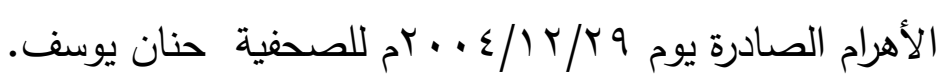
ومن المعروف أن الصحف لا تعد أحد مصادر المعرفة المستخدمة في الأبحاث العلمية بصفة عام ، وبالتالي فعدم وجودها كأحد مصادر المعرفة المتضمنة في الأبحاث العلمية التربوية المنشورة بالمجالات الثلاث شيء طبيعي، إلا إذا كان الباحث راجعا إلى مقال

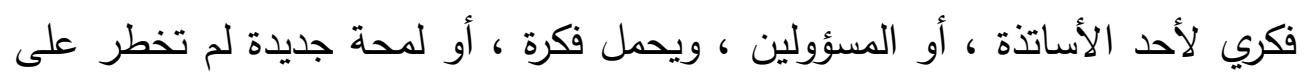

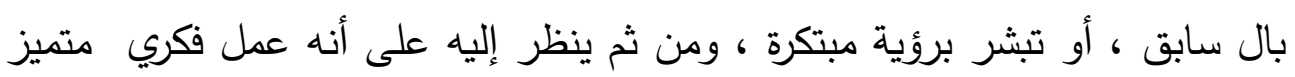
يستحق التقدير ، ربما يفوق التقدير الذي يعطي لعمل تضمن مئات الصفحات .

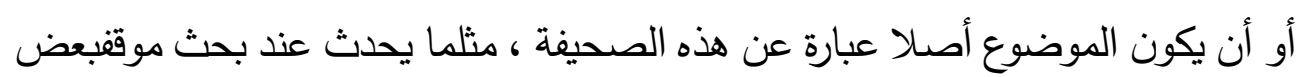

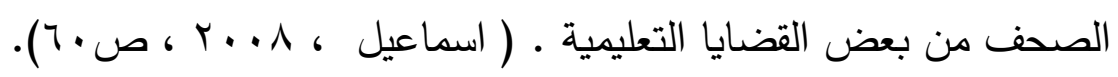

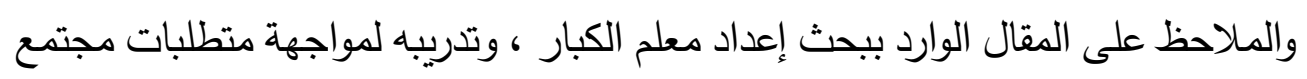
المعرفة ، لم يحمل فكرة مبتكرة لم تخطر على بال سابق ولم يبشر برؤية مبتكرة .وإنما استخدم على سبيل الاستشهاد فقط في موضعين ،كما أن الكاتبة ليست مسئولة عن أي

$$
\text { فكرة تحمل فكر تربوي مبتكر . }
$$

سابعا - وحده طبيعة الأدوات المستخدمة في الابحاث التي تتاولت دور كليات

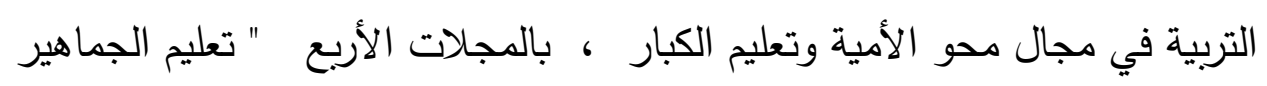
- رسالة التربية وعلم النفس - رسالة الخليج العربي - اتحاد الجامعات العربية "

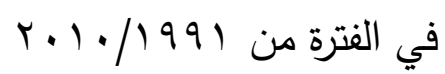


موقف المجلات التربوية العربية من بعض القضايا الخاصة أ.م. دـ ـ محمد أحمد محمد اسماعيل

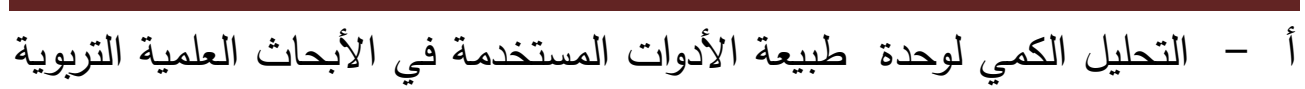
التي تتاولت دور كليات التربية في مجال محو الأمية وتعليم الكبار ، بالمجلات الأربع " تعليم الجماهير - رسالة التربية وعلم النفس - رسالة الخليج العربي - اتحاد

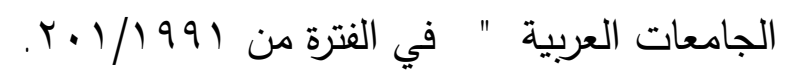
جدول ( )

طبيعة الأدوات المستخدمة في الأبحاث العلمية التربوية التي تتاولت دور كليات التربية في مجال محو الأمية وتعليم الكبار ، بالمجلات الاربع - تعليم الجماهير - رسالة التربية وعلم النفس - رسالة الخليج العربي - اتحاد الجامعات العربية - في الفترة من

\begin{tabular}{|c|c|c|c|c|c|c|c|c|c|}
\hline \multicolumn{3}{|c|}{$.4 .1 / 1991$} & & & & & & & \\
\hline$\%$ & 5) & $\%$ & المجموع & الجاداد العربية\% & الخليج & رالترالة & تعليم & $\begin{array}{r}\text { طبيعة الأدوات } \\
\text { في البحثدة }\end{array}$ & م \\
\hline & & & & & & & 1 & الألدي مناسبة & 1 \\
\hline & & & & & & & 1 & تأتنين & r \\
\hline
\end{tabular}


مجلة دراسات فى التعليم الجامعى

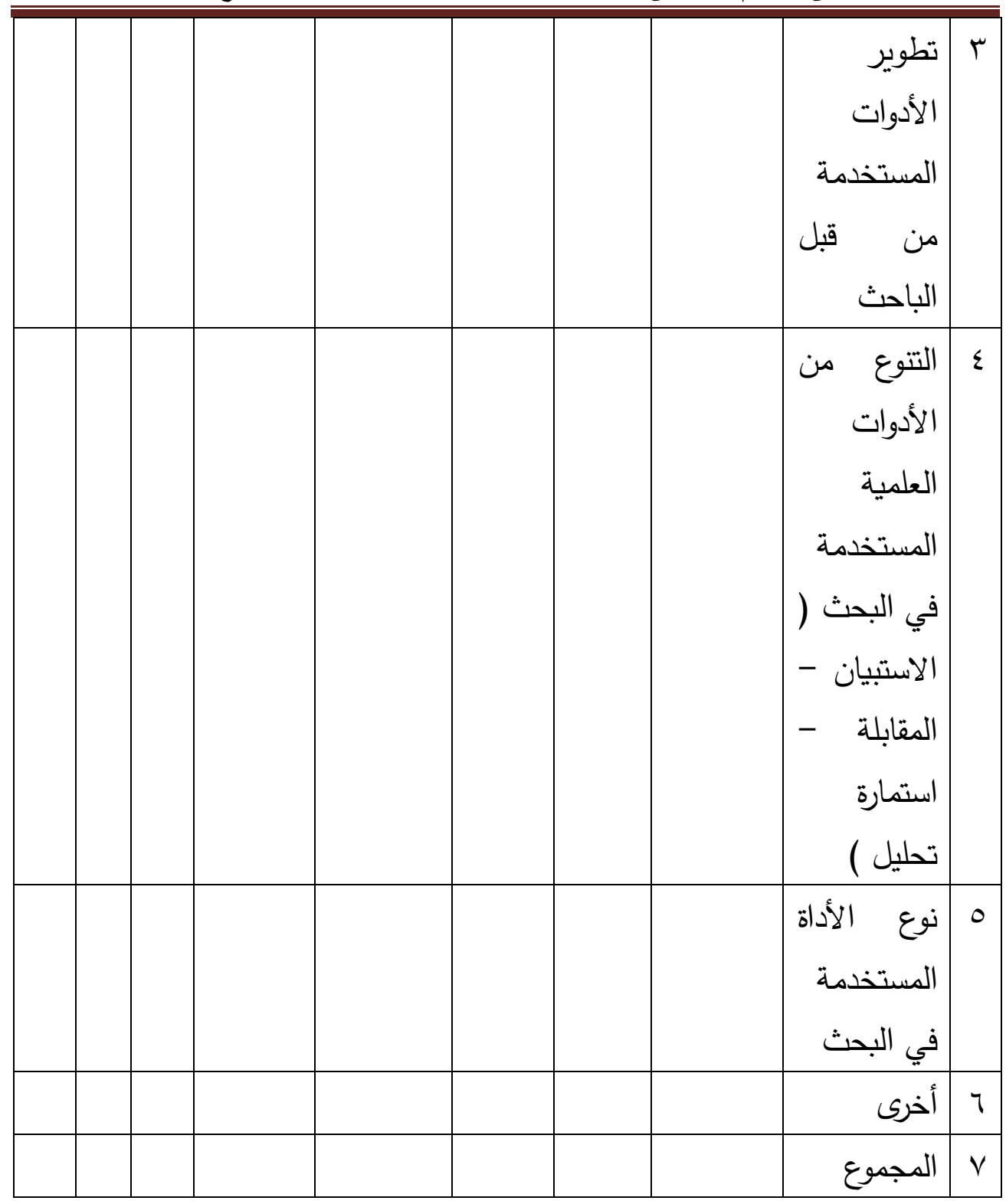

ب - التحليل الكيفي لوحدة طبيعة الأدوات المستخدمة في الأبحاث العلمية التربوية التي تتاولت دور كليات التربية في مجال محو الأمية وتعليم الكبار ،بالمجلات الأربع 
موقف المجلات التربوية العربية من بعض القضايا الخاصة ا..م. دـ ـ محمد أحمد محمد اسماعيل

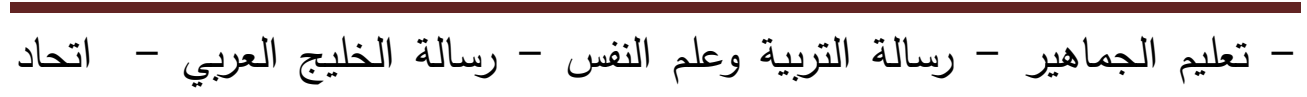

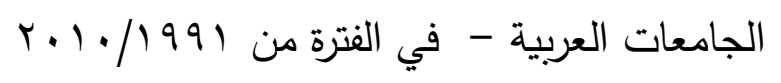

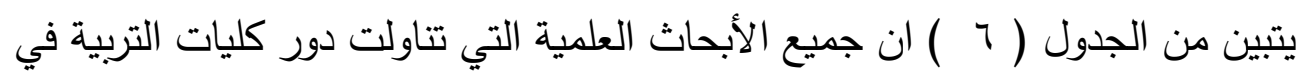
مجال محو الأمية وتعليم الكبار ،بجميع المجلات موضوع الدان الدراسة ،لم تستخدم إيه أداه

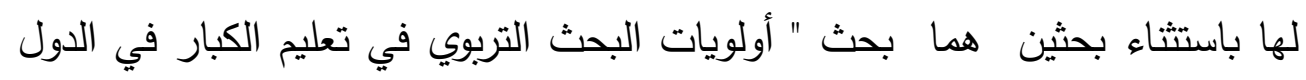

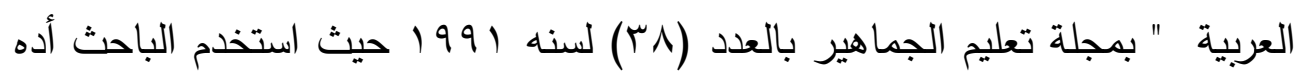

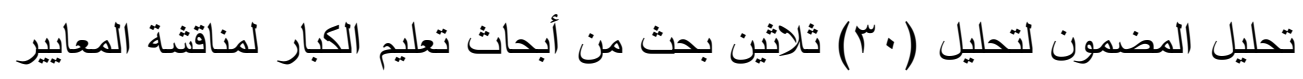

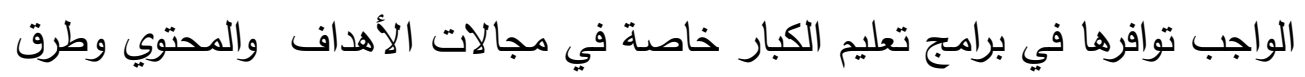

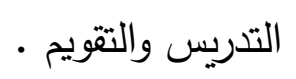

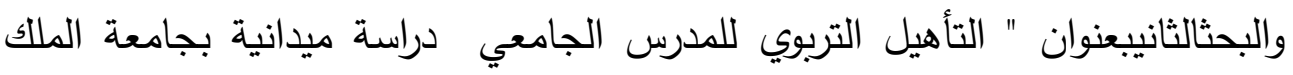

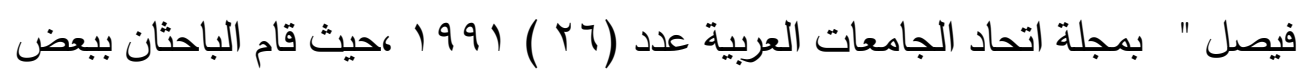

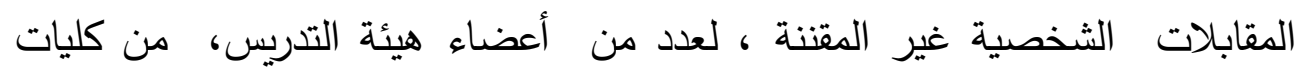

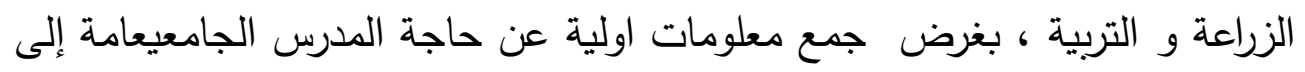

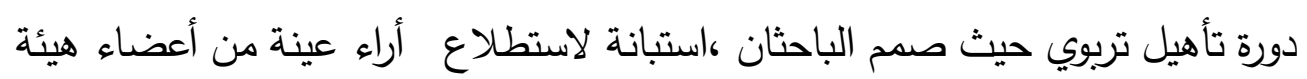

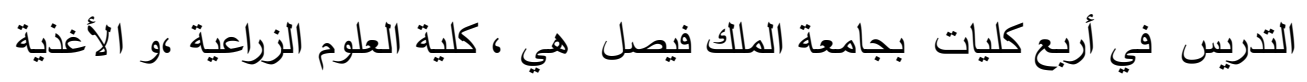

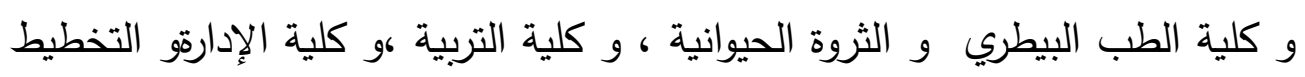

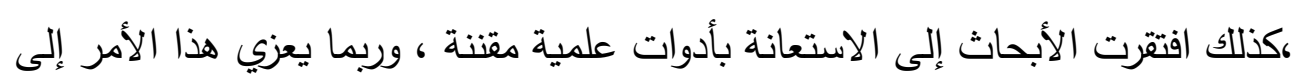

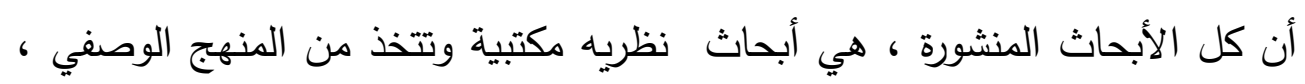
والمنهج المقارن منهجا لها هذا من ناحية . ومن ناحية أخري لم يطرح أي من الباحثين رؤية لتطوير أدوات جديدة لبحثه

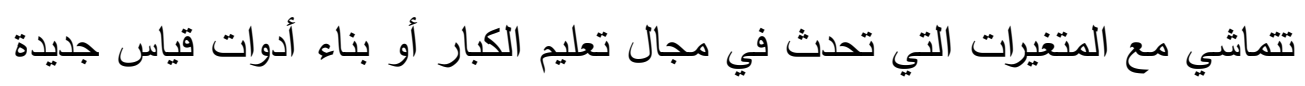


لجمع البيانات بحيث تستطيع أن تقيس تفاصيل المتغيرات بدرجة عالية ، بحيث تشمل جميع متغيرات الدراسة أو استخدام أدوات حديثه تتماشي مع التغيرات التي تحدث، أو بناء أدوات خاصة ببحث تتمتع بخصائص سيكومتريه عالمية وتقيس تفاصيل المتغيرات بدقة ، كذلك يلاحظ خلو الأبحاث من استخدام الملاحظة ، أو الاختبارات ،و عدم استخدامها للاستبيانات ، أو المقابلة بصيغها المختلفة ، ( المقننة - شبه المقننة - غير المقننة ) ثامنا - وحدة طبيعة النتائج والتوصيات التي طرحتها البحوث التي تتاولت دور كليات التربية في مجال محو الأمية و وتعليم الكبار ، بالمجلات الأبع " تعليم الجماهير - رسالة التربية وعلم النفس - رسالة الخليج العربي - اتحاد الجامعات

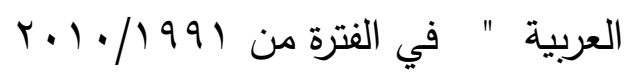

$$
\begin{aligned}
& \text { جدول ( ) ( ) }
\end{aligned}
$$

أ - التحليل الكمي لوحدة طبيعة النتائج والتوصيات التي طرحتها البحوث التي تناولت دور كليات التربية في مجال محو الأمية وتعليم الكبار ، بالمجلات الأربع " تعليم الجماهير - رسالة التربية وعلم النفس - رسالة الخليج العربي - اتحاد الجامعات

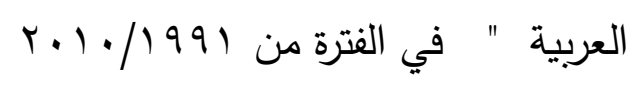

\begin{tabular}{|c|c|c|c|c|c|}
\hline الجاملة اتحاد & رجلة الخليج & رجلة التربية & تعليه & فئات طبيعة النتائج & r \\
\hline & & & 1 & توصل النتائج والتوصيات التي & 1 \\
\hline
\end{tabular}


موقف المجلات التربوية العربية من بعض القضايا الخاصة ا..م. د ـ محمد أحمد محمد اسماعيل

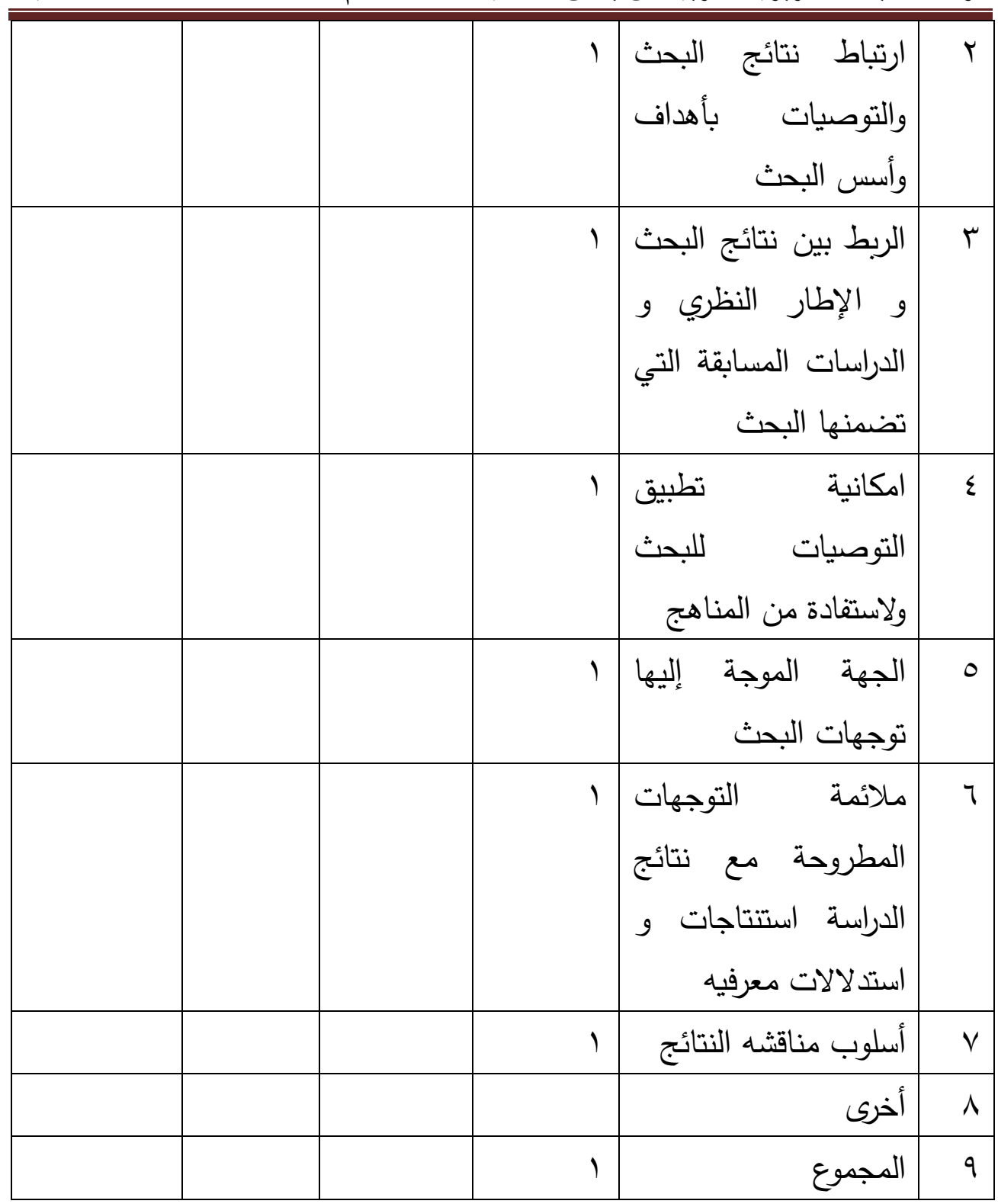

ب - التحليل الكيفي لوحدة طبيعة النتائج والتوصيات التي طرحتها البحوث التي تناولت دور كليات التربية في مجال محو الأمية، و تعليم الكبار بالمجلات الأربع في

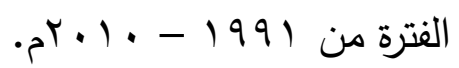


تبين من التحليل الكمي والكيفي أن جل الأبحاث لم تتضمن مساحة لفئة النتائج والتوصيات التي توصل الباحث إليها، وأغفلنها باستثناء بحث : المحتوى التعليمي لمناهج إعداد معلمي الكبار في كليات إعداد المعلمين بالجامعات العربية مجلة تعليم الجماهير عدد (1) (9) ام لمحمد حسين اللقانى ، وبحث: الجذع المشترك كمدخل

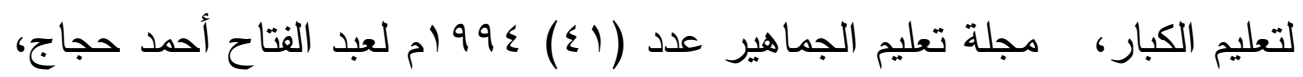

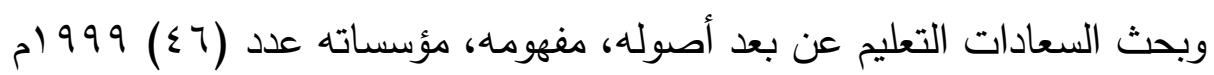
وبحث النشوان أولويات البحث التربوي في تعليم الكبار في الدول العربية عدد(^؟)

و بحث السعادات: تطبيق التربية الميدانية في مدارس تعليم الكبار الليلية عدد (0؛) 199 ام إلى أهمية التربية العملية، وإعداد طالب التربية الميدانية للتطبيق في مدارس تعليم الكبار الليلية.

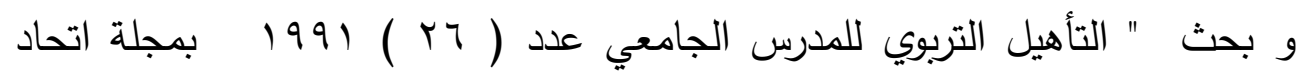
الجامعات العربية ،ولعل ذللك يرجع إلى أن كثيراً من هذه الأبحاث جاء على هيئة

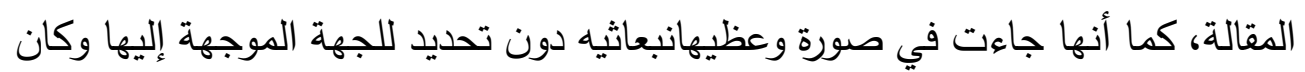
من المفترض أن يكون لكل بحث مساحة لمناقشة النتائج وتفسيرها وأن تتم مناقشة كل نتيجة بدلالة الفرضية الأساسية، أو السؤال المرتبط بها وفي ضوء توافقها او تعارضها

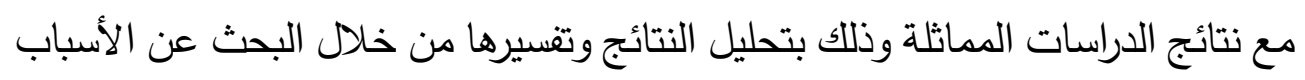
أو آثارها أو بعلاقاتها بالمتغيرات المختلفة، كذلك كان يجب الحكم على مدى دلالة هذه النتائج والاستنتاجات التي امكن التوصل إليها. كذلك تفتقد جل الدراسات لتقديم النتائج بشكل متسلسل منطقياً وفقاً لأسئلة وفروض التبات الدراسة ، فلم تبدأ أي من البحوث بالفرض أو السؤال الأول ثم تجمع الأدلة التي تؤيده 


\section{موقف المجلات التريوية العربية من بعض القضايا الخاصة أ.م. دـ ـ محمد أحمد محمد اسماعيل}

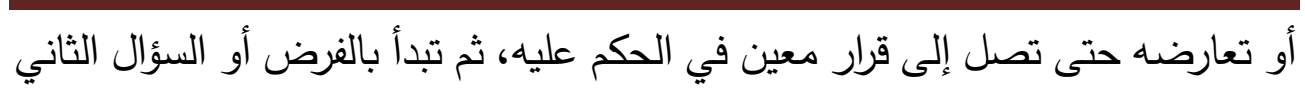
فالثالث وهكذا حتى تتضح العلاقات الارتباطية بين النتائج والأسباب. كذلك يلاحظ افتقار جل الأبحاث عن إعطاء معنى لنتائجها من خلال جعلها ممكنة

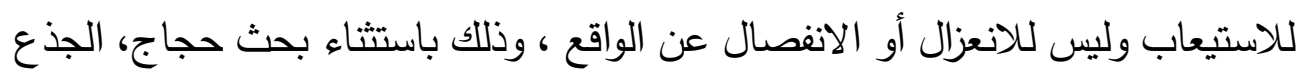

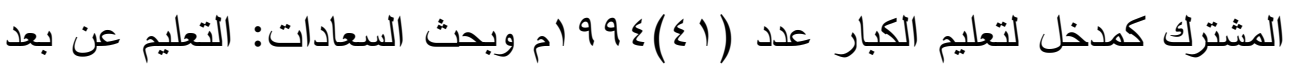
أصوله، مفهومه، مؤسساته عدد(7) ) 999 ام وبحث نشوان : أولويات البحث التربوي

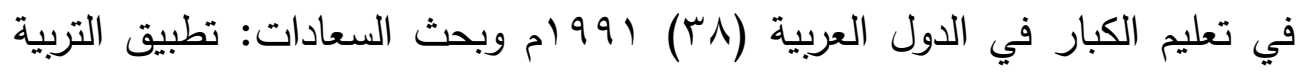

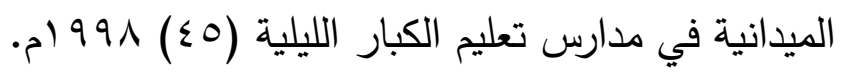

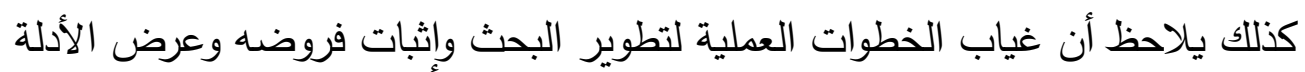

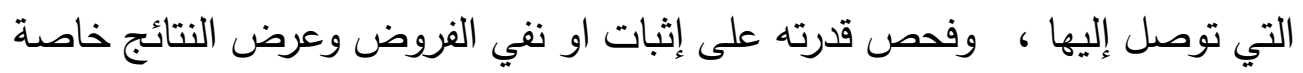

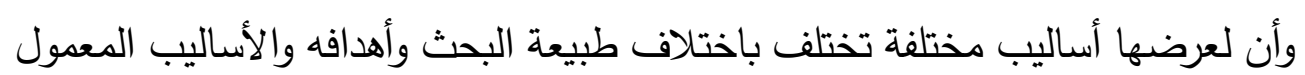

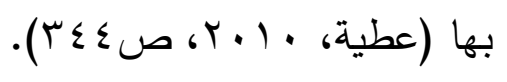

ففي البحوث الأساسية تقتصر النتائج على زيادة المعرفة العلمية عن موضوع معين

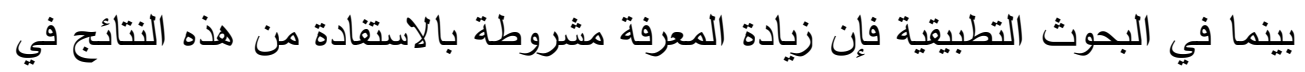

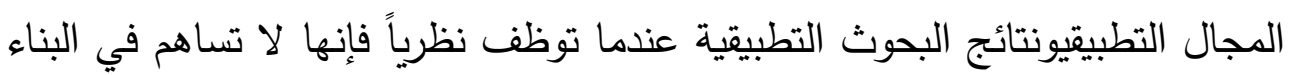

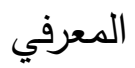
كذللك يلاحظ أن البحث الذي طرح نتائج قد خلط بينها وبين تفسيره لها وهو بحث:

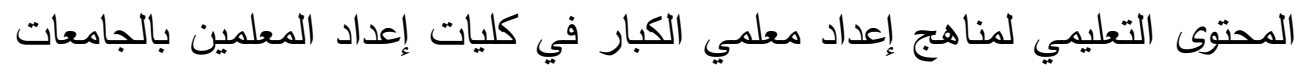

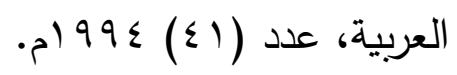
كما أظهر التحليل الكيفي للأبحاث أن ما طرحته من توصيات كانت قائمة على النتائج

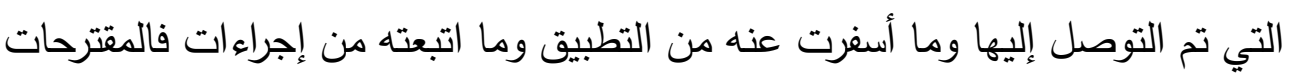


تمت في ضوء ما أسفرت عنه النتائج وأسهمت في تقديم حلول ناجحة للمشكلة التي تم البحث فيها.

كذلك بين التحليل الكيفي قدرة الباحثين على اقتراح بعض الحلول بشكل توصيات عامة قدمت للجهات المعنية للإفادة منها في مجال التطبيق العملي من ذلك بحث اولويات البحث التربوي في تعليم الكبار في الدول العربية عدد (^r) ا99 (م، حيث قدم الباحث مجموعة توصيات من بينها دراسة برامج تعليم الكبار دراسة تقويمية في مجالاتها المختلفة كالأهداف والمحتوى وطرق التعليم والتعلم ومن ثم الكثف عن جوانب القوة والضعف في هذه البرامج في ضوء معايير محددة تشتق في أساسها من حاجات الفرد والمجتمع في البلاد العربية وضرورة المراجعة المستمرة لبرامج تعليم الكبار باستخدام التغذية الراجعة وضرورة التركيز على الدراسات الميدانية لمعالجة مشكلات التربية المستمرة وإجراء بحوث ميدانية وتقويمية من أجل التعرف على جوانب القوة والضعف في أداء معلمي الكبار الأمر الذي من شأنه أن يطور برامج إعداد معلمي الكبار في ضوء الواقع التعليمي لممارستهم. ويرى الباحث أن تأمل التوصيات كعنصر منتخب في الدراسة الحالية يرتبط ارتباطاً وثيقاً بالنتائج فلا حلول وبدائل إبداعية دون نتائج يستند إليها والتي بدروها تأتي استجابة لأسئلة الدراسة بلحمة موضوعية شديدة التعقيد، وبالتالي تصبح مرحلة التوصيات هي مرحلة الإبداع. ومما يلاحظ كذللك على النتائج إنها عرضت وجمعت بطريقة أظهرت قدرة القائم بالبحث، وفهمه لبحثه كما أنها تساعد الباحثين الآخرين والمتخصصين على استخدامها في المجال النظري والتطبيقي - بموضوعية غير متحيزة، إلا أنها لم تعرض بطريقة إبداعية أو بأسلوب مبتكر ولم تتاقش في ضوء نظريات متعددة فعرضت بطريقة نمطية تقليدية ولم تضف إلى المخزون المعرفي وقد يرجع ذلك لكونها لم تطرح تساؤلات جديدة كما 


\section{موقف المجلات التربوية العربية من بعض القضايا الخاصة أ.م. د ـ محمد أحمد محمد اسماعيل}

أنها غير مؤثرة في الأفكار السائدة في مجال تعليم الكبار بصفة عامة ودور كليات التربية في مجال محو الأمية وتعليم الكبار و علم تعلم الثيخوخة ، بصفة خاصة. كما يلاحظ على النتائج أنها عرضت بدون أشكال توضيحية بيد أنها جاءت

واضحة وملموسة ويمكن الاستفادة منها عمليا، وتعكس احتياجات المجتمع المحلي لها، ويمكن توظيفها في خدمة المجتمع وإن كانت لم تستخدم مراجع متتوعة في تفسيرها وبالتالي لم تحلل تحليل كيفي من جوانب تشعيبية مختلفة، كذلك خلت من عمق التفسير والمناقشة والمقارنة مع غيرها من النتائج التي توصلت إليها أبحاث أخرى. كما يلاحظ على التوصيات انها جاءت متجردة من الآليات التي تمكن من تطبيقها ووضعها موضع التنفيذ باستثناء بحث الجذع المشترك كمدخل لتعليم الكبار لعبدالفتاح حجاج عدد (1) §99 19 حيث قدم مقترح عام لتعليم الكبار في ضوء الجذع المشترك مع تحديد أدوار الجامعات وكليات التربية في هذا المجال، وبحث تطبيق التربية

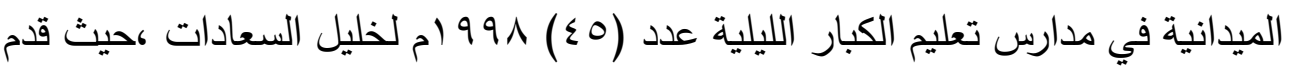
لإعداد طالب التربية الميدانية للتطبيق في مدارس تعليم الكبار الليلية إلا أنها كانت واقعية موضعيتها قابلة للتطبيق وواضحة ومحددة ومرتبطة مع النتائج وإن كانت لم

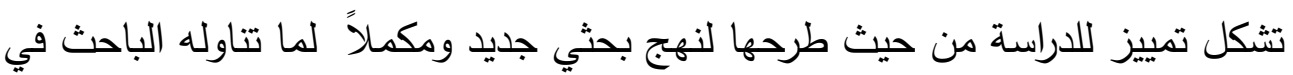
بحثه.

\section{التوصيات و المقترحات :}

يعرض الباحث بعض التوصيات و المقترحات و هي على مستويين في المستوى الأول يعرض رؤى و أفكار لتطوير حركة البحث العلمي في مجال محو الأمية و تعليم الكبار في الوطن العربي ، وفى المستوى الثاني يطرح الباحث بعض التصورات و الأفكار لتطوير هذه المجلات العلمية التربوية ونعرض فيما يلي هذه التوصيات و المقترحات 
أولا توصيات خاصة بتطوير البحث العلمي الخاص بدور كليات التربية في مجال محو الأمية و تعليم الكبار

ا - دعوة كليات التربية في الوطن العربي ، إلى ايلاء أهمية خاصة بمسألة البحث

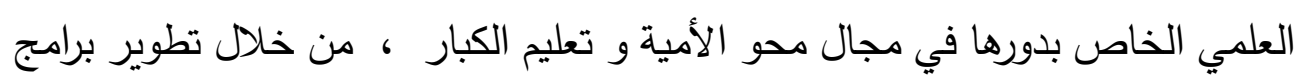

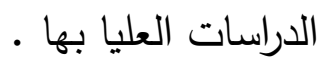

r - دعوة المنظمات العربية و الإسلامية و الدولية إلى التعاون فيما بينها ، و بين كليات التربية في الوطن العربي ، لإنشاء قاعدة بيانات تشتمل على أهم القضايا

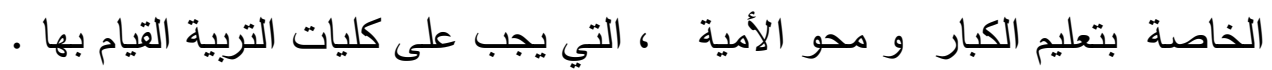

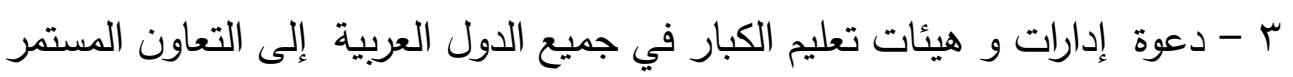

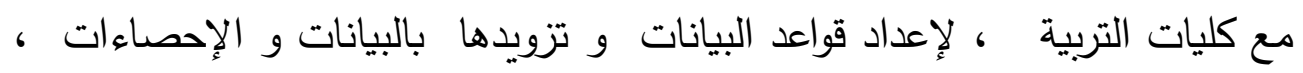
حتى يتسنى لها تجهيز المطلوب منها . ؟ - دعوة أعضاء هيئة التدريس التربويين بكليات التربية إلى المحافل ، و لقاءات مع الإدارات ، و الأجهزة المسئولة عن محو الأمية و تعليم الكبار في الوطن العربي ، بغية تحقيق التسيق و التكامل و التعاون و تبادل الخبرات و الرأي و المشورة ،

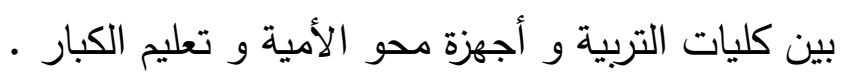

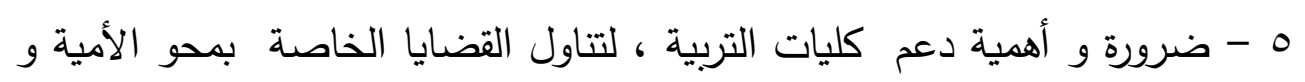

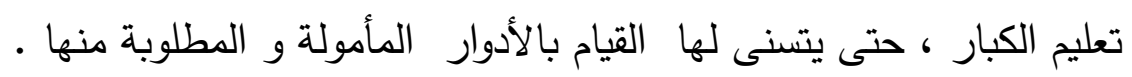
7 - دعوة كليات التربية إلى تعزيز الاهتمام بتتاول قضايا محو الأمية و تعليم الكبار

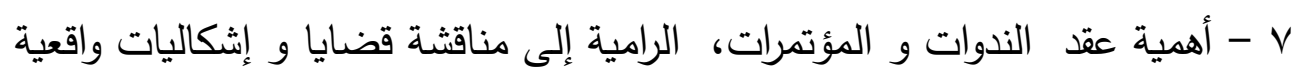
و مهمة ،تمس حركة تعليم الكبار و تؤصلها . 


\section{موقف المجلات التربوية العربية من بعض القضايا الخاصة أ.م. دـ ـ محمد أحمد محمد اسماعيل}

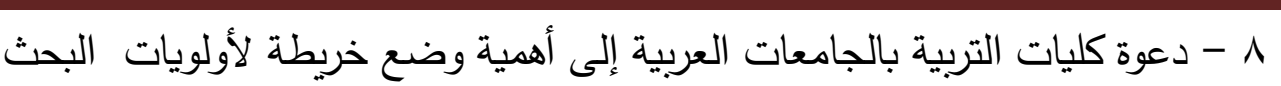

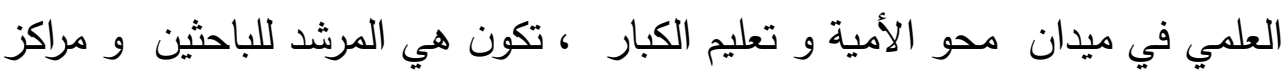
البحوث العربية بصوص مسائل النشر و أولوياته .

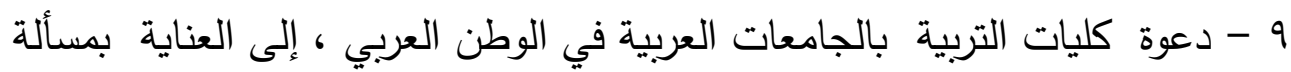

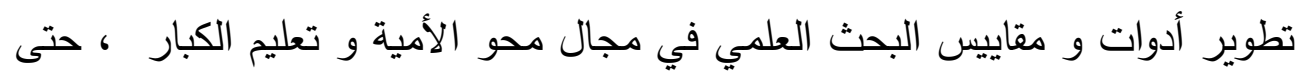

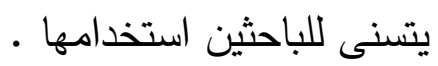

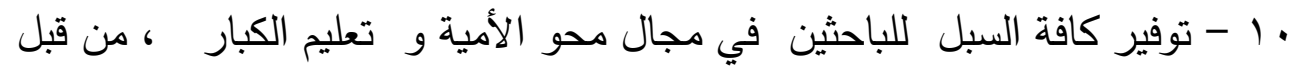

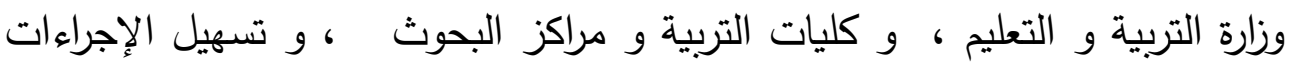

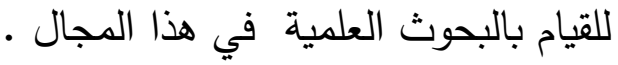

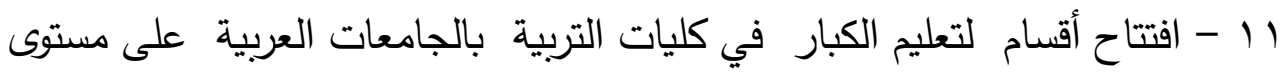

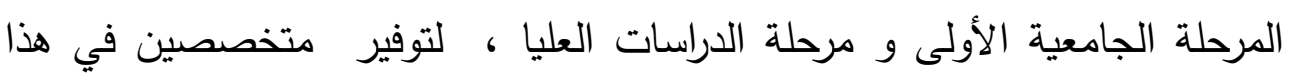
المجال يساهمون في القضاء على الأمية ، و تعليم و تدريس الكبار ، و و إجراء

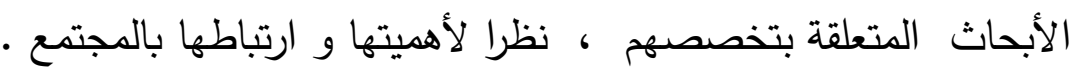

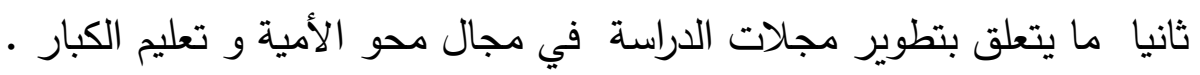

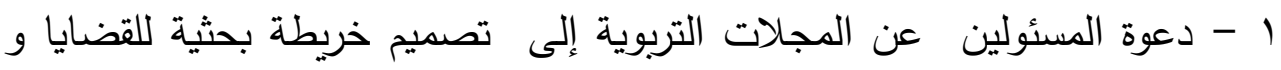

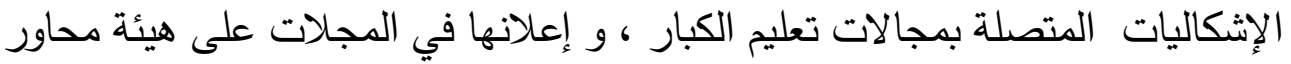

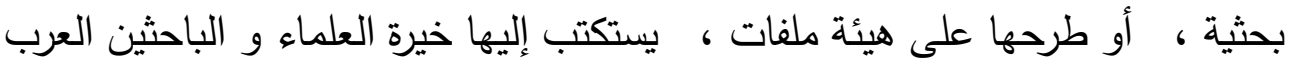

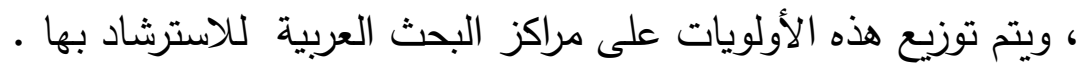

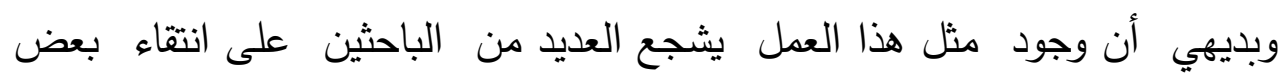

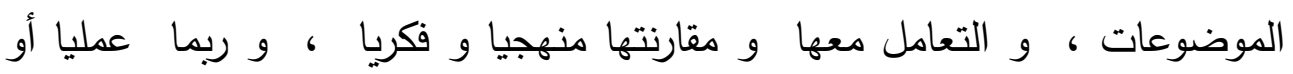

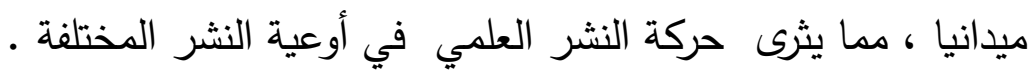


r - استكتاب كبار الباحثين التربوين في القضايا ذات الأهمية البالغة أو تلك التي تتطلب معالجة فورية ، فخبرة و حكمة كبار الباحثين ، يمكن أن تخدم أهداف المجلة ، وأن تقدم نماذج يحتذي بها عند المعالجة البحثية لقضايا و مسائل تعليم الكبار . r - النظر في تبويب المجلات التربوية ، على أن يتضمن تقارير و متابعة دورية لما يجرى في مجال التربية بشكل عام و في مجال محو الأمية و تعليم الكبار بشكل

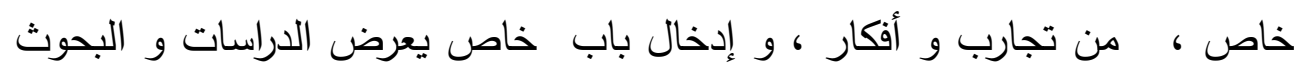
الخاصة بدور كليات التربية في مجال التعليم بصفة عامة ، و و محو الأمية و تعليم الكبار بصفة خاصة . الكبة ع - الحرص على إصدار أعداد خاصة من المجلات ، بحيث يتتاول كل عدد قضية معينة من القضايا الخاصة بدور كليات التربية في مجال محو الأمية و تعليم

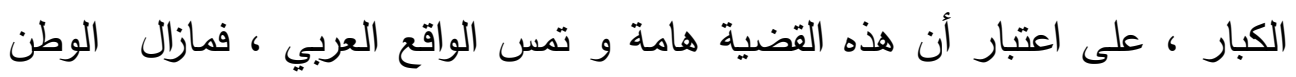

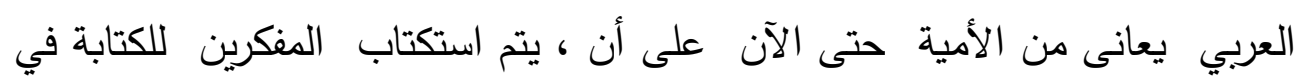

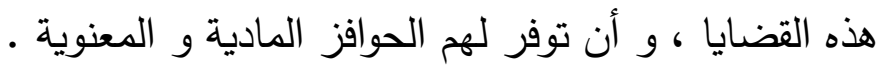
0 - تنظيم دورات منتظمة للتنمية المهنية للباحثين العرب بخصوص القضايا الخاصة بمحو الأمية و تعليم الكبار و دور كليات التربية تجاهها ، مما يقرب هؤلاء الباحثين أكثر من الهم العربي بخصوص مشكلات و قضايا تعليم الكبار ، و لعل المسئولين عن إصدار هذه المجلات يضمنون برنامجا في كل سنة لإعداد مثل هذه الورش أو لو الدور المهنية المهمة 
موقف المجلات التربوية العربية من بعض القضايا الخاصة أ.م. دـ ـ محمد أحمد محمد اسماعيل

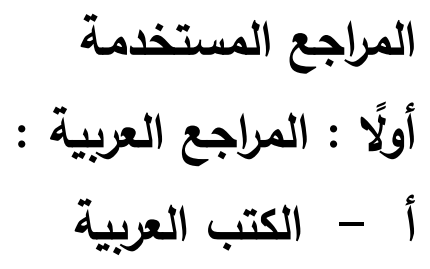

1- السيد يسين : الحوار الحضاري في عصر العولمة ، دار نهضة مصر للطباعة

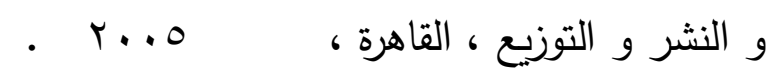

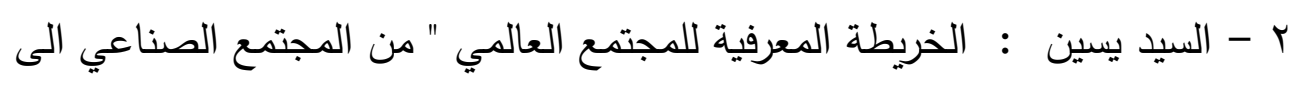

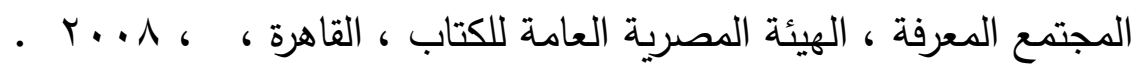
r - ابتسام عبد الرحمن البسام و صلاح الدين المتبولي: التعليم للجميع في الوطن العربي، مكتب التربية العربي لدول الخليج ، الرياض ، المملكة العربية السعودية ، .r. . $\varepsilon$

ع - إبراهيم بدران : تطلعات لمصر المستقبل في السياسة و التتمية البشرية ، و البحث العلمي ، نهضة مصر للطباعة و النشر و التوزيع ، القاهرة ، 1999 ـ 0 - إحسان مصطفى شعراوي و فتحي على يونس : مقدمة في البحث التربوي ، دار

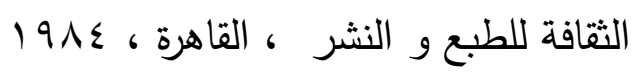
7 ، و أدواته ، و أساليبه ، دارا لفكر ، عمان ، المملكة الأردنية الهاشمية ، ع ـ . . ب. 


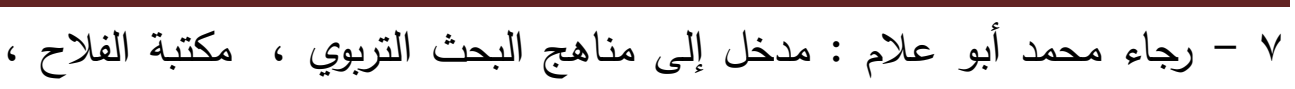

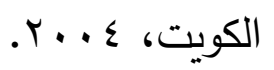

1 - رشدي أحمد طعمية : تحليل المحتوى في العلوم الإنسانية ، دار الفكر العربي ،

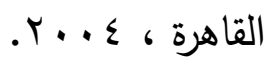

9 - سامي نصار : الاتجاهات الجديدة في تعليم الكبار ، دراسة في الإنتاج الفكري

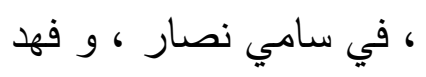

• 1 - سعيد إسماعيل على : جامعات تحت الحصار ، عالم الكتب ، القاهرة ، م . . ؟ . 11 - سعيد إسماعيل على : المعرفة التربوية الحاضر و المستقبل ، عالم الكتب ،

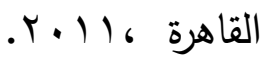

rا - صلاح الدين جوهر : خريطة الطريق في البحث التربوي: نادية جمال الدين ، ( محرر ) إدارة المعرفة التربوية ، اجتهادات في البحث التربوي ، محاولة للخروج من

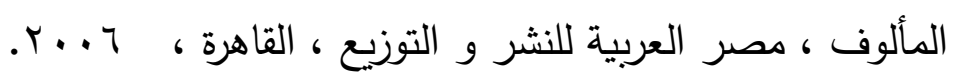
rا - ضياء الدين عبد الثكور زاهر : مقدمة في الدراسات المستقبلية ، مفاهيم و

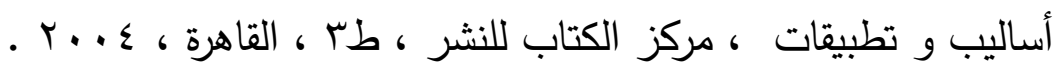
10 17 ، علم تعليم الكبار ، المنظمة العربية للتربية و الثقافة و العلوم ، تونس ، 1991 ـ . - عبد العزيز عبد الله السنبل :المشروعات التعليمة الذاتية لمعلمي الكبار في المملكة العربية السعودية ، دار جامعة الملك سعود للنشر ، الرياض ، المملكة

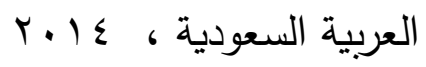




\section{موقف المجلات التربوية العربية من بعض القضايا الخاصة أ.م. د ـ محمد أحمد محمد اسماعيل}

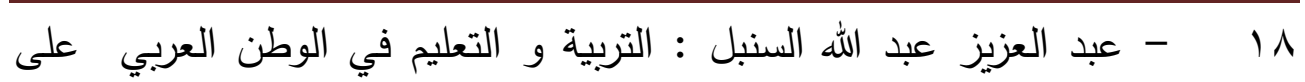
مشارف القرن الحادي و العشرين ، دار المريخ ، الرياض ، المملكة العربية السعودية . Y.. $\leqslant 6$

19 19 - فريد كامل أبو زينه ، و مروان الابراهيم ،و عامر قنديلجى ، و عبد الرحمن

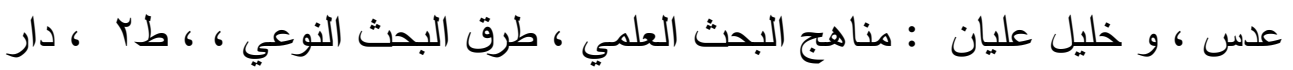

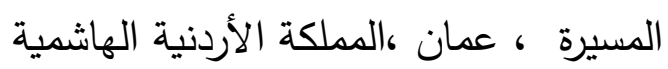
• r - مجدي صلاح طه المهدي : البحث العلمي التربوي بين دلالات الخبراء و

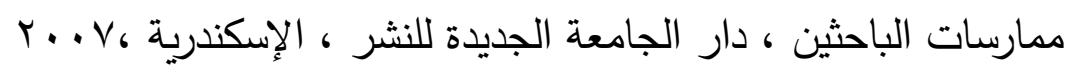
ا Y T - محمد إبراهيم القداح : البحث الإجرائي في تطوير المؤسسات التربوية ،

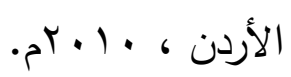
r T T - محمد الطيب ، و حسين الدرينى ، و شبل بدران ، و حسين الببلاوى ، و

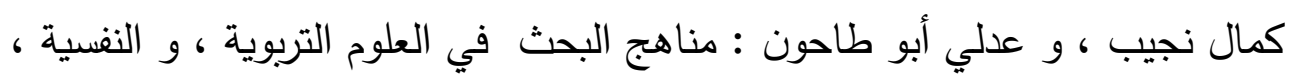
الأنجلو المصرية ، القاهرة ، ... rr - محمد عبد الله غازي قسايمة : محو الأمية و تعليم الكبار طريق للعلم و

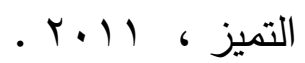

ع T T - محمد عطية : تحليل المضمون بين النظرية و التطبيق، مؤسسة طيبة ،

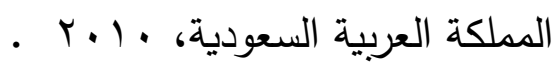
O T - حسن على عطية : البحث العلمي في التربية ، مناهجه ، أدواته ،

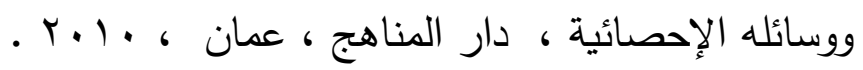

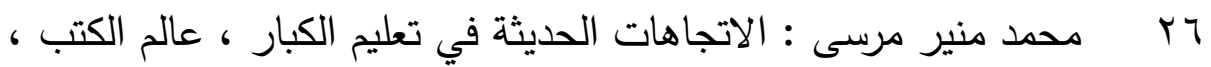
$.199 V$ 


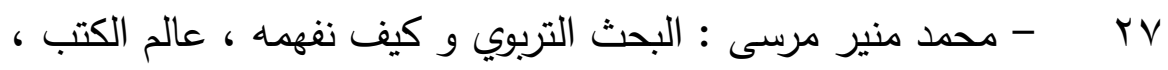
القاهرة ، ع99 19

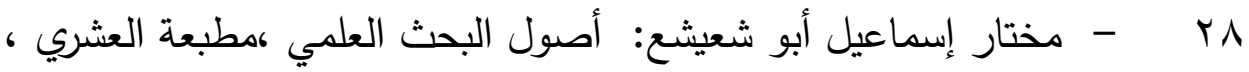

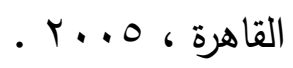

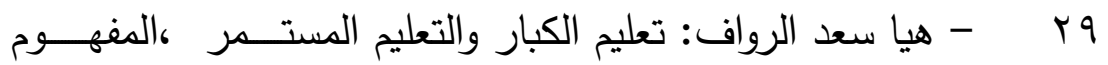

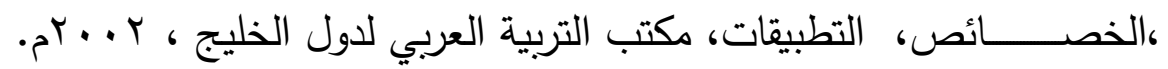
• r - يحيى هندام ، و محمد منير مرسى ، و آخرون : تعليم الكبار و محو

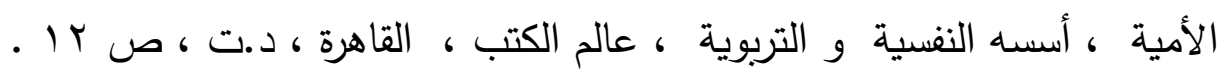
ب - متب مترجمة

اس - بولا ، ت ، س : تعليم الكبار ، اتجاهات و قضايا عالمية ، ترجمة عبد العزيز عبد الله السنبل ، وصالح العزب ، المنظمة العربية للتربية و الثقافة و

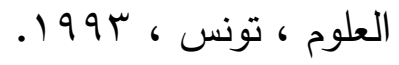
ج - الدوريات العلمية r - أحمد اسماعيل حجى : جامعة العمر الثالث الافتراضية في المملكة المتحدة

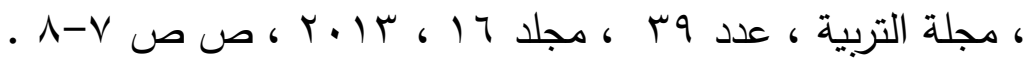
سب- حامد مصطفى عمار : تساؤلات حول تعليم الكبار و نحو رسالة ومؤسسة جديدة ، أفاق جديدة في تعليم الكبار ، مركز تعليم الكبار ، عدد ؛ ، القاهرة .V) T. T. T، ع ب- خليل إبراهيم السعادات: التعليم عن بعد أصوله ، مفهومه ، مؤسساته ، مجلة

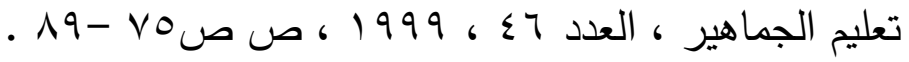


موقف المجلات التربوية العربية من بعض القضايا الخاصة أ.م. دـ ـ محمد أحمد محمد اسماعيل هم - خليل إبراهيم السعادات : تعليم الكبار في كلية التربية و معاهد إعداد المعلمين ، مجلة جامعة الإمام محمد بن سعود الإسلامية ، العدد التاسع ، الرياض ، المملكة

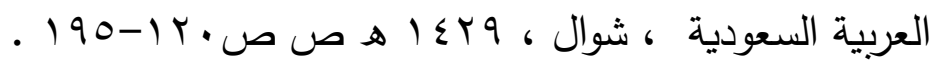

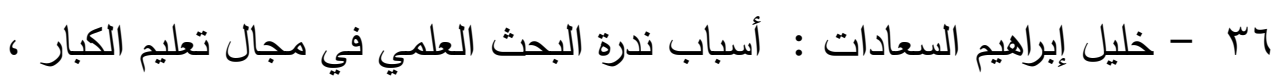
دراسة ميدانية ، مركز البحوث التربوية ، كلية التربية ، جامعة الملك سعود ، الرياض

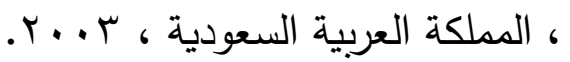

rV - صالحة عبد الله عيسى : الدراسات العليا و البحث العلمي ، و خدمة المجتمع في مؤسسات التعليم العالي بسلطنة عمان ، دراسة تحليلية ، مجلة الأكاديمية

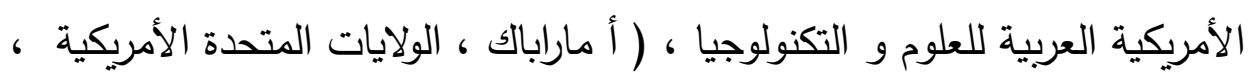

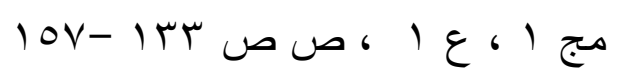

مب - - عبدا لله البريدي : مشكلة ضعف الإنتاج البحثي الإبداعي للأستاذ الجامعي في العالم العربي المظاهر و المعوقات و الحلول مع التركيز على العلوم الإدارية ،

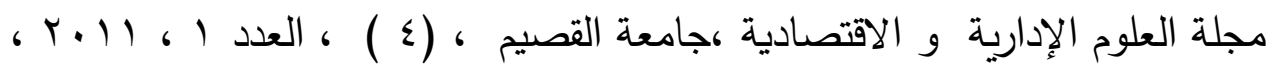
ص ص ص

q" - عبد العزيز البسام : البحث التربوي في تعليم الكبار بين النظرية و التطبيق، علم تعليم الكبار ، المنظمة العربية للتربية و الثقافة و العلوم ، تونس ، 1991 •ـ - - عبد الناصر عبد الرحيم فخرو : معايير تميز الأداء البحثي في الجامعات

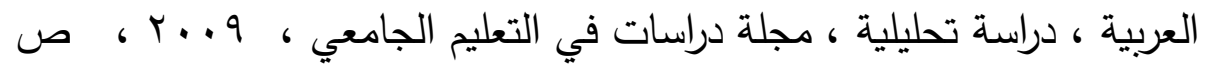
- $1 \leqslant \Lambda-110$ 
اء - عبد الفتاح حجاج : الجزع المشترك كمدخل لتعليم الكبار ، مجلة تعليم

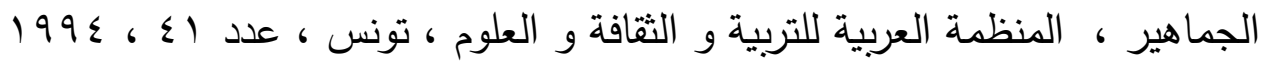

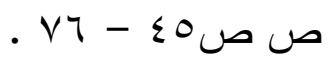

r؟- عبد الله الملا و حميد فيصل : المعوقات التي تواجه البحث العلمي التربوي و تحول دون الاستفادة من نتائجه في تطوير التعليم و التدريب ، مجلة اتحاد الجامعات العربية ، العدد 9؟ ، عمان ، المملكة الاردنية الهاشمية ، ديسمبر ،

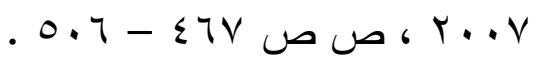
r؟- عبد الله محمد بيومي : تطوير إجراء البحوث التربوية في مجال تعليم الكبار " تصور مقترح ،مجلة البحث التربوي ، مج I ، عدد ب ، الجزء الأول ، القاهرة

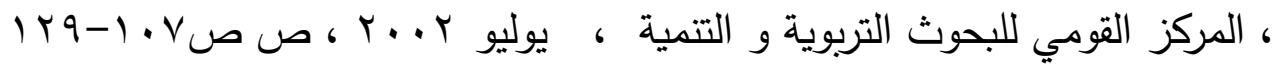
؟ ـ - فهد سلطان السلطان : المنهج الاثتوغرافى : رؤية تجديدية لواقع البحث التربوي ، مجلة رابطة التربية الحديثة ، السنة الثانية ، العدد الرابع ، ح • م • ع ،

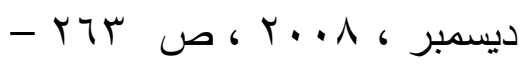

0

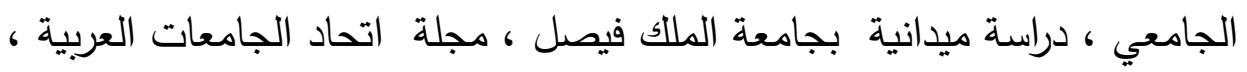

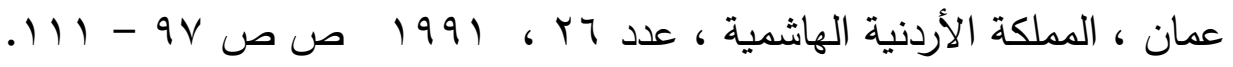
7؟ - مجدي عزيز إبراهيم : البحث العلمي التربوي كنشاط أبداعي في عصر العولمة ، مجلة البحث التربوي، المركز القومي للبحوث التربوية و التنمية ،

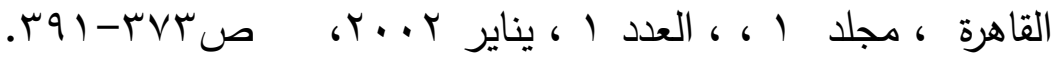
SV المعرفة ، مجلة تعليم الجماهير ، المنظمة العربية للتربية و الثقافة و العلوم ، ،

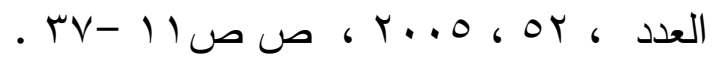




\section{موقف المجلات التربوية العربية من بعض القضايا الخاصة أ.م. د ـ محمد أحمد محمد اسماعيل}

؟ Y - محمد حسين اللقانى : المحتوى التعليمي لمناهج اعداد معلمي الكبار في كليات اعداد المعلمين بالجامعات العربية ، مجلة تعليم الجماهير ، المنظمة العربية

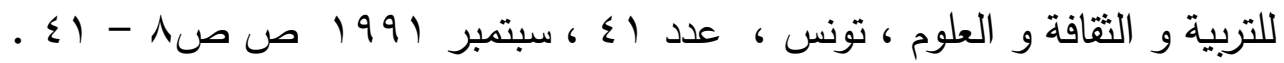
^ـ - - محى الدين شعبان توق و عبد الطيف خيرى : واقع مناهج تعليم الكبار

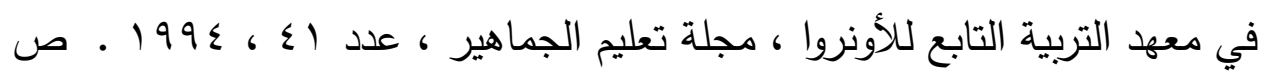

$$
\text { . } 91-V V
$$

9 - مكتب اليونسكو الإقليمي للتربية في البلاد العربية : نموذج مقترح لمنهج اعداد معلمي المرحلة الابتدائية للقيام بدور تعليمي مزدوج للكبار و الصغار ، الدورة التدرببية للمسئولين عن برامج محو الأمية و تعليم الكبار بمعاهد إعداد المعلمين في

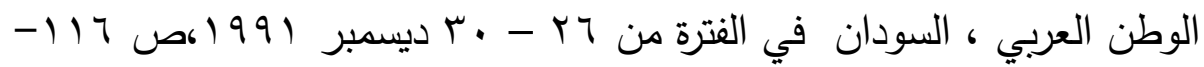
$.1 Y A$

• ، علم تعليم الكبار ، مجلة تعليم الجماهير ، الجزء السابع ،المنظمة العربية للتربية و

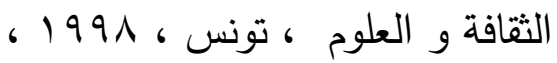
10 - - اليونسكو : التعليم للجميع ،، الوفاء بالتزاماتتا الجماعية ، نص اعتمده

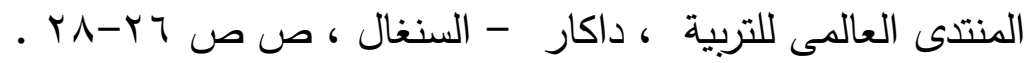
Or - - داليا طه محمود يوسف : المعوقات الإدارية و التنظيمية لمحو الأمية بمحافظة المنيا ، دراسة تحريرية ، مجلة آفاق جديدة في تعليم الكبار ، العدد الثامن ، جامعة عين شمس ، 9 ، . . . . rه - صالحة عبدا لله عيسان و محمد الطاهر : الدراسات العليا و البحث العلمي و خدمة المجتمع في مؤسسات التعليم العالي بسلطنة عمان ، دراسة 
تحليلية ، مجلة الأكاديمية الأمريكية العربية للعلوم و التكنولوجيا ، ( أ ماراباك )

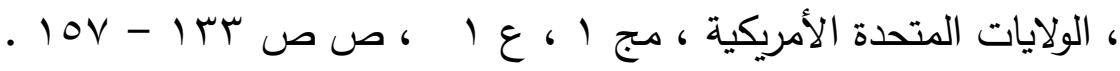
\& متغير • مجــلة تعليم الجماهير ، العدد (\&V)، كتونس: المنظمة العربية للتربية

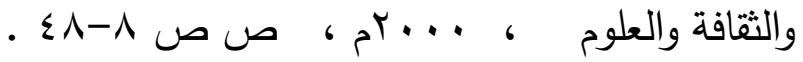
000 - - عبد العزيز عبد الله السنبل ، الأبعاد السياسية لحركة تعليم الكبـار من

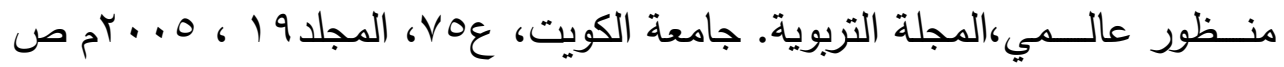

$$
\text { ص }
$$

or - - عبد العزيز عبد الله السنبل : دراسة تحليلية للبحوث المنشورة بمجلة

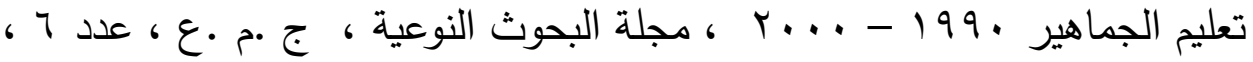

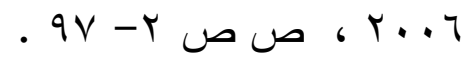

- - ov

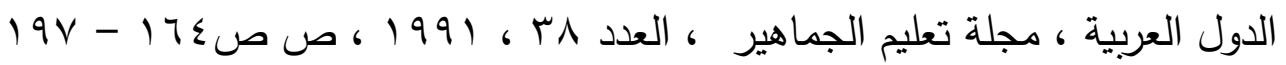

ON الوطنية لمحو الأمية ، مجلة تعليم الجماهير ، المنظمة العربية للتربية والثقافة و

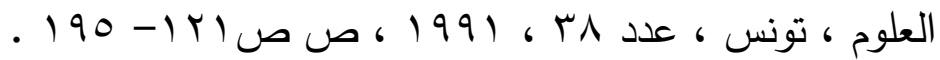
ه9

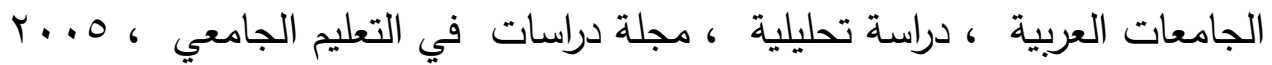
. 


\section{موقف المجلات التربوية العربية من بعض القضايا الخاصة أ.م. د ـ محمد أحمد محمد اسماعيل}

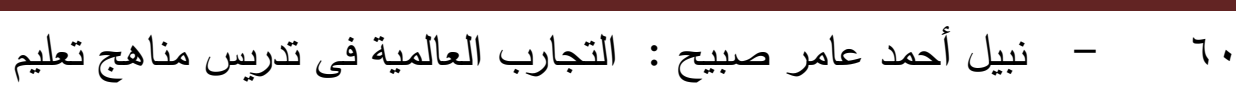

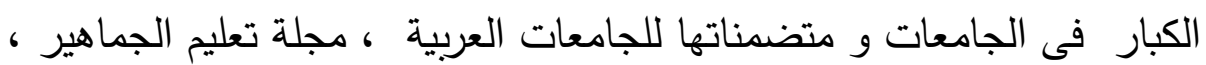
عدد إ)

ال7

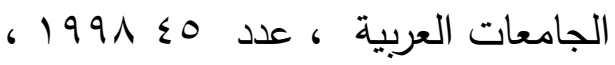
د - المؤتمرات و الندوات

rT

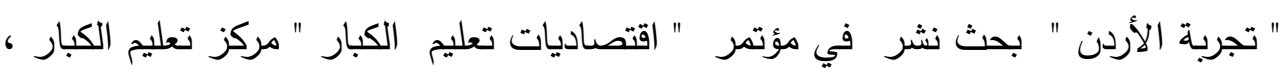
جامعة عينن شمس ، المؤتمر السنوي الخامس ، مركز تعليم الكبار ، جامعة عين شمس ،

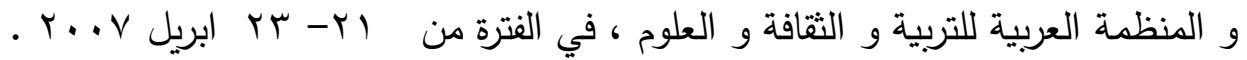
rا7 - دعاء عثمان عبد اللطيف لا و دنيا حسن عبد الثافي : العائد الاجتماعي

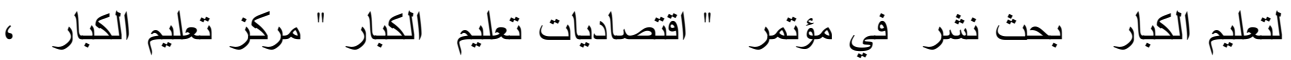
جامعة عينن شمس ، المؤتمر السنوي الخامس ، مركز تعليم الكبار ، جامعة عين شمس ،

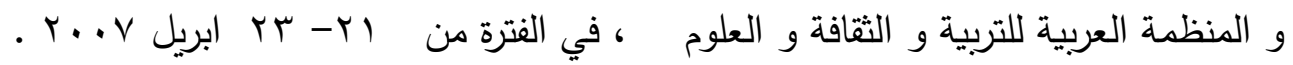

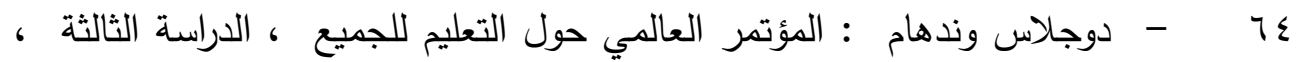
. 1.1 - 1.V ص ص ص 1991 10 الكبار بحث نشر في مؤتمر " اقتصاديات تعليم الكبار " مركز تعليم الكبار ، جامعة لهيم عينن شمس ، المؤتمر السنوي الخامس ، مركز تعليم الكبار ، جامعة عين شمس ، و و

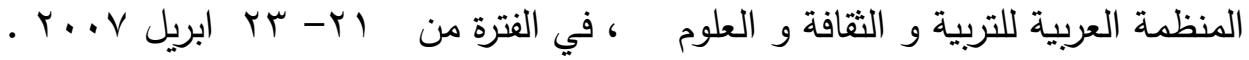
77 7

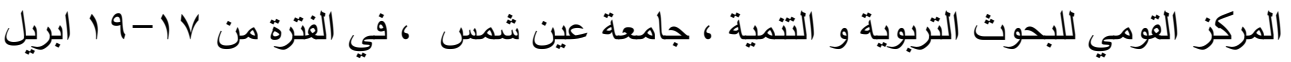

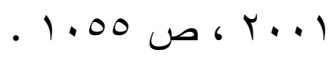


TV

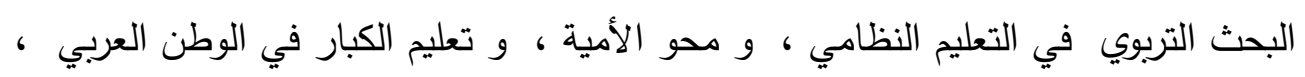

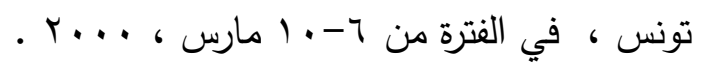

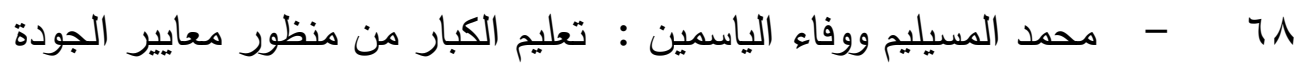

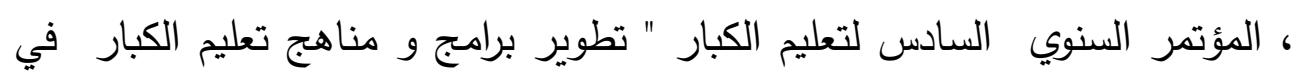

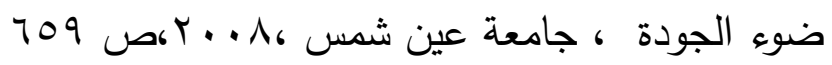
79 فى الجامعات و متضمناتها للجامعات العربية ، عدد اء ، ـ99 19 ص ص .

$$
\text { ه - التقارير : - (التير }
$$

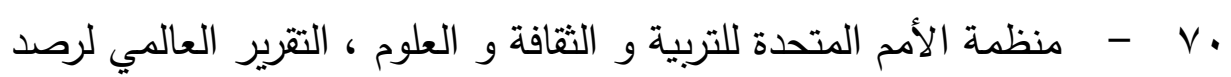

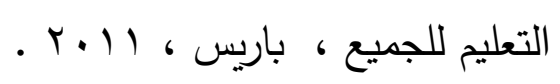

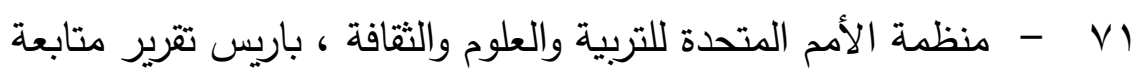
الجمعية العالمية للشيخوخة ، تقرير ( (1) م) م). الجمعية العامة للأمم

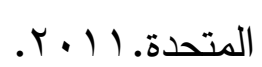

\section{ج الرسائل الجامعية}

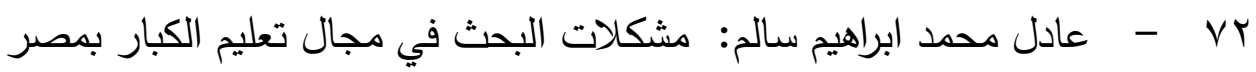
، دراسة ميدانية ، رسالة دكتوراه غير منشورة ، جامعة الأزهر ، كلية التربية ، قسم

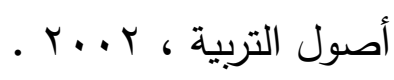
المواقع الاكترونية : 
موقف المجلات التربوية العربية من بعض القضايا الخاصة أ.م. دـ ـ محمد أحمد محمد اسماعيل

(http://www.unesco.org)-Vr ثانتاء

ثانيًا : المراجع الأجنبية :

1 - Dean, Gary j., 1999, "Reality and Research in Adult Education : Do Opposites really attract " PAACE , Journal of lifelong, Volume 8, Pennsylvania Association for adult continuing Education

2 - Quigley, Allan B . 1999 " lion at Gate : Adult

Education Research $m$ Research in practice, and speculative Audacity ", PAACE , journal of lifelong learning ,Pennsylvania Association for adult continuing Education

1- Chou,C.C\&Yang,C.C ( 2009 )Retirement preparation education :A comparison of Norway and Taiwan. International J ournal of Continuing Education and Lifelong Learning. Volume

$$
\text { 2, Issue 1. pp 118- } 130 .
$$

2 - Huang, Chin-Shan(2010)The Development of Educational Gerontology in Taiwan: An Interpretive and Critical Perspective Source:Educational Gerontology, v36 n10-11 p968-987 2010. 20 pp. 3 - Lin, Yi-Ying; Huang, Chin-Shan(2013 )Policies and Practices in Educational Gerontology in Taiwan. Source: Educational Gerontology, v39 n4 p 228- 240 2013. 13 pp. 
4 - Muratore ,A.M \& Earl, J .E (2010)Predicting retirement preparation Australian Psychologist, J une .through the design of a new measure 2010; 45(2). pp 98-111.

5 - Malayer, M. K. ( 2003 ). Preretirement training and the early retiree, Thesis Ph.D, Unpublished dissertation, Walden University,

US.

6 - Eigenmann Hall \& Bloomington, IN (2005): The Role of College Faculty in Student Learning and Engagement, Indiana University Center for Postsecondary Research 1900 E. 10th St. 7 - Watters,Shirley(1997) Globalization, Adult Education\& Training :Impact and Issues , CACE Publication, cape Town, south Africa . 8 - International Council for Adult Education, J amaica declaration , 2001, Toronto . 